Alexandre Paciencia Bernardes

\title{
Esquema Completo de Proteção Diferencial de Transformadores para Testes em um Relé Digital
}

Dissertação apresentada à Escola de Engenharia de São Carlos, da Universidade de São Paulo, como parte dos requisitos para obtenção do Título de Mestre em Engenharia Elétrica.

Orientador: Prof. Dr. Mário Oleskovicz 
A minha mulher Jesiane, pelo amor e incentivo infinitos. 


\section{AGRADECIMENTOS}

Ao professor Mário Oleskovicz, pela excelente orientação, pela atenção dispensada, apoio, incentivo e amizade a todos os momentos.

Ao professor Denis Vinicius Coury, por ter-me dado voto de confiança para que eu realizasse o mestrado e também pela atenção concedida.

Aos amigos e colegas da pós-graduação, Daniel, Silvio, Luiz, Odilon, Wesley, Rodrigo e Marco Aurélio, dentre outros, pela amizade e auxílio valiosos.

A todos os professores e funcionários do Departamento de Engenharia Elétrica, que de algum modo colaboraram durante a minha permanência nesta universidade.

Ao Departamento de Engenharia Elétrica da Escola de Engenharia de São Carlos (EESC) - Universidade de São Paulo (USP).

Ao Laboratório de Sistemas de Energia Elétrica - LSEE, pela acomodação e equipamentos disponíveis usados para desenvolver esse trabalho.

A Schweitzer Engineering Laboratories, Comercial Ltda. - SEL, Campinas - SP, Brasil, devido à parceria firmada com a EESC - USP, o que veio a possibilitar e a viabilizar esta pesquisa e, especialmente, ao Engenheiro Ricardo Abboud pelo imprescindível apoio técnico e pessoal no decorrer dos trabalhos.

Ao amigo Murilo da Silva pelo estímulo, apoio e dedicação.

A minha mulher Jesiane, pelo seu amor, presença, compreensão, companheirismo e incentivo.

Aos meus pais Adriano e Ana Maria pela minha vida e amor.

A Deus pela minha vida e famílias. 


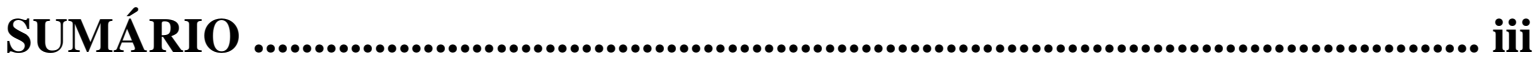

LISTA DE FIGURAS .................................................................................. v

LISTA DE TABELAS .........................................................................

LISTA DE ABREVIATURAS E SIGLAS ................................................. xii

LISTA DE SÍMBOLOS ......................................................................... xiv

RESUMO …........................................................................................... xvi

ABSTRACT ................................................................................................... xvii

1. INTRODUÇÃO ............................................................................................. 1

2. A PROTEÇÃO DIFERENCIAL ............................................................... 3

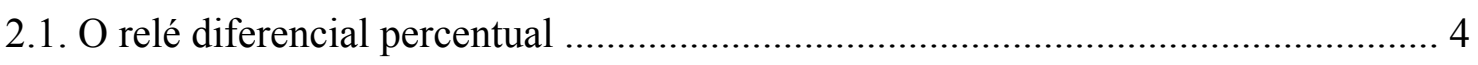

2.2. Causas do surgimento de correntes diferenciais indesejadas .................................. 8

2.2.1. Correntes de magnetização (inrush) ............................................................. 9

2.2.2. Remoção de faltas próximas ao transformador ............................................... 13

2.2.3. Sobreexcitação do transformador ............................................................... 13

2.2.4. Saturação dos transformadores de corrente ……………………………….... 14

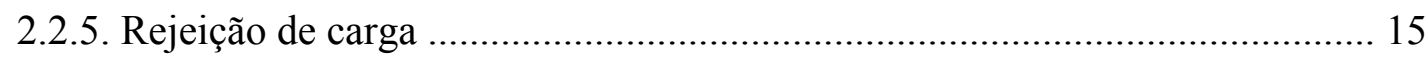

3. LEVANTAMENTO BIBLIOGRÁFICO ............................................. 17

4. O SISTEMA ELÉTRICO EM ANÁLISE ........................................ 22

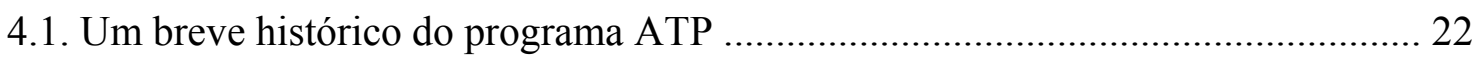

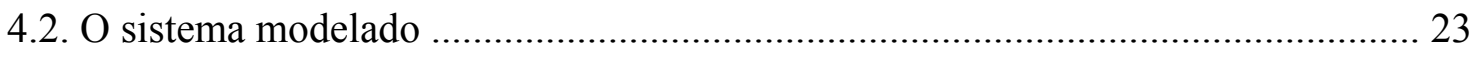

4.2.1. O modelo do transformador principal ...................................................... 24

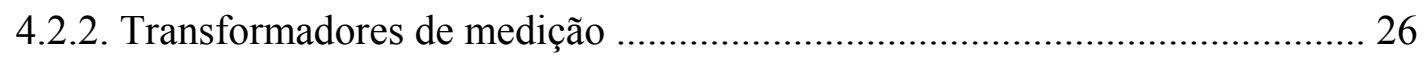

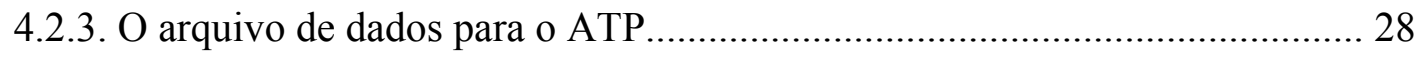

4.3. Situações de faltas aplicadas ................................................................................. 32

4.4. O Arquivo COMTRADE ……………………............................................. 48 
5. METODOLOGIA E RESULTADOS OBSERVADOS 56

5.1. Metodologia aplicada 56

5.2. Resultados observados 59

6. CONCLUSÕES FINAIS 79

6.1. Sugestões para a continuidade do trabalho 80

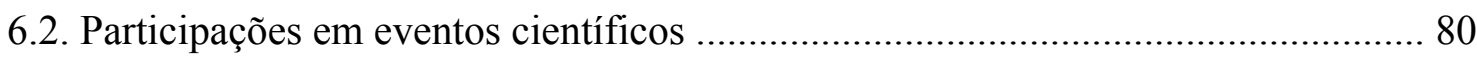

7. REFERÊNCIAS BIBLIOGRÁFICAS 82

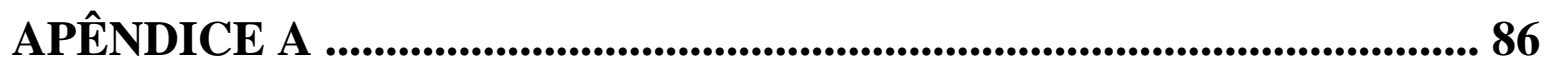

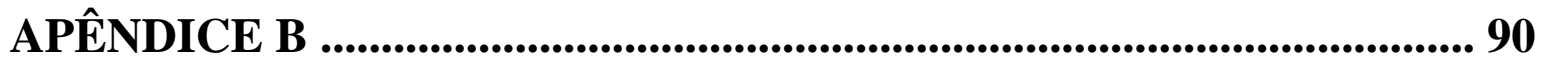

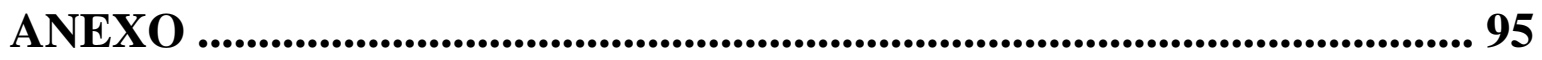




\section{LISTA DE FIGURAS}

Figura 1. Esquema da proteção diferencial percentual aplicada a um transformador monofásico.

Figura 2. Característica de atuação da proteção diferencial percentual................................... 7

Figura 3. Amplitudes das correntes de inrush e nominal.................................................. 11

Figura 4. Modelo do sistema elétrico utilizado no ATP. .................................................... 23

Figura 5. Modelo do transformador monofásico empregado - ATP................................... 24

Figura 6. Detalhe das conexões dos enrolamentos............................................................ 25

Figura 7. Detalhe da ligação triângulo-estrela aterrado.................................................... 25

Figura 8. Partição do enrolamento primário do transformador em 10, 50 e $80 \%$................ 26

Figura 9. Detalhe das ligações do transformador principal e TC's ...................................... 28

Figura 10. Curva de saturação do transformador de potência do sistema elétrico................. 31

Figura 11. Curva de saturação dos transformadores de corrente do sistema elétrico .......... 32

Figura 12. Condição de energização com tensão de $112,7 \mathrm{kV}$ e fechamento em $80,52 \mathrm{~ms}$ na fase $A, 82,52 \mathrm{~ms}$ na fase $\mathrm{B}$ e $84,52 \mathrm{~ms}$ na fase $\mathrm{C}$ com ângulo incidência da falta de $0^{\circ}$.

Figura 13. Componentes harmônicas da corrente secundária do TC (fase C), com referência ao primário do transformador de potência, quando da condição de energização.

Figura 14. Condição de energização seguida de falta interna, tensão de $112,7 \mathrm{kV}$, fechamento em $80,52 \mathrm{~ms}$ na fase A e falta aplicada a $82,52 \mathrm{~ms}$ com âng. inc. de $0^{\circ}$.

Figura 15. Componentes harmônicas da corrente secundária do TC (fase C), com referência ao primário do transformador de potência, quando da condição de energização seguida de falta.

Figura 16. Valores das correntes do secundário do TC, com referência ao primário do transformador de potência, tensão de $112,7 \mathrm{kV}$, sob condição de falta interna em $10 \%$ do enrolamento (delta) e carga de 10 MVA conectada em estrela com âng. inc. da falta de $0^{\circ}$.

Figura 17. Valores das correntes do secundário do TC, com referência ao secundário do transformador de potência, tensão de $13,8 \mathrm{kV}$, sob condição de falta interna em 
$10 \%$ do enrolamento (delta) e carga de 10 MVA conectada em estrela com âng. inc. da falta de $0^{\circ}$.

Figura 18. Componentes harmônicas da corrente do secundário do TC, fase A, quando da condição de falta interna em 10\% do enrolamento (delta) e carga de 10MVA conectada em estrela com âng. inc. da falta de $0^{\circ}$.

Figura 19. Valores das correntes do secundário do TC, com referência ao primário do transformador de potência $(112,7 \mathrm{kV})$, sob condição de falta interna em $10 \%$ do enrolamento (estrela) e carga média de 10 MVA conectada em delta com âng. inc. da falta de $0^{\circ}$.

Figura 20. Valores das correntes do secundário do TC, com referência ao secundário do transformador de potência $(13,8 \mathrm{kV})$, condição de falta interna em $10 \%$ do enrolamento (estrela) e carga média de 10 MVA conectada em delta com âng. inc. da falta de $0^{\circ}$.

Figura 21. Valores das correntes do secundário do TC, com referência ao primário do transformador de potência $(112,7 \mathrm{kV})$, sob condição de falta interna em 25\% do enrolamento (estrela) e carga leve conectada em delta com âng. inc. da falta de $0^{\circ}$.

Figura 22. Valores das correntes do secundário do TC, com referência ao secundário do transformador de potência $(13,8 \mathrm{kV})$, sob condição de falta interna em $25 \%$ do enrolamento (estrela) e carga leve conectada em delta com âng. inc. da falta de $0^{\circ}$.

Figura 23. Valores das correntes do secundário do TC, com referência ao primário do transformador de potência $(112,7 \mathrm{kV})$, sob condição de falta interna em $25 \%$ do enrolamento (estrela) e carga pesada conectada em delta com âng. inc. da falta de $0^{\mathbf{0}}$

Figura 24. Valores das correntes do secundário do TC, com referência ao secundário do transformador de potência $(13,8 \mathrm{kV})$, sob condição de falta interna em $25 \%$ do enrolamento (estrela) e carga pesada conectada em delta com âng. inc. da falta de $0^{\circ}$.

Figura 25. Valores das correntes do secundário do TC, com referência ao primário do transformador de potência $(13,8 \mathrm{kV})$, sob condição de falta interna em $80 \%$ do 
enrolamento (estrela) e carga de 10MVA conectada em estrela com âng. inc. da falta de $0^{\circ}$

Figura 26. Valores das correntes do secundário do TC, com referência ao secundário do transformador de potência $(13,8 \mathrm{kV})$, sob condição de falta interna em $80 \%$ do enrolamento (estrela) e carga de 10 MVA conectada em estrela com âng. inc. da falta de $0^{\circ}$

Figura 27. Valores de corrente do secundário do TC, com referência ao primário do transformador de potência sob condição de falta externa na linha de distribuição com âng. inc. da falta de $0^{\circ}$.

Figura 28. Valores de corrente do secundário do TC, com referência ao secundário do transformador de potência sob condição de falta externa ocorrida na linha de distribuição e âng. inc. da falta de $0^{\circ}$.

Figura 29. Gráfico das componentes harmônicas da corrente do secundário do TC, com referência ao primário do transformador de potência, fase $\mathrm{A}$, na condição de falta externa à linha de distribuição e âng. inc. da falta de $0^{\circ}$.

Figura 30. Valores de corrente do secundário do TC, com referência ao primário do transformador de potência, na condição de saturação do TC secundário, ocorrida devido a uma falta externa próxima ao transformador de potência com âng. inc. da falta de $0^{\circ}$.

Figura 31. Valores de corrente do secundário do TC, com referência ao secundário do transformador de potência, na condição de saturação do TC secundário, ocorrida devido a uma falta externa próxima ao transformador de potência com âng. inc. da falta de $0^{\circ}$.

Figura 32. Componentes harmônicas da corrente do secundário do TC com referência ao secundário do transformador de potência, fase A, quando da condição de saturação do TC devido a uma falta externa próxima ao transformador de potência.

Figura 33. Valores de corrente do secundário do $\mathrm{TC}$, fase $\mathrm{A}$, com referência ao primário do transformador de potência, devido condição de sobreexcitação de $140 \%$ da tensão, estando o sistema em regime com uma carga de 10 MVA 
Figura 34. Componentes harmônicas da corrente do secundário do TC, com referência ao primário do transformador de potência, fase $\mathrm{A}$, devido condição de sobreexcitação de $140 \%$ da tensão, estando o sistema em regime com carga de 10 MVA.

Figura 35. Exemplo do arquivo .HDR referente a uma aplicação de falta interna a 10\% do enrolamento A-B com conexão delta-estrela e âng. inc. da falta de $0^{\circ}$......

Figura 36. Exemplo do arquivo .CFG de uma aplicação de falta interna com conexão deltaestrela em $10 \%$ do enrolamento A-B com âng. inc. da falta de $0^{\circ}$ 53

Figura 37. Estrutura do arquivo .DAT. 54

Figura 38. Exemplo do arquivo .DAT de uma aplicação de falta interna com conexão deltaestrela em $10 \%$ do enrolamento A-B com âng. inc. da falta de $0^{\circ}$ 55

Figura 39. Seqüência de eventos caracterizando a metodologia aplicada. 57

Figura 40. Correntes observadas nos transformadores de medição com a conseqüente posição do sistema de proteção para a situação de energização do transformador principal a vazio, com proteção por bloqueio comum das componentes de $2^{\mathrm{a}}$ harmônica.

Figura 41. Correntes observadas nos transformadores de medição com a conseqüente posição do sistema de proteção para a situação de energização do transformador principal a vazio, com proteção por bloqueio independente das componentes harmônicas de segunda ordem. 62

Figura 42. Correntes observadas nos transformadores de medição com a conseqüente posição do sistema de proteção para a situação de energização do transformador principal a vazio, com proteção por restrição.

Figura 43. Correntes diferenciais observadas pelos TC's com a conseqüente posição do sistema de proteção para a situação de energização do transformador principal a vazio.

Figura 44. Correntes observadas nos transformadores de medição com a conseqüente posição do sistema de proteção para a situação de energização com falta no secundário (estrela) do transformador, com proteção por bloqueio comum das componentes de segunda harmônica. 
Figura 45. Correntes observadas nos transformadores de medição com a conseqüente posição do sistema de proteção para a situação de energização com falta no secundário (estrela) do transformador principal a vazio, com proteção por bloqueio independente das componentes de segunda harmônica. 65

Figura 46. Correntes observadas nos transformadores de medição com a conseqüente posição do sistema de proteção para a situação de energização com falta no secundário (estrela) do transformador principal a vazio, com proteção por restrição. 66

Figura 47. Oscilografia das correntes observadas nos TC's com a conseqüente posição do sistema de proteção para uma falta interna, aplicada a 10\% do enrolamento (delta), carga média de 10 MVA sendo conectada em estrela. 67

Figura 48. Oscilografia das correntes diferenciais observadas nos TC's com a conseqüente posição do sistema de proteção para uma falta interna, aplicada a $10 \%$ do enrolamento (delta), carga média de 10MVA sendo conectada em estrela.

Figura 49. Oscilografia das correntes observadas nos TC's na proteção para uma falta interna, aplicada a 10\% do enrolamento (estrela), carga média de 10 MVA sendo conectada em delta e função "falta terra restrita" habilitada. 68

Figura 50. Oscilografia das correntes diferenciais observadas nos TC's com a conseqüente posição do sistema de proteção para uma falta interna, aplicada a 10\% do enrolamento (estrela), carga média de 10 MVA sendo conectada em delta e função "falta terra restrita" habilitada.

Figura 51. Oscilografia das correntes observadas nos TC's na proteção para uma falta interna, aplicada a $25 \%$ do enrolamento (estrela), carga conectada em delta, carga pesada e função falta terra restrita habilitada.

Figura 52. Correntes observadas nos TC's com a conseqüente posição do sistema de proteção para uma falta interna, aplicada a $80 \%$ do enrolamento (estrela) do transformador carga média de 10MVA conectada em estrela.

Figura 53. Correntes diferenciais observadas nos TC's com a conseqüente posição do sistema de proteção para uma falta interna, aplicada a $80 \%$ de um enrolamento (estrela) do transformador. 
Figura 54. Correntes observadas nos $\mathrm{TC}^{\prime}$ 's com a conseqüente posição do sistema de proteção para uma falta externa, caracterizada na linha de distribuição. 72

Figura 55. Correntes diferenciais observadas nos TC's com a conseqüente posição do sistema de proteção para uma falta externa, aplicada na linha de distribuição... 73

Figura 56. Oscilografia de uma falta externa aplicada próxima ao TC do lado secundário do transformador de potência com saturação do mesmo.

Figura 57. Correntes diferenciais observadas nos $\mathrm{TC}^{\prime}$ s de uma falta externa aplicada próxima ao TC do lado secundário do transformador de potência com saturação do mesmo.

Figura 58. Oscilografia de uma condição de sobreexcitação, com 140\% de tensão e sistema em regime normal. 76

Figura 59. Oscilografia das correntes observadas nos $\mathrm{TC}^{\prime}$ 's na proteção para uma falta interna, aplicada a $20 \%$ do enrolamento (estrela), carga pesada e conectada em estrela com a "função falta terra restrita" habilitada. 90

Figura 60. Oscilografia das correntes observadas nos TC's na proteção para uma falta interna, aplicada a $25 \%$ do enrolamento (estrela), carga leve e conectada em estrela com a função "falta terra restrita" habilitada.

Figura 61. Oscilografia das correntes observadas nos $\mathrm{TC}^{\prime}$ 's na proteção para uma falta interna, aplicada a $25 \%$ do enrolamento (estrela), carga pesada e conectada em estrela com a função "falta terra restrita" habilitada.

Figura 62. Oscilografia das correntes observadas nos $\mathrm{TC}^{\prime}$ 's na proteção para uma falta interna, aplicada a 10\% do enrolamento (delta), carga média de 10 MVA sendo conectada em delta com a função "falta terra restrita" desabilitada.

Figura 63. Oscilografia das correntes observadas nos $\mathrm{TC}^{\prime}$ s na proteção para uma falta interna, aplicada a $15 \%$ do enrolamento (estrela), carga pesada e conectada em delta com a função "falta terra restrita" habilitada.

Figura 64. Oscilografia das correntes observadas nos $\mathrm{TC}^{\prime}$ 's na proteção para uma falta interna, aplicada a $25 \%$ do enrolamento (estrela), carga leve e conectada em delta com a função "falta terra restrita" habilitada. 
Figura 65. Oscilografia das correntes observadas nos TC's na proteção para uma falta interna, aplicada a $30 \%$ do enrolamento (estrela), carga leve e conectada em delta com a função "falta terra restrita" habilitada......................................... 93

Figura 66. Oscilografia das correntes observadas nos $\mathrm{TC}^{\prime}$ 's na proteção para uma falta interna, aplicada a $30 \%$ do enrolamento (estrela), carga pesada e conectada em delta com a função "falta terra restrita" habilitada........................................... 94

Figura 67. Oscilografia das correntes observadas nos TC's na proteção para uma falta interna, aplicada a 50\% do enrolamento (estrela), carga média de 10 MVA e conectada em delta com a função "falta terra restrita" habilitada. 


\section{LISTA DE TABELAS}

Tabela 1. Conteúdo harmônico das correntes de energização 12

Tabela 2. Conteúdo das harmônicas da corrente de excitação durante a sobreexcitação do banco de transformadores 14

Tabela 3. Dados de tensão e corrente para a rotina SATURATION 31

Tabela 4. Divisão do enrolamento primário, Triângulo, em 10, 50 e 80\% na aplicação de faltas internas com conexão delta-estrela aterrada.

Tabela 5. Divisão do enrolamento secundário, Estrela, em 80, 50 e 10\% na aplicação de faltas internas com conexão delta-estrela aterrada.

Tabela 6. Divisão de enrolamento secundário, Estrela, de 5\% a 40\%, com passos de 5\%, na aplicação de faltas internas com conexão delta-estrela aterrada, para testes em carga leve, média ou pesada na ligação em estrela e delta 34

Tabela 7. Resumo das situações aplicadas no trabalho. 


\section{LISTA DE ABREVIATURAS E SIGLAS}

ATP - Alternative Transient Program

EMTP - Electromagnetic Transients Program

LEC - Leuven EMTP Center

BPA - Bonneville Power Administration

EPRI - Electric Power Researched Institute

IEEE - Institute for Electric and Electronic Engineer

COMTRADE - Common Format for Transient Data Exchange for Power Systems

.HDR - Arquivo tipo cabeçalho, necessário para o arquivo COMTRADE

.CFG - Arquivo tipo configuração, necessário para o arquivo COMTRADE

.DAT - Arquivo tipo dados, necessário para o arquivo COMTRADE

TC - Transformador de Corrente

.PL4 - Arquivo de saída do ATP, tipo ASCII

.LIS - Arquivo de saída do ATP, tipo ASCII

ASCII - American Standard Code for Information Interchange

SATURATION - Rotina de geração da curva de saturação do transformador do ATP

CHESF - Companhia Hidro Elétrica do São Francisco - MG

CIGRE - Grupo de Trabalho em "Digital Protection Techniques and Substation Functions".

CPFL - Companhia Paulista de Força e Luz

CTR1 - Ajuste da relação de TC de alta

CTR2 - Ajuste da relação de TC de baixa

TAP1 - Ajuste do tape da alta

TAP2 - Ajuste do tape da baixa

O87P - Ajuste do pick-up elemento diferencial

SLP1 - Ajuste da primeira inclinação

SLP2 - Ajuste da segunda inclinação

IRS1 - Ajuste do ponto de transição inclinação

U87P - Ajuste do elemento diferencial instantâneo

32IF1 - Corrente residual de neutro

PCT2 - Ajuste do bloqueio $2^{\circ}$ harmônico

PCT4 - Ajuste do bloqueio $4^{\circ}$ harmônico 
PCT5 - Ajuste do bloqueio $5^{\circ}$ harmônico

REF - Restrict Earth Fault (falta a terra restrita)

8701 - Partida (pickup) individual do elemento diferencial da fase A;

87R - Elemento diferencial com restrição;

$87 \mathrm{U}$ - Elemento diferencial sem restrição (instantâneo);

TRIP1 - Comando individual de disparo (87R ou 87U) da fase A;

87BL1 - Bloqueio individual da proteção diferencial da fase A;

2HB1 - Bloqueio individual por $2^{\circ}$ harmônica da fase A;

4HBL - Bloqueio comum por $4^{\circ}$ harmônica;

5HB1 - Bloqueio individual por $5^{\circ}$ harmônica da fase A;

IOP1 - Corrente diferencial de operação da fase A;

IRT1 - Corrente diferencial de restrição da fase A;

I1F2 - Corrente de $2^{\circ}$ harmônica da fase A;

I1F5 - Corrente de $5^{\circ}$ harmônica da fase A;

IRT1 - Corrente de restrição calculada.

HRSTR - Função de restrição. 


\section{LISTA DE SÍMBOLOS}

$N_{1} \quad$ - Número de espiras do primário do transformador

$N_{2} \quad$ - Número de espiras do secundário do transformador

$n_{1} \quad$ - Número de espiras do secundário do transformador de corrente no primário do transformador de potência

$n_{2} \quad$ - Número de espiras do secundário do transformador de corrente no secundário do transformador de potência

$i_{1 P} \quad$ - Corrente primária do transformador de corrente no primário do transformador de potência

$i_{2 S} \quad$ - Corrente primária do transformador de corrente no secundário do transformador de potência

$i_{1 S} \quad$ - Corrente secundária do transformador de corrente no primário do transformador de potência

$i_{2 P} \quad$ - Corrente secundária do transformador de corrente no secundário do transformador de potência

R - Elemento de sobrecorrente

$i_{d} \quad$ - Corrente diferencial

$i_{r} \quad$ - Corrente de restrição

K - Corrente mínima de operação

K’ - Inclinação percentual da característica diferencial

ipu - Corrente mínima de pickup

$v_{1} \quad$ - Tensão no enrolamento primário do transformador de potência

$r_{1} \quad$ - Resistência do enrolamento primário do transformador de potência

$i_{0} \quad$ - Corrente a vazio

$l_{1} \quad$ - Comprimento do enrolamento primário do transformador de potência

$\phi \quad$ - Fluxo de dispersão

$V_{1 m} \quad$ - Tensão no instante da energização $\mathrm{t}=0$

$\phi_{0} \quad$ - Fluxo residual no instante $\mathrm{t}=0$ 


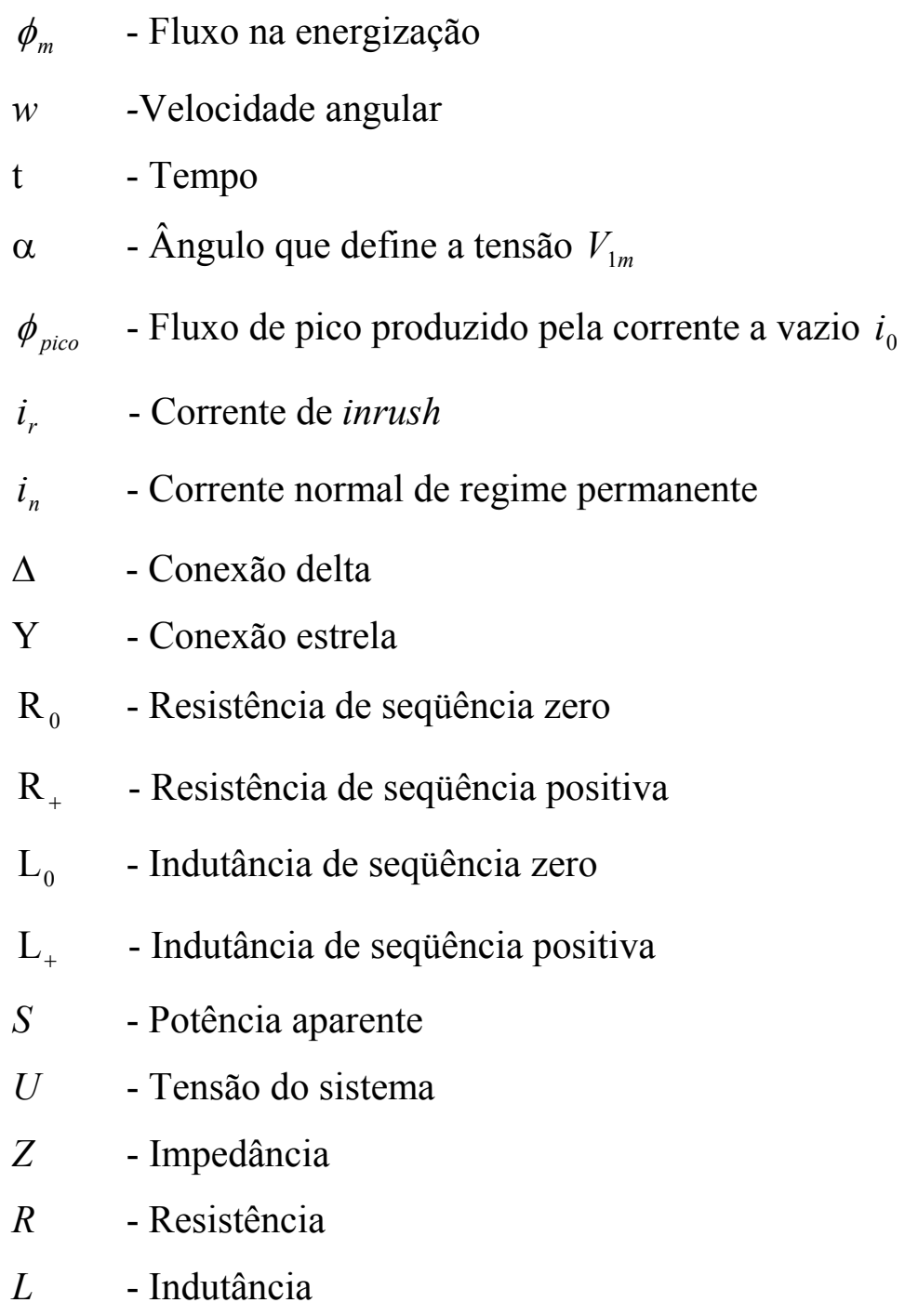




\section{RESUMO}

BERNARDES, A. P. (2006). Um Esquema Completo de Proteção Diferencial de Transformadores para Testes em um Relé Digital. São Carlos, 2006. 90p. Dissertação (Mestrado) - Escola de Engenharia de São Carlos, Universidade de São Paulo.

Este trabalho apresenta um procedimento completo de simulação da proteção digital diferencial aplicada a transformadores de potência, visando o emprego deste à avaliação do comportamento de relés comercialmente disponíveis.

Foi escolhido o software ATP (Alternative Transients Program) como ferramenta para a simulação de distintas situações sobre um sistema diferencial de proteção aplicado a um transformador de 25 MVA. Dentre as ocorrências evidenciadas, destacam-se: situações de faltas internas, faltas externas, situações de energização e energização com falta interna do transformador, condição de sobreexcitação e de saturação de TC (Transformador de Corrente).

Cabe comentar que das simulações a real caracterização sobre o relé em teste, fez-se necessário todo um pré-processamento e análise da informação que será convenientemente abordada e justificada no trabalho apresentado, denotando-se um procedimento comum de teste a ser adotado a esta filosofia de proteção.

A metodologia e esquema prático adotado trazem uma contribuição importante para a análise laboratorial de modelagens e simulações aplicadas a relés de proteção presentes no mercado e contribui de maneira substancial para os estudos teóricos de possíveis soluções para limitações eventualmente encontradas.

Palavras-chaves: Transformador de Potência; Transformador de Corrente; Proteção Diferencial; ATP; Corrente de Inrush; Relé Digital. 


\section{ABSTRACT}

BERNARDES, A. P. (2006). A Complete Model of Differential Protection of Transformers for Tests in a Digital Relay. São Carlos, 2006. 90p. Dissertação (Mestrado) - Escola de Engenharia de São Carlos, Universidade de São Paulo.

This dissertation presents a complete procedure of simulation of digital differential protection applied to power transformers, focusing on its use to evaluate of the behavior of commercially available relays.

Software ATP (Alternative Transients Program) was chosen as a tool for the simulation of distinct situations in a differential protection system applied to a $25 \mathrm{MVA}$ three-phase transformer. Amongst the evidenced occurrences internal and external fault conditions, energization with or without internal fault of a three-phase transformer, overexcitation and CT (Current Transformer) saturation conditions were distinguished.

It should be mentioned that from simulations to the characterization the real situations on the relay in test, a pre-processing and analysis of the information were necessary, and will be justified in the present study, denoting a common test procedure to be adopted to this philosophy of protection.

The methodology and practical model adopted bring an important contribution to the laboratorial analysis of modeling and simulations applied to protection relays in the market and contribute in an essential way to the theoretical studies of possible solutions for limitations to be found.

Keywords: Power Transformer; Current Transformer; Differential Protection; ATP; Inrush Current; Digital Relay. 


\section{INTRODUÇÃO}

De fato, temos que os transformadores são equipamentos que requerem cuidados especiais tanto de manutenção, quanto de operação, devido à sua importância para o sistema elétrico como um todo, ao qual estão conectados.

Para a proteção contra faltas internas ao transformador, convencionalmente utilizase do conhecido esquema de proteção diferencial, pelo qual se realiza a comparação entre os sinais de correntes registrados na entrada e saída do equipamento. Destas grandezas, a partir de parâmetros predeterminados, decide-se pelo desligamento do mesmo mediante a situação de falta caracterizada.

Neste trabalho utilizou-se o software ATP (Alternative Transients Program) (DOMMEL, 1984 e ATP-Rule Book, 1987) para a modelagem real de um sistema elétrico de potência contendo, entre outros elementos, um transformador de potência de 25 MVA e seus Transformadores de Correntes (TC's) associados. Cabe comentar que o ATP permite uma representação detalhada dos diversos componentes desejáveis a esta aplicação, além da caracterização de diversas condições de operações e situações que possam vir a afetar os mesmos.

Sobre a modelagem em específico, conforme será relatado posteriormente, foram realizadas diversas simulações de prováveis situações que o relé diferencial poderá experimentar em campo. Tais situações caracterizam faltas internas, faltas externas próximas ao transformador e na linha de distribuição, condição de energização e desta, seguida de uma situação de falta interna, condição de sobreexcitação e de saturação de TC's, as quais vêm a permitir a observação do comportamento do relé diferencial empregado.

Neste contexto, esse trabalho apresenta uma metodologia contemplando a simulação dos sinais observáveis por um relé diferencial comercial aplicado à proteção de um 
determinado transformador nas situações descritas. Para a conseqüente utilização desta em testes de relés de proteção encontrados na prática, um esquema completo de laboratório foi montado para a geração dos dados mencionados, que formatados ao padrão COMTRADE (IEEE standard C37_111_1991) são direcionados à caixa de testes e injetados em relés comerciais para avaliação da sua operação. 


\section{A PROTEÇÃO DIFERENCIAL}

Ao longo do tempo, diversas filosofias de proteção foram desenvolvidas de forma a evitar condições anormais de funcionamento dos sistemas de potência. No caso dos transformadores, o principal método aprimorado foi o da proteção diferencial, onde o dispositivo de proteção compara as correntes que entram e saem do equipamento ou sistema protegido, conforme evidenciam HOROWITZ e PHADKE (1992). Tem-se então que, durante a disposição do transformador ao sistema elétrico de potência, as formas de onda de corrente no primário e secundário do mesmo são constantemente monitoradas. Para a aquisição destas grandezas elétricas, utiliza-se de Transformadores de Corrente (TC's) acoplados em série como os ramos primário e secundário do transformador. Desta maneira, as correntes registradas terão formas de onda semelhantes às das correntes do transformador sob proteção, a menos da relação de transformação. Estes sinais são então transferidos para o relé, cuja função é analisá-las e, na situação de falta, desligar o transformador do sistema caso a corrente diferencial que o atravesse seja maior que um limiar (pickup) estipulado.

Em condições normais de funcionamento do transformador, as correntes dos lados primário e secundário serão praticamente iguais após a passagem pelos TC's, a menos de uma pequena diferença considerada esperada. Nestes casos, em função da filosofia de proteção empregada, o relé estabelece que não haja nenhum problema ocorrendo na região considerada, região esta delimitada pelos TC's empregados.

No caso de uma falta interna ao transformador, haverá um desbalanceamento destes sinais e a diferença entre a corrente primária e secundária torna-se significativa, sensibilizando o relé, que por sua vez, enviará um comando de operação ao disjuntor associado (condição de trip) com a finalidade de isolar o transformador do sistema como um todo. 
Neste contexto, é esperado que o relé atue somente para os casos de ocorrência de faltas internas ao transformador. Desta maneira, o relé deverá permanecer em bloqueio permitindo a operação normal do sistema nas situações de falta externa ao transformador, nas condições de sobreexcitação (tensão observada a níveis superiores a nominal) e nos casos de energização (manobra que provoca as correntes de inrush, que são transitórias, mas de elevadíssima amplitude). Cabe salientar que todas estas situações (faltas externas, sobreexcitação, energização e saturação de TC) irão acusar níveis de correntes diferenciais indesejáveis à proteção diferencial. Medidas paliativas a estas situações bem como uma maior explanação das mesmas serão apresentados no seguimento deste.

\subsection{O relé diferencial percentual}

Historicamente, a proteção diferencial tem sido constantemente abordada evidenciando o surgimento de vários esquemas que seguem os princípios básicos da filosofia, como por exemplo, a proteção diferencial percentual (CAMINHA, 1977; PHADKE e THORP, 1988 e HOROWITZ e PHADKE, 1992).

Com a proteção diferencial percentual, introduziu-se o conceito da "bobina de retenção", sendo esta prática percentual comumente aplicada para a proteção de transformadores de potência com capacidade superior a 2,5 MVA (Figura 1).

O esquema de proteção diferencial percentual, conforme encontrado e difundido na literatura consultada (PHADKE e THORP, 1988 ; HOROWITZ e PHADKE, 1995 ; COURY, 2004), é ilustrado na Figura 1, a seguir:

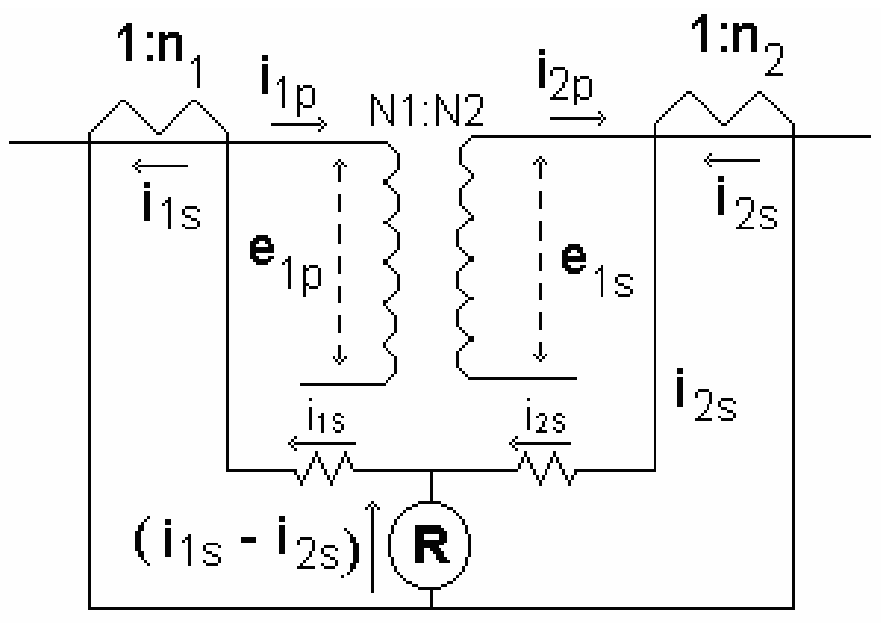

Figura 1. Esquema da proteção diferencial percentual aplicada a um transformador monofásico. 
O esquema mostra também a conexão dos TC's acoplados aos ramos primário e secundário. Neste, $N_{1}: N_{2}$ é a relação de transformação entre o primário e o secundário do transformador protegido, e $1: n_{1}$ e $1: n_{2}$ são as relações de transformação entre as correntes dos ramos e as correntes dos secundários dos TC's respectivamente.

Em condições normais de operação e em caso de faltas externas, as correntes $i_{1 S}$ e $i_{2 S}$ (correntes do secundário dos TC's) serão iguais, desde que $N_{1} / N_{2}=n_{2} / n_{1}$.

Normalmente $N_{1} \neq N_{2}$, significando que para condições normais de operação $i_{1 P} \neq i_{2 P}$. Porém se utilizarmos TC's que possuam relação de tapes, estes devem obedecer à igualdade $N_{1} / N_{2}=n_{2} / n_{1}$ e as correntes $i_{2 S}$ e $i_{1 S}$ terão a mesma magnitude. Logo, se definirmos a corrente diferencial (ou corrente de operação), $i_{d}$, como sendo:

$$
i_{d}=i_{1 S}-i_{2 S}
$$

então, para a condição normal de operação, esta corrente diferencial será nula. Já no caso de faltas internas, a corrente diferencial torna-se significativa, sensibilizando o elemento de sobrecorrente "R" (Figura 1). Desta lógica, a corrente diferencial $i_{d}$ poderá ser utilizada como medida para a corrente de falta.

Para os casos em que $N_{1} / N_{2} \neq n_{2} / n_{1}$, o relé diferencial deverá ser provido de múltiplos tapes para a medição das correntes do primário e do secundário do transformador, o que irá fornecer um meio de correção para a diferença esperada entre as correntes dos secundários dos TC's. No caso dos relés digitais temos ajustes contínuos para os tapes, o que permite anular totalmente a diferença entre as correntes secundárias devido à desigualdade $N_{1} / N_{2} \neq n_{2} / n_{1}$.

Vale comentar que a aplicação da proteção diferencial percentual de corrente, faz com que o relé não seja sensibilizado por pequenas correntes diferenciais, já que as suas bobinas de retenção ou de "restrição" serão percorridas por uma média das correntes passantes.

$$
i_{r}=\frac{\left(i_{1 S}+i_{2 S}\right)}{2} .
$$

Além desta média das correntes analisadas, a proteção diferencial percentual também objetiva a fornecer um fino ajuste considerando os eventuais erros proporcionados pelas 
diferentes relações de transformação dos TC's de medição e do transformador sob proteção, bem como de prováveis erros em função das características construtivas destes equipamentos. Todos estes prováveis erros serão considerados adotando-se um determinado limiar ou valor de pickup para a operação do relé, sendo condicionados a um determinado fator " $K$ " que indicará a declividade da curva de operação, determinado em função dos erros intrínsecos aos sinais analisados.

De uma determinada margem de segurança definida em função da corrente diferencial, o relé deverá atuar respeitando a relação abaixo fornecida.

$$
\begin{aligned}
& i_{d} \geq i_{p u} \\
& i_{d} \geq K .\left(i_{1 S}+i_{2 S}\right) / 2 \\
& i_{d} \geq K . i_{r}
\end{aligned}
$$

Onde, $i_{p u}$ representa a corrente mínima de operação e $K$ representa a inclinação percentual da característica diferencial. Assim, pequenas correntes diferenciais podem ser observadas sem que o relé seja sensibilizado sobre as mesmas. Portanto, podemos afirmar que a corrente diferencial (ou de operação), $i_{d}$, deverá ser maior ou igual que uma percentagem da corrente de restrição, $i_{r}$ para indicar com uma maior precisão a situação de trip acusada pelo relé, conforme a equação (5).

A Figura 2 representa a característica do relé diferencial percentual, mostrando sua região de operação (trip) e não operação, conforme ilustrada em HOROWITZ e PHADKE, 1992 e GUZMÁN et. al., 2001. 


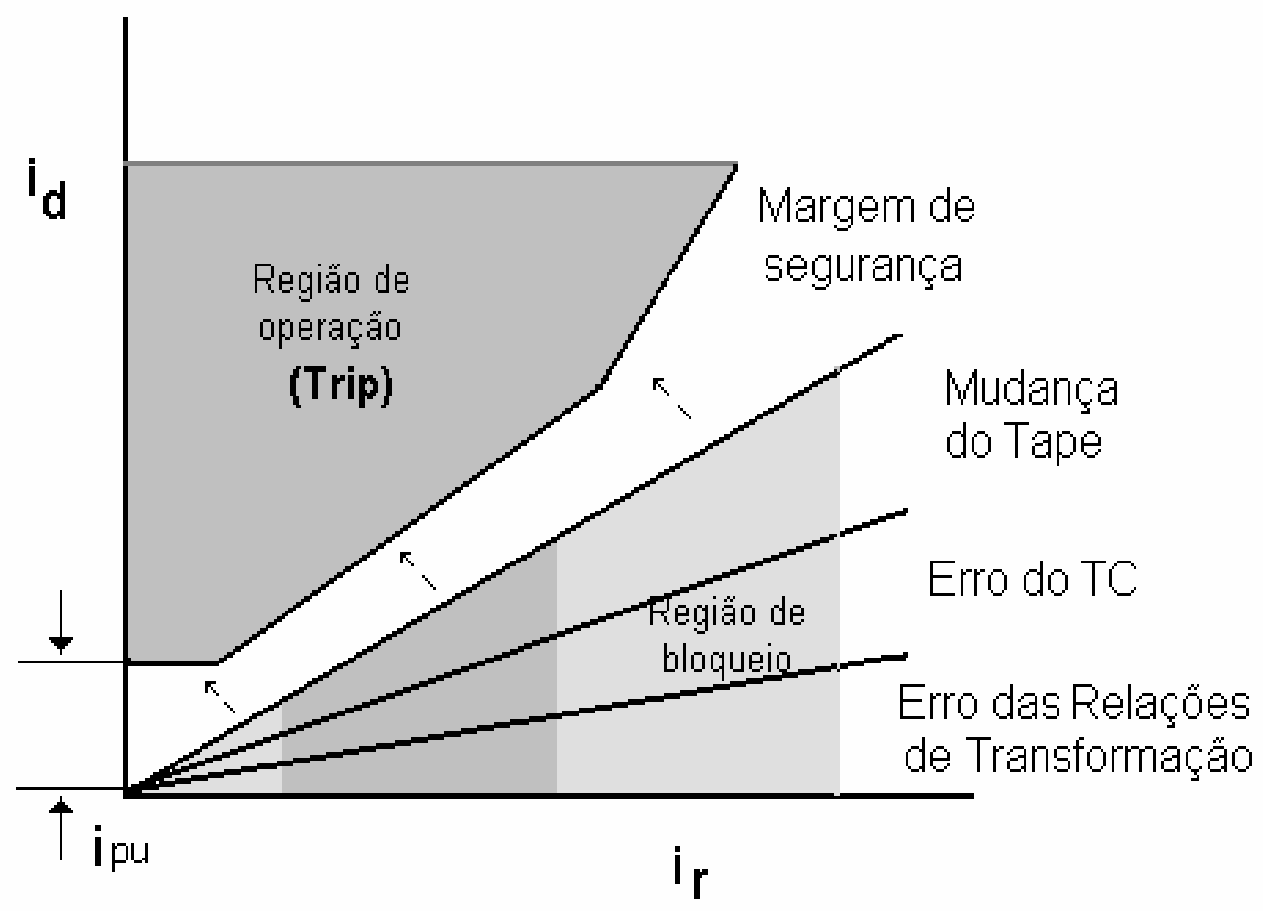

Figura 2. Característica de atuação da proteção diferencial percentual.

A inclinação da curva, ou seja, o ajuste percentual de atuação do relé é utilizado para determinar o nível de corrente no qual o relé irá atuar. Estas percentagens (inclinações) são definidas por fatores como relação de transformação, erros dos TC's e mudanças nos tapes do transformador conforme anteriormente já evidenciadas. Estes valores de $K$ são geralmente expressos em percentagens, com valores típicos de 10, 20 e 40\%. Destas inclinações, comenta-se que um relé ajustado a uma inclinação de $10 \%$ será muito mais sensível do que um relé ajustado à inclinação de 40\%, dado a maior abrangência da sua situação de operação (trip) (Figura 2).

Com relação ao valor da corrente inicial mínima (pickup, $i_{p u}$ ) (Figura 2), necessitase de um pequeno ajuste inicial a ser parametrizado no relé, para evitar a operação deste devido a pequenas correntes diferencias referente às imprecisões nos TC's. Uma outra característica é o deslocamento desse patamar sempre quando o algoritmo implementado detectar uma situação de tolerância, como por exemplo, uma sobreexcitação ou uma falta externa, a qual pode saturar o TC. Este patamar é deslocado acima do valor estipulado, para evitar a operação (trip) desnecessária do relé. 
A necessidade deste deslocamento será apontada pelo monitoramento das componentes harmônicas ainda a ser apresentado.

Como uso prático, é comum o emprego de duas diferentes inclinações, sendo que a primeira inclinação é mais sensível e utilizada para baixas correntes de carregamento, já que o erro introduzido pelos TC's é menor. A segunda inclinação é menos sensível e usada para altas correntes. O objetivo dessa segunda inclinação é acomodar os maiores erros introduzidos pelos TC's devido às altas correntes de carga e possíveis saturações em condições de faltas externas (GUZMÁN et. al., 2001).

\subsection{Causas do surgimento de correntes diferenciais indesejadas}

Certos tipos de manobras operacionais nos transformadores podem causar 0 aparecimento de correntes diferenciais, que não de defeito, mas que podem sensibilizar a proteção diferencial. Entretanto, em algumas dessas situações, não se deseja que a proteção desative o sistema, pois as mesmas não constituem faltas internas ao transformador. Assim, torna-se necessário um estudo sobre estes tipos de manobras no sentido da sensibilização destas à proteção diferencial do transformador, para que se possa distinguir entre a atuação ou não da proteção caracterizada. Abaixo, citam-se algumas dessas situações que serão posteriormente comentadas:

- Corrente de magnetização (corrente de "inrush") durante a energização do transformador;

- Sobreexcitação do transformador;

- Corrente de magnetização em decorrência da remoção de falta próxima ao transformador;

- Saturação de TC's devido às altas correntes que o percorrem;

- Rejeição de carga.

No que segue, serão comentados alguns destes tipos de manobras que podem provocar o aparecimento de correntes diferenciais significativas a ponto de sensibilizar a corrente diferencial e originar uma operação incorreta do sistema de proteção. 


\subsubsection{Correntes de magnetização (inrush)}

Este tipo de transitório surge durante a energização do transformador devido à magnetização e a saturação do seu núcleo. Sua magnitude é definida pela inclinação da característica de magnetização na região saturada.

Como fato temos que, durante a energização, o transformador encontra-se a vazio, isto é, seu lado secundário está desconectado do restante do circuito (sem carga). Assim, a corrente deste lado é nula, enquanto que a corrente primária é elevada devido à energização. Por esta situação o relé poderá ser sensibilizado, causando uma indevida operação. Este efeito transitório pode persistir por vários segundos até a condição de regime permanente ser alcançada e causar uma desnecessária operação do relé pela filosofia da proteção diferencial adotada. Logo, para evitar operações desnecessárias pela corrente de magnetização, os relés devem ser projetados com uma reduzida sensibilidade para a corrente transitória de inrush.

O fenômeno da corrente de magnetização, ou corrente de inrush durante a energização dos transformadores tem sido ponto de estudo nos projetos e desenvolvimentos da proteção diferencial aplicados a sistemas de potência, tanto na distribuição como na transmissão (LING.e BASAK, 1988, 1989 ; LIN et. al., 1993 ; STIGANT e LACEY, 1929). Como observado na literatura (LING.e BASAK, 1988), a corrente de magnetização, na situação de regime permanente, comumente representa de 1 a $2 \%$ da corrente nominal, podendo, no entanto, alcançar de 10 a 20 vezes quando da energização do transformador.

Para equacionar a situação da energização de um transformador, segue-se dos esclarecimentos apresentados por OLIVEIRA et. al. (1984, p. 8-10), onde, aplicando-se uma tensão senoidal ao enrolamento primário do transformador, estando o secundário a vazio, tem-se que:

$$
v_{1}=r_{1} i_{0}+l_{1} \frac{d i_{0}}{d t}+N_{1} \frac{d \phi}{d t}
$$

Sendo:

$$
\begin{aligned}
r_{1} \cdot i_{0} & =\text { queda de tensão na resistência do primário; } \\
l_{1} \frac{d i_{0}}{d t} & =\text { queda de tensão devido ao fluxo de dispersão do enrolamento primário e }
\end{aligned}
$$


$N_{1} \frac{d \phi}{d t}=$ força eletromotriz induzida no primário.

A solução desta equação diferencial passa pela relação existente entre o fluxo $\phi$ e a corrente a vazio $i_{0}$, a qual evidencia a relação não-linear dada pelo ciclo de histerese. Em função desta não-linearidade, torna-se necessário alguma aproximação para a obtenção de $i_{0}$ a partir da equação (6). Desta maneira, a solução desejada consistirá de duas partes fundamentais:

- da solução complementar (termo transitório) e da

- $\quad$ solução particular (regime permanente)

O termo transitório da solução complementar representa exatamente a corrente de magnetização (inrush), detectada pela primeira vez por Fleming em 1892 (PIOVESAN, 1997). O fenômeno observado mostrou que quando um transformador é conectado a rede, por vezes há o aparecimento de uma grande corrente transitória de magnetização (corrente de inrush). O efeito da referida corrente é causar momentaneamente uma queda na tensão alimentadora e a provável atuação instantânea dos relés. Conforme apresentado por Fleming, o valor atingido na fase transitória dependerá de dois fatores:

a) do ponto do ciclo referente à tensão, no qual a chave para a energização é fechada e das

b) condições magnéticas do núcleo, incluindo a intensidade e a polaridade do fluxo residual.

Considerando como primeira aproximação que os dois primeiros termos da equação (6) podem ser desprezados, e admitindo-se que, no instante inicial do processo de energização, a tensão da fonte passa por um valor $V_{1 m}$. $\operatorname{sen} \alpha$, em que $\alpha$ é um ângulo qualquer cujo propósito é definir o valor da tensão da fonte no instante $t=0$, tem-se que:

$$
v_{1}=V_{1 m} \cdot \operatorname{sen}(w t+\alpha)=N_{1} \frac{d \phi}{d t}
$$


Onde:

$V_{1 m}$ é a tensão no instante de energização $(t=0)$ e

$\alpha$ o ângulo que define o valor da tensão.

Integrando-se a equação (7), vem:

$$
\phi=\phi_{0}+\phi_{m} \cdot \cos (\alpha)-\phi_{m} \cdot \cos (w t+\alpha)
$$

Sendo $\phi_{0}$ o fluxo residual no instante $t=0$ e $\phi_{m}$ o fluxo na energização.

Em casos reais, o termo $\phi_{0}+\phi_{m} \cdot \cos (\alpha)$ sofre amortecimento e após encerrado o transitório da energização, apenas o termo $\phi_{m} \cdot \cos (w t+\alpha)$ irá representar o fluxo do núcleo.

$\mathrm{O}$ valor $\phi_{\text {pico }}$ é muito elevado e, conseqüentemente, a corrente $i_{0}$ necessária para produzi-lo torna-se muito alta na energização. A Figura 3 traz a exata idéia do nível de corrente de magnetização, comparando-a com a corrente de regime permanente, ainda que esta tenha ocorrido no instante zero da tensão (STIGANT e LACEY, 1925), onde $i_{r}$ é a corrente de inrush e $i_{n}$ a corrente nominal em regime permanente.

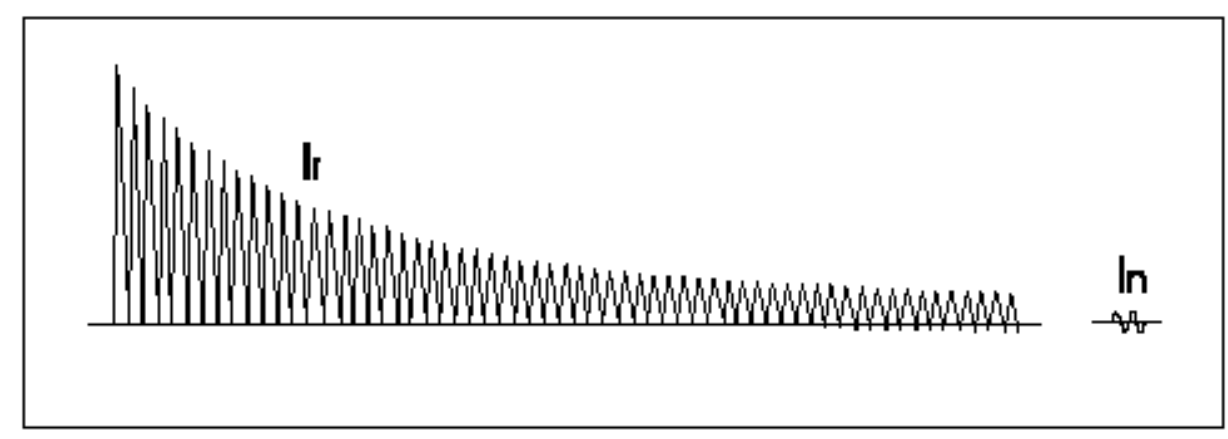

Figura 3. Amplitudes das correntes de inrush e nominal.

Dos apontamentos levantados, faz-se então necessário prover a proteção diferencial da habilidade de distinção entre uma condição de energização e a de falta propriamente dita. Um dos métodos utilizados para tal habilidade é baseado na restrição por componentes harmônicos. De conhecimento, tem-se que a corrente de magnetização é rica em 
componentes harmônicos de $2^{\mathrm{a}}$ ordem, alcançando valores típicos acima de $16 \%$ da componente de freqüência fundamental, e, em alguns casos, atingindo até $70 \%$ da mesma (PIHLER et. al., 1997 ; KOLLA, 1995). Já no caso de uma real situação de falta, a menos de um possível descaimento do componente DC, os componentes harmônicos estarão limitados à freqüência do sistema $(60 \mathrm{~Hz})$. Assim, as formas de onda da corrente diferencial podem ser analisadas pelo conteúdo presente do segundo harmônico, utilizando-se da sua magnitude em relação a fundamental para restringir o disparo do relé nas situações de magnetização (KOLLA e GEDEON, 1995).

De acordo com que foi colocado, é apresentada a seguir a Tabela 1, cortesia da INEPAR (PIOVESAN, 1997), a qual caracteriza o conteúdo harmônico das possíveis correntes de magnetização para as classes de transformadores ilustrados. Ela confirma a forte presença do componente de $2^{\circ}$ harmônico nas correntes de magnetização, característica esta, amplamente empregada nos usuais sistemas de proteção como descrito anteriormente.

Tabela 1. Conteúdo harmônico das correntes de energização

\begin{tabular}{c|c|c|c|c}
\cline { 2 - 5 } \multicolumn{2}{c|}{} & \multicolumn{4}{c}{ TRANSFORMADORES TRIFÁSICOS } \\
\hline & $\begin{array}{c}\mathbf{6 6 k V} \\
\text { 12MVA }\end{array}$ & $\begin{array}{c}\text { 275kV } \\
\text { 150MVA }\end{array}$ & $\begin{array}{c}\text { 275kV, 50MVA } \\
\text { 20mponcos em paralelo }\end{array}$ & $\begin{array}{c}\text { 500kV, 1000MVA } \\
\text { 2 bancos em paralelo }\end{array}$ \\
\hline & $(\%)$ & $(\%)$ & $(\%)$ & $(\%)$ \\
\hline Fundamental & 100 & 100 & 100 & 100 \\
\hline Corr. Contínua & 62 & 100 & 100 & 97,1 \\
\hline $2^{\text {a }}$ & $\mathbf{6 0}$ & $\mathbf{3 0 , 4}$ & $\mathbf{3 3 , 1}$ & $\mathbf{7 8}$ \\
\hline $3^{\text {a }}$ & 9,4 & 9,6 & 18,2 & 31 \\
\hline $4^{\text {a }}$ & 5,4 & 1,6 & 6,5 & 18 \\
\hline $5^{\text {a }}$ & & 0,7 & 7,2 & 11,4 \\
\hline
\end{tabular}

A extração de componentes de freqüência é geralmente realizada pela aplicação da Transformada de Fourier (TF). A TF apresenta-se como um recurso matemático eficiente, mas que não evita que o relé eventualmente confunda as situações descritas, além de esbarrar no fato de que a ferramenta muitas vezes leva um tempo excessivo para a obtenção dos componentes desejados (além de um ciclo). Por estas razões, justifica-se o emprego de técnicas de Inteligência Artificial, como, por exemplo, de Redes Neurais Artificiais, Lógica Fuzzy e Algoritmos Genéticos, entre outras. 


\subsubsection{Remoção de faltas próximas ao transformador}

Quando uma falta externa e próxima ao transformador é removida, surge uma situação similar àquela encontrada durante a energização do transformador (HOROWITZ e PHADKE, 1995).

Como a tensão aplicada aos enrolamentos do transformador passa de um valor de falta para um valor normal de pós-falta, o fluxo concatenado também se comporta do mesmo modo, e, dependendo do instante no qual a falta é removida, esta transição leva à produção de um deslocamento da componente DC no fluxo concatenado. Deste modo, as formas de onda de corrente primária serão similares às correntes de inrush obtidas durante a energização do transformador. Deve ser notado que como não existe fluxo remanescente no núcleo durante este processo, essa corrente é em geral menor que durante a energização do transformador.

\subsubsection{Sobreexcitação do transformador}

O fluxo de magnetização dentro do núcleo do transformador é diretamente proporcional à tensão aplicada e inversamente proporcional à freqüência do sistema. Condições de sobretensão e ou subfreqüência podem produzir níveis de fluxo os quais podem a vir a saturar o núcleo do transformador (equação 9). Tais condições anormais de operação podem ser caracterizadas em qualquer parte do sistema de potência, expondo os equipamentos a este conectado (PIOVESAN, 1997 e GUZMÁN et. al., 2001). Observa-se então que esta sobreexcitação reflete-se nos transformadores, por mudanças na temperatura e aumento tanto na corrente de excitação, quanto no ruído e vibração. Destes fatos, a boa prática recomenda que um transformador sob uma severa condição de sobreexcitação deva ser desconectado do sistema a fim de se evitar maiores danos. Da dificuldade de controlar a tolerância do transformador a sobreexcitação, tem-se uma condição indesejável à proteção diferencial.

$$
V_{e f}=4,44 * n * \phi^{*} f
$$

De fato, a condição de sobreexcitação acontece quando o transformador está submetido a um valor de tensão muito superior à tensão nominal. Nesta situação, há um comportamento não-linear das correntes ante a variação de fluxo. Como conseqüência, 
ocorre distorções de $3^{\circ}$ e $5^{\circ}$ harmônicos, gerando assim um aumento nos valores de magnetização e também um aumento na corrente diferencial que percorre o relé. A Tabela 2 mostra o conteúdo de harmônicas ímpares no sinal de corrente em um banco de transformadores de 15kVA (três transformadores monofásicos de $5 \mathrm{kVA}$ ), para uma sobretensão de 150\% (GUZMÁN et. al., 2001). Por esta, pode-se notar a terceira e quinta harmônica, as quais fornecem grandezas confiáveis para detectar condições de sobreexcitação.

Tabela 2. Conteúdo das harmônicas da corrente de excitação durante a sobreexcitação do banco de transformadores

\begin{tabular}{c|c|c}
\hline $\begin{array}{c}\text { Componentes de } \\
\text { freqüência }\end{array}$ & $\begin{array}{c}\text { Magnitude } \\
\text { (Amperes Primários) }\end{array}$ & $\begin{array}{c}\text { Percentagem da } \\
\text { Fundamental }\end{array}$ \\
\hline Fundamental & 22,5 & 100,0 \\
\hline Terceira & 11,1 & 49,2 \\
\hline Quinta & 4,9 & 21,7 \\
\hline Sétima & 1,8 & 8,1 \\
\hline
\end{tabular}

Para os transformadores mais novos, a situação é ainda mais grave, pois existe a ocorrência de maiores distorções devido ao material constituinte do núcleo (LING.e BASAK, 1988). O monitoramento nesse caso é então executado em relação aos componentes de $5^{\circ}$ harmônico das correntes diferenciais. Caso esses valores excedam a um limite pré-estabelecido, o relé pode bloquear a operação ou considerar uma nova inclinação e corrente de pickup (ipu) de acordo com a Figura 2 mostrada anteriormente, possibilitando um aumento na tolerância do dispositivo de proteção como mencionado.

\subsubsection{Saturação dos TC's}

Um dos grandes problemas enfrentados pelos projetistas de sistemas de potência reside em situações nas quais os equipamentos elétricos ficam sujeitos à saturação de alguns de seus componentes (SEGATTO, 2005).

No caso específico da proteção de transformadores de potência, os transformadores de correntes (TC's) constituem os equipamentos que ficam expostos a esse fenômeno.

A função dos TC's, também conhecidos como transdutores, é transformar as correntes oriundas do sistema de potência em correntes de baixa magnitude e fornecer 
isolação galvânica entre a rede elétrica e os relés ou outros instrumentos conectados ao seu enrolamento secundário.

Os ajustes dos enrolamentos secundários dos TC's são padronizados entre 1 e 5A. Estes são valores nominais e os transdutores devem, portanto, ser projetados para tolerar valores maiores oriundos de condições anormais de operação do sistema. Desta maneira, os TC's são concebidos para suportar correntes de falta e outros surtos por pouco segundos. Tais sinais podem atingir valores de até 50 vezes a magnitude da corrente de carga nominal.

O desempenho dos transdutores sob corrente de carga não é tão preocupante quanto à situação em que o relé deve operar. Quando faltas ocorrem, além dos valores de corrente atingir níveis elevados, os sinais podem conter substanciais conteúdos de componentes DC, além da existência de fluxo remanescente no núcleo do transformador de corrente, produzindo significante distorção na forma de onda da corrente secundária do dispositivo. Portanto, a corrente secundária de um TC pode não representar precisamente sua corrente primária se o dispositivo saturar. Assim, os relés que dependem desta corrente podem facilmente operar de forma incorreta durante este período, comprometendo a eficiência da proteção do equipamento em questão.

\subsubsection{Rejeição de carga}

A rejeição de carga esta ligada diretamente com a freqüência e a tensão do sistema. Quando um sistema se encontra estável (freqüência de $60 \mathrm{~Hz}$ ), a potência mecânica de entrada do eixo do gerador é igual à soma das cargas conectadas a este, somadas ainda as perdas de potência reais no sistema. Qualquer significativa interferência neste balanço causa uma mudança na freqüência. Como fato temos que, a enorme massa rotacional do rotor (turbina e gerador) atua como um depósito de energia cinética. Logo, quando existe potência mecânica insuficiente na entrada do sistema (como por exemplo, em função de um aumento de carga), o rotor diminui de velocidade, suprindo energia para o sistema (ELMORE, 1982). De modo oposto, quando há um excesso de potência mecânica na entrada do sistema, ou seja, redução considerável de carga, este acelera, absorvendo energia. Sendo assim, qualquer mudança na velocidade causa uma variação proporcional à freqüência. 
Podemos analisar esta situação ao análogo da ocorrência no transformador. Usualmente os transformadores são projetados para operar perto do "joelho" da curva de saturação do núcleo de ferro. Isto significa que qualquer sobretensão, ou subfreqüência irá causar um aumento além do normal no fluxo do material do núcleo, podendo resultar em um aumento substancial da temperatura no núcleo (ANDERSON, 1999). Como uma afirmação geral da condição, podemos escrever o fluxo em função da tensão, freqüência e de uma constante de proporcionalidade, a qual é definida em função dos parâmetros do sistema.

$$
\phi=k\left(\frac{V}{f}\right)
$$

Sendo assim, podemos dizer que para uma condição de rejeição de carga, a proteção do transformador irá funcionar como no caso de uma sobreexcitação, detectando as componentes de $5^{\mathrm{a}}$ harmônico das correntes diferenciais. 


\section{LEVANTAMENTO BIBLIOGRÁFICO}

Um grande número de publicações em revistas especializadas, conferências, dissertações e teses indicam o relevante progresso dos trabalhos na área da proteção digital diferencial envolvendo basicamente a proteção do transformador e estudos sobre os mecanismos de prevenção contra problemas nos dispositivos do sistema, como os transformadores de corrente e as conexões envolvidas.

Cabe ressaltar que o objetivo desta revisão é a de somente apresentar alguns dos aprimoramentos encontrados no que se referem à proteção digital direcionada a transformadores. Poucos foram os relatos encontrados a respeito de metodologias e práticas laboratoriais que ilustrem um procedimento para se avaliar o comportamento dos relés digitais, disponíveis comercialmente, frente às situações simuladas.

Com relação ao esquema de detecção de correntes de inrush em transformadores, destaca-se inicialmente o trabalho de LING e BASAK (1988) no qual se analisa computacionalmente o conteúdo de $2^{\circ}$ harmônico presente na corrente de magnetização de um transformador monofásico e de outro trifásico, variando-se as suas conexões. O estudo mostra que a magnitude do conteúdo da segunda harmônica é afetada por vários parâmetros tais como o ângulo de chaveamento na onda da tensão, a densidade do fluxo remanescente no momento da energização, a resistência do enrolamento primário e a geometria do enrolamento. Apresentou-se neste estudo o uso de um novo algoritmo baseado na integração da forma de onda da corrente de inrush com um tempo de reconhecimento de 1 ciclo, o qual se mostrou consistente a qualquer condição de chaveamento.

Neste mesmo tema, LIN et. al., parte I e II (1993) demonstram uma proposta genérica de uma técnica de simulação da corrente de inrush em transformadores monofásicos de 3kVA e 7600V/130V/130V. Foram apresentados vários dados obtidos de simulações decorrentes da energização a vazio e da reenergização alterando a 
carga para resistiva, indutiva e capacitiva, sob diferentes condições de operação (considerando fluxo remanescente no núcleo e variação no ângulo de fase). Os resultados das simulações foram comparados com os resultados experimentais. Caracteriza-se também o relacionamento das harmônicas para todos os parâmetros discutidos. Na primeira parte do trabalho, é demonstrado o método empregado para a simulação das condições dos diferentes carregamentos propostos e a comparação destes com os resultados experimentados, com já afirmado. Na segunda parte foram realizadas análises harmônicas dos dados simulados e experimentados. Os resultados estabeleceram uma perspectiva para a eliminação dos componentes harmônicos decorrentes da corrente de inrush, sendo uma importante referência para projetos neste contexto.

No trabalho de LING e BASAK (1989) o objetivo foi de fornecer um melhor entendimento do efeito combinacional entre vários parâmetros como magnitude, duração e conteúdo harmônico, decorrentes da corrente de magnetização em um transformador, no instante da energização. O algoritmo foi desenvolvido para se obter informações sobre corrente de magnetização em termos de magnitude, duração e conteúdo harmônico a cada ciclo. O programa executa a amostragem dos dados em intervalo de tempo de $47 \mu$ s sobre os 50 primeiros ciclos da corrente de inrush e avalia ciclo por ciclo a magnitude, duração e o conteúdo harmônico caracterizados. Medições reais sobre um transformador monofásico de 2,5 kVA, o qual fora computacionalmente estudado mostrou certos detalhes de análises importantes não somente para o projeto da proteção, mas também para um estudo de interferências na rede elétrica.

No trabalho de BRONZEADO e YACAMINI (1995), o objetivo foi mostrar o efeito da corrente transitória de inrush em sistemas com considerável resistência, como por exemplo, as longas linhas de transmissão do sistema da CHESF (Companhia Hidro Elétrica do São Francisco-MG). Este sistema possui em operação vários transformadores que podem experimentar inesperadas saturações devido à entrada de novos transformadores acoplados ao sistema. Isto gera uma interação transitória entre os transformadores, chamada de "sympathetic interaction", a qual afeta a magnitude e duração da corrente de inrush. Como conseqüências, podem ocorrer problemas na operação dos sistemas, como falsas operações nos relés diferenciais dos transformadores e sobretensões harmônicas de longa duração. O impacto e a duração desta interação dependerão dos níveis de saturação 
alcançados pelo transformador e do padrão de dissipação de energia do sistema. Foram investigados e validados para este modelo de sistema, transformadores conectados em paralelo e em série.

A apresentação de GUZMAN et. al., parte I e II (2001 e 2002) traz, na primeira parte, uma revisão dos conceitos básicos relacionados à proteção diferencial e métodos para a discriminação entre faltas internas, correntes de inrush e condições de sobreexcitação, como uma possível causa de má operação de relé. Ainda nesta parte o estudo traz a teoria do método baseado em restrição por harmônicas e do método de reconhecimento de forma de onda. Na segunda parte do trabalho, descreve-se um novo conceito para a proteção de corrente diferencial, combinando a restrição por harmônicos e método de bloqueio com a técnica de reconhecimento da forma de onda analisada, vista na parte I. Este método emprega os harmônicos pares para restringir e também bloquear as operações, somando-se ainda uma análise do componente DC e do quinto harmônico quando caracterizado. Segundo os autores, a restrição por harmônicos pares provê uma segurança para as correntes de inrush com baixo conteúdo de segundo harmônico, mantendo a confiança para faltas internas com saturação de TC. O uso do bloqueio pelo quinto harmônico garante uma resposta invariante do relé para a sobreexcitação. Usando o bloqueio pelo deslocamento da forma de onda caracterizado pelo componente DC, asseguram-se as condições de inrush com baixa distorção harmônica total.

O trabalho de STRINGER et. al. (1997) traz um apanhado bibliográfico sobre a condição de magnetização (inrush) dos transformadores e simulações através do software EMTP (Electro-Magnetic Transient Program) para aplicações industriais. Este, primeiramente apresenta os testes realizados em bancada de acordo com norma ANSI (American National Standards Institute), simulando testes em serviço e, posteriormente, em fábrica, dispondo de transformadores trifásicos de $52 \mathrm{kVA}$ conectados ao sistema local.

O trabalho de KASZTENNY e KEZUNOVIC (1998) faz um breve resumo do estado da arte, discutindo propostas e futuras direções para a proteção digital aplicado a transformadores de potência. Deixam claro que os relés de proteção para transformadores de potência impõem altas exigências para seu correto funcionamento. As necessidades incluem confiança na proteção (sem perdas de operação), segurança (sem falsas operações) e velocidade de operação (curto tempo de extinção da falta). Os autores comentam das 
técnicas avançadas de processamento digital do sinal, denotando as técnicas de inteligência artificial, as quais vêm a favorecer os princípios clássicos da proteção, propiciando rapidez, segurança e confiança na proteção de transformadores de potência.

CROSSLEY ; LI e PARKER (1998), propõem a aplicação de um novo simulador em substituição ao comumente empregado para testes de proteção digital. O modelo físico comumente empregado está em utilização a mais de 30 anos pelos fabricantes para aprovações de testes de proteção do relé diferencial. A nova abordagem dispõe do EMTP (Electro-Magnetic Transient Program) para avaliação do desempenho da proteção digital referente às zonas de proteção associadas. Os resultados apontados descrevem a operação do sistema frente a condições de faltas internas e externas, comparando-os aos resultados do modelo fisicamente modelado. As conclusões apontadas validam o uso do EMTP em um sistema de testes em respeito à filosofia da proteção diferencial.

KANG et. al. (1996 e 1997), apresentam algoritmos para estimar a corrente secundária decorrente da relação do TC sob saturação, dispondo da curva do fluxo versus a corrente. Os resultados da implementação em hardware dos algoritmos usando um processador digital de sinais foram apresentados no trabalho. A principal vantagem dos métodos é que eles podem melhorar a sensibilidade dos relés para faltas internas de baixa amplitude, maximizar a estabilidade dos relés para faltas externas e reduzir a seção requerida para o núcleo do TC.

KEZUNOVIC et. al. (1994), apresentam neste trabalho modelagens de TC's digitais, objetivando a análise do seu desempenho na proteção frente aos transitórios caracterizados. A primeira fase consistiu na avaliação experimental dos TC's em um laboratório de alta tensão, seguindo-se das suas modelagens e implementações empregando o software EMTP (Electro-Magnetic Transient Program). Os resultados baseados no programa EMTP apresentaram-se satisfatórios para a maioria dos casos quando comparados aos testes reais em laboratório. Foram utilizados para este estudo dois modelos de TC's, um com proporção de 600/5A, e outro de 2000/5A. Estes foram levados à condição de saturação, sofrendo variações nos valores de carga, ângulo de fase e na consideração do fluxo remanescente.

MOZINA (1999), mostra em seu trabalho a tendência da proteção de transformadores de potência. Hoje, com o advento dos modernos pacotes multifuncionais 
para transformadores, a proteção diferencial e a de sobrecorrente são duas das muitas filosofias de proteção e funções lógicas incorporadas. Funções essas que podem ser selecionáveis pelo usuário. Dentre as funções, destacam-se: sobreexcitação, sobretensão de neutro, diferencial de neutro e rejeição de carga. Essas funções permitem a parametrização do relé para distintas e específicas aplicações. Vale lembrar que associada a todas as funções habilitadas, há um considerável custo envolvido, como bem lembram os autores. 


\section{O SISTEMA ELÉTRICO EM ANÁLISE}

Este capítulo traz um pequeno histórico sobre o programa ATP - Alternative Transients Program, juntamente com o modelo do sistema elétrico estudado, compreendendo o transformador de potência trifásico e dos Transformadores de Corrente (TC's) empregados na simulação. São apresentados também os cálculos realizados para a formatação dos arquivos de dados utilizados, além de gráficos que ilustram algumas das situações envolvidas no trabalho.

\subsection{Um breve histórico do programa ATP}

O presente estudo sobre proteção diferencial digital dos transformadores de potência contou com o emprego do software ATP, na simulação de um sistema elétrico composto por uma fonte equivalente, um transformador trifásico, dois transformadores de corrente, uma pequena linha de distribuição com $5 \mathrm{~km}$ de extensão e uma carga indutiva, a qual teve sua potência variada durante a realização dos testes.

O programa EMTP (Electro-Magnetic Transients Program, do qual o ATP é originado) foi desenvolvido a partir da década de 60 por Herman W. Dommel, para a Bonneville Power Administration (BPA). Inicialmente o software trabalhava simulando circuitos monofásicos através de modelos de indutâncias, capacitâncias e resistências em linhas sem perdas, incluindo uma chave e uma fonte de excitação. A partir de 1973, Scott Meyer assumiu a coordenação e o desenvolvimento do programa na BPA, estabelecendo um método de desenvolvimento em conjunto com os usuários do EMTP, que o tornou uma poderosa ferramenta de estudos dos transitórios em sistemas elétricos. Algumas divergências entre Scott Meyer e o EPRI - Electric Power Researched Institute - que investiu no projeto do EMTP a partir de 1984, levaram a criação de uma nova versão do 
EMTP, a qual foi enviada para a Bélgica, onde se instalou o Leuven EMTP Center (LEC). Esta nova versão foi denominada ATP - Alternative Transients Program, que representa a continuação das versões precedentes do programa (ATP-Rule Book, 1987).

O programa EMTP-ATP trabalha com arquivos de entrada em formato texto, gerando entre outros, arquivos com extensão .LIS. e .PL4 após a sua execução, os quais apresentam os resultados obtidos na simulação. O arquivo de dados fornecido para o ATP tem um formato rigidamente prefixado, de modo que os dados são inseridos em posições definidas, sob pena de erro de processamento. O ATP apresenta uma saída crítica do arquivo de dados de entrada em execução. Assim, caso haja a ocorrência de erros, muitas vezes é possível corrigi-los simplesmente pela análise da resposta constante deste arquivo de saída.

\subsection{O sistema modelado}

A Figura 4 a seguir mostra um esquema representativo do sistema elétrico envolvido, com a designação dos nós utilizados nos arquivos de dados do EMTP-ATP.

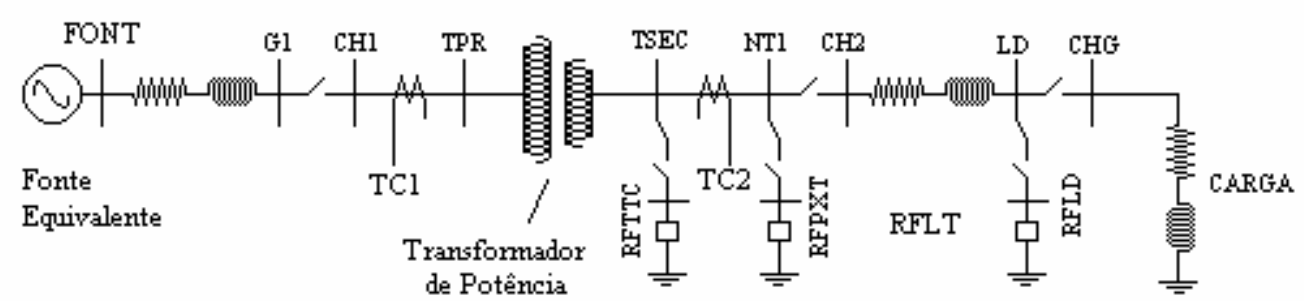

Figura 4. Modelo do sistema elétrico utilizado no ATP.

O sistema elétrico consiste de uma fonte equivalente de $138 \mathrm{kV}$, potência de 30 MVA, conectada a um transformador de potência de 25 MVA, relação de transformação de $138 \mathrm{kV}$ para $13,8 \mathrm{kV}$, em ligação triângulo-estrela aterrado, dois transformadores de corrente para a medição das magnitudes (relação de transformação sendo no primário de 200 : 5A e no secundário de 2000 : 5A), seguido de uma pequena linha de distribuição com $5 \mathrm{~km}$ de extensão (entre os nós CH2 e LD da figura mostrada), conectando uma carga (leve 
de 1,25MVA, média de 10 MVA e pesada de 23,75 MVA), com fator de potência 0,92 indutivo.

As demais chaves presentes na ilustração são operadas durante o estudo para a simulação de faltas e condições de energização do transformador principal.

Cabe observar que as ligações entre os TC's e o transformador de potência foram executadas para não haver a compensação do respectivo defasamento que ocorre devido à ligação delta-estrela do transformador de potência. Essa compensação foi observada quando da parametrização do relé digital.

\subsubsection{O modelo do transformador principal}

As Figuras 5 e 6 apresentam o modelo do transformador empregado e o detalhe das conexões dos enrolamentos respectivamente.

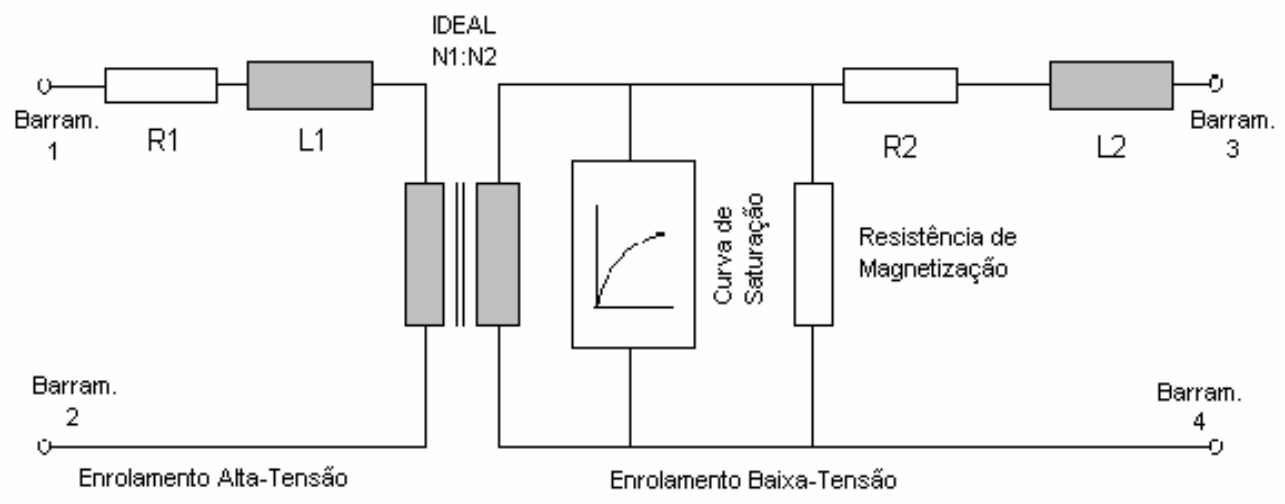

Figura 5. Modelo do transformador monofásico empregado - ATP. 


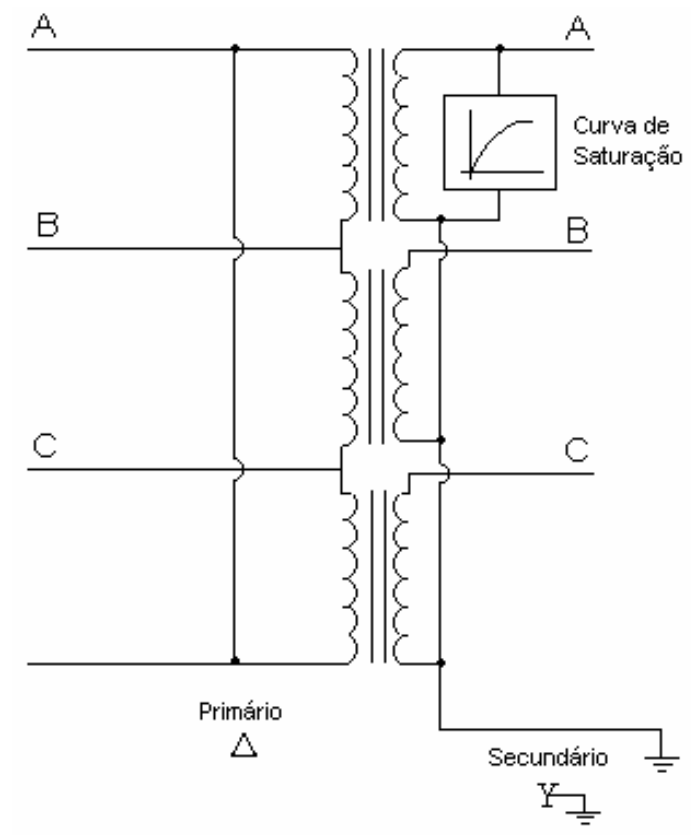

Figura 6. Detalhe das conexões dos enrolamentos.

Para a formatação das situações a serem simuladas pelo software ATP, a partir do modelo monofásico do transformador, modelou-se uma configuração trifásica $(138 \mathrm{kV}$ para 13,8 kV), com conexão delta-estrela aterrado (detalhe Figura 6). Seus enrolamentos foram então divididos em percentagens do total de modo que se pudesse fazer um estudo aprofundado das situações de faltas internas ao mesmo (Figura 7). Como exemplo, podemos descrever uma divisão com 10, 50 e 80\% no enrolamento primário, como mostrado na Figura 8.
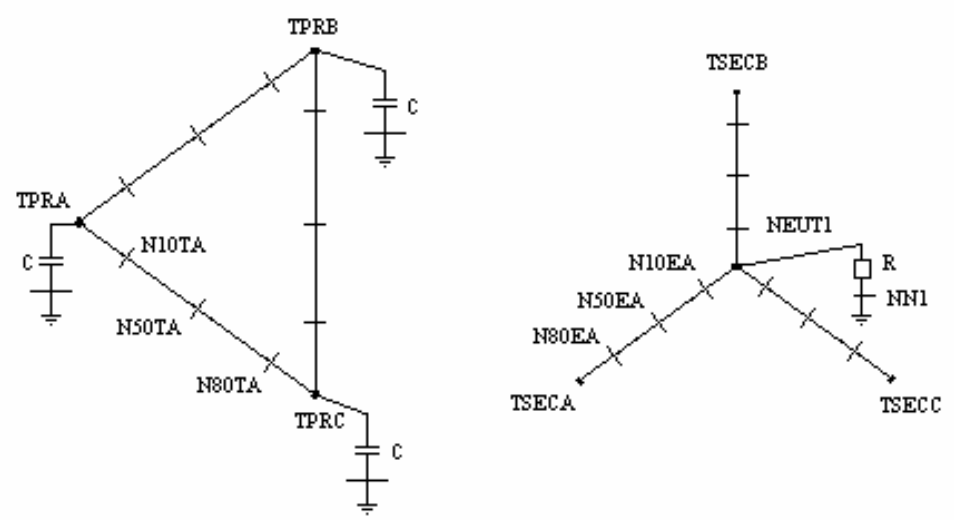

Figura 7. Detalhe da ligação triângulo-estrela aterrado. 


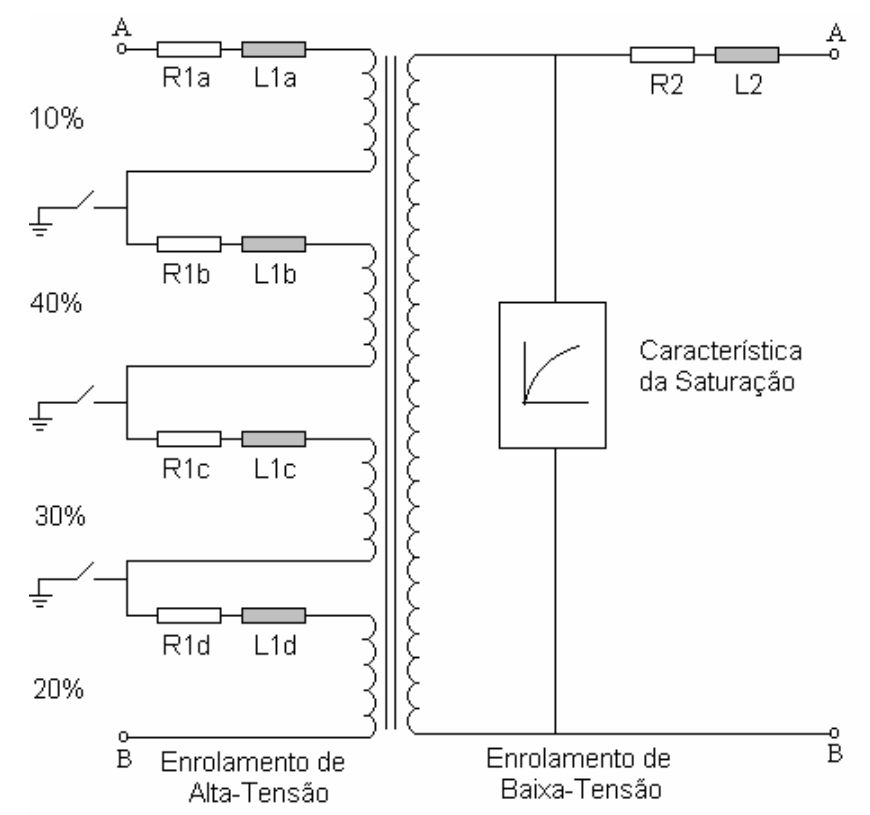

Figura 8. Partição do enrolamento primário do transformador em 10, 50 e 80\%.

\subsubsection{Transformadores de medição}

Como já frisado, os TC's constituem uma importante composição para o sistema de proteção como um todo. Os TC's destinam-se a evitar a conexão direta dos medidores ao circuito de corrente alternada de alta tensão, reduzindo assim os valores de corrente para níveis seguros e manipuláveis pelo acesso humano. Pelos seus aspectos construtivos, são acoplados em série com os ramos primário e secundário do transformador principal, sendo que as correntes medidas obedecerão a uma relação de transformação e terão as formas fiéis às do sistema representado.

Vale relembrar algumas situações práticas entre as conexões adotadas para os TC's de medição e para o transformador principal. Deve-se citar uma característica presente em qualquer sistema constituído de um transformador trifásico ligado em conexão do tipo estrela-triângulo ou triângulo-estrela. Sabe-se que em ligações desse tipo, há o surgimento de uma defasagem angular de 30 graus entre as correntes dos lados primário e secundário do transformador (OLIVEIRA et. al.,1984). Para corrigir esta defasagem angular, é usado na prática um artifício que consiste em instalar os equipamentos de medição (TC's) de maneira inversa às ligações dos lados do transformador principal. Desta forma, para um 
transformador ligado em estrela-triângulo, por exemplo, usam-se os TC's conectados em triângulo-estrela.

Alguns fabricantes recomendam o uso de um transformador de corrente auxiliar para a realização desta compensação de fase, localizado antes da entrada das correntes no relé, ao invés da inversão de conexões citadas.

Para esse estudo em específico, foi empregada a conexão estrela para os enrolamentos secundários dos dois TC's associados, para assim, continuar a existir o defasamento de 30 graus da ligação delta-estrela aterrado do transformador de potência. Esse defasamento será compensado pelo próprio relé digital, evidenciando uma das vantagens de seu uso em relação aos eletrônicos e ou eletromecânicos convencionais.

Para o trabalho foram utilizados dois TC's com relação de transformação de 40:1, sendo 200:5 A no lado do enrolamento de alta tensão e com relação de transformação de 400:1, sendo 2000:5 A no lado do enrolamento de baixa tensão.

Vale ressaltar que na prática todos os TC's apresentam erros intrínsecos de transformação e, portanto, é desejável que aqueles na entrada e saída finais da zona de proteção sejam idênticos para tentar assegurar que seus erros durante condições normais e de falta externa sejam controláveis. Nessas condições, o balanceamento das correntes secundárias do par de transformadores será igual todo o tempo, e corrente zero fluirá nos relés exceto quando da caracterização de situações de faltas internas. 


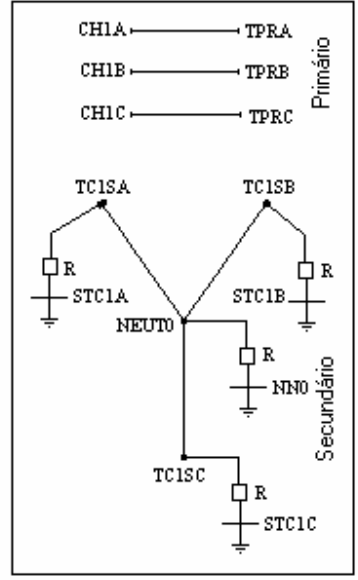

Conexão do Translormador de Corrente no Primário doTranstormador de Potencia

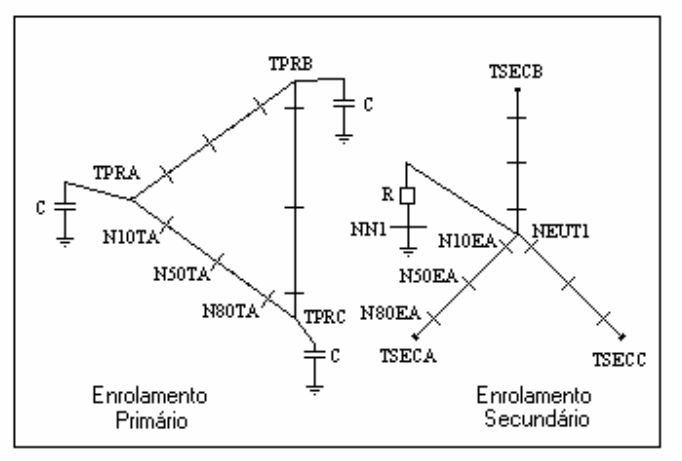

Conexã̃o do Transtormador de Potência

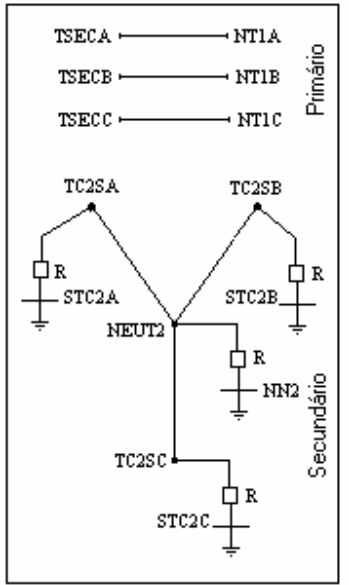

Conexã̃o do Transformador de Corrente lado no Secundárió doTransformador de Potencia

Figura 9. Detalhe das ligações do transformador principal e TC's

\subsection{3. $\mathrm{O}$ arquivo de dados para $\mathrm{o}$ ATP}

Serão apresentados a seguir os cálculos realizados na formatação do arquivo de dados para o sistema elétrico em questão.

\section{a) Fonte equivalente}

Os dados empregados para caracterizar a fonte equivalente são expostos abaixo.

- Resistência de seqüência zero $\mathrm{R}_{0}=7,5962 \Omega$

- Resistência de seqüência positiva $\mathrm{R}_{+}=7,1003 \Omega$

- Indutância de seqüência zero $\mathrm{L}_{0}=115,45 \mathrm{mH}$

- Indutância de seqüência positiva $\mathrm{L}_{+}=53,99 \mathrm{mH}$

\section{b) Parâmetros para a linha de distribuição}

Os dados para a linha de distribuição foram fornecidos pela concessionária de energia elétrica CPFL (Companhia Paulista de Força e Luz) e estão listados abaixo. 
- Resistência de seqüência zero $R_{0}=0,7186 \Omega$

- Resistência de seqüência positiva $R_{+}=0,3101 \Omega$

- Indutância de seqüência zero $L_{0}=11,45 m H$

- Indutância de seqüência positiva $L_{+}=2,41 \mathrm{mH}$

\section{c) Dados referentes à carga conectada em estrela com valor médio de 10MVA}

Para a carga conectada ao sistema em estrela, foram fornecidos os seguintes dados:

$-\mathrm{S}=10 \mathrm{MVA}$

- $\mathrm{U}=13,8 \mathrm{kV}$

- Fator de Potência =0,92 indutivo

No cálculo da impedância da carga, utilizou-se a seguinte relação:

$$
Z=\frac{U^{2}}{S}
$$

Desta forma, obtemos:

$$
Z=\frac{\left(13,8 \times 10^{3}\right)^{2}}{10 \times 10^{6}}=19,044 \Omega
$$

Através do fator de potência é possível obter os valores de resistência e indutância para a carga. Sabemos que:

$$
R=|Z| \cdot \cos (\theta) \quad \text { e } \quad X=|Z| \cdot \operatorname{sen}(\theta)
$$

Sendo: $\quad \theta=\operatorname{arcos}(0,92) \Rightarrow \theta=23,07^{\circ}$, e $X=W . L$

Portanto, os valores constituintes do arquivo de dados serão:

$$
R=17,520 \Omega \text { e } L=19,789 m H
$$

Para a caracterização dos valores de carga leve e pesada foi realizado o mesmo procedimento de cálculo, usando-se como base o valor de 5\% da carga do transformador para leve, e de $95 \%$ da carga do transformador, para pesada.

Para cálculo dos valores com carga conectada em delta, faz-se o uso da seguinte regra:

$$
\mathrm{Z} \Delta=3 * \mathrm{ZY}
$$




\section{d) Cálculos referentes ao transformador de potência com conexão delta - estrela} aterrada

No arquivo de dados principal, faz-se necessário à caracterização da curva de saturação do transformador, obtida através da rotina SATURATION (ATP - Rule Book, 1987).

Originalmente, faz-se uso de uma tabela com dados de tensão e corrente medidos no transformador. Esses dados são inseridos em um arquivo especialmente formatado para gerar valores de corrente e fluxo, através de uma rotina intrínseca do ATP, chamada SATURATION. Esses dados de tensão e fluxo são então empregados no arquivo principal de dados para a modelagem do transformador.

Os cálculos elaborados são os seguintes:

- Potência do transformador $=25$ MVA

- Potência-base:

$$
S_{\text {BASE }}=\frac{S_{\text {TRANSFORMADOR }}}{3}=\frac{25}{3}=8,33 M V A
$$

- Tensão-base:

$$
V_{B A S E}=\frac{13,8 \mathrm{kV}}{\sqrt{3}}=7,968 \mathrm{kV}
$$

- Corrente-base:

$$
I_{B A S E}=\frac{S_{B A S E}}{V_{B A S E}}=1,0459 \mathrm{kA}
$$

Os valores de tensão e corrente, medidos no secundário do transformador são fornecidos e os valores de corrente em p.u. são calculados, dividindo-se o valor da corrente (A) pelo valor da corrente-base $\left(I_{B A S E}\right)$. Esses valores são representados na Tabela 3 abaixo: 
Tabela 3. Dados de tensão e corrente para a rotina SATURATION

\begin{tabular}{c|c|c}
\hline Tensão (p.u.) & Corrente (A) & Corrente (p.u.) \\
\hline 0,90 & 0,75 & $0,717 \times 10^{-03}$ \\
\hline 1,00 & 1,51 & $1,450 \times 10^{-03}$ \\
\hline 1,10 & 8,34 & $7,978 \times 10^{-03}$ \\
\hline 1,15 & 43,00 & $41,112 \times 10^{-03}$ \\
\hline 1,18 & 119,00 & $113,777 \times 10^{-03}$ \\
\hline
\end{tabular}

De posse dos dados de tensão e corrente, os campos de entrada da rotina SATURATION são preenchidos e a curva de saturação (corrente versus fluxo) é calculada ponto a ponto, preenchendo o arquivo principal de dados para a simulação. A Figura 10 mostra a curva de saturação calculada para o transformador de 25 MVA.

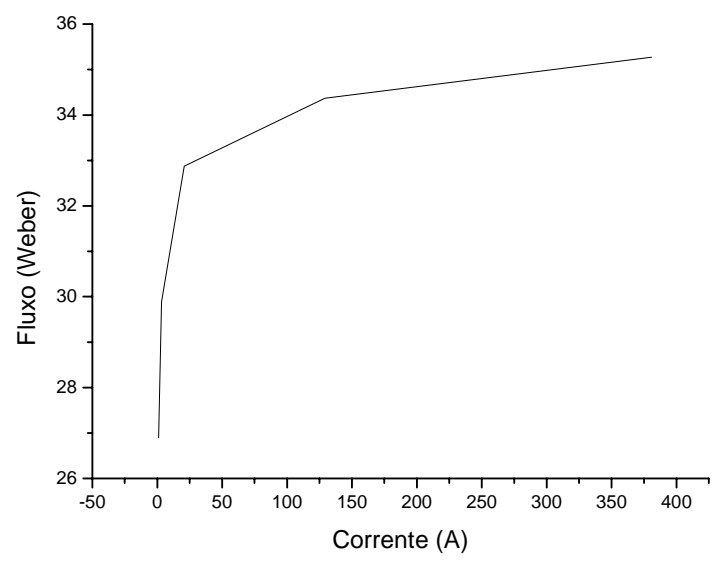

Figura 10. Curva de saturação do transformador de potência do sistema elétrico

Um dos aspectos deste estudo diz respeito à curva de saturação do transformador protegido e dos TC's considerados.

Foi observado durante o estudo que a curva de saturação do transformador de potência influi diretamente no descaimento exponencial da corrente de inrush presente nas manobras de energização, ao passo que, a saturação dos TC's, influi sobre o comportamento do relé diferencial, no que diz respeito a sua situação nos casos de faltas externas ocorridas próximas ao transformador de potência. 


\section{e) Parâmetros para os transformadores de corrente (TC’s)}

Ao contrário do transformador de potência, que teve a sua curva de saturação calculada através da sub-rotina SATURATION, os dados para a modelagem da curva de saturação e dos demais parâmetros relacionados aos TC's foram fornecidos pela concessionária de energia elétrica CPFL e adaptados diretamente ao sistema em estudo (Figura 4).

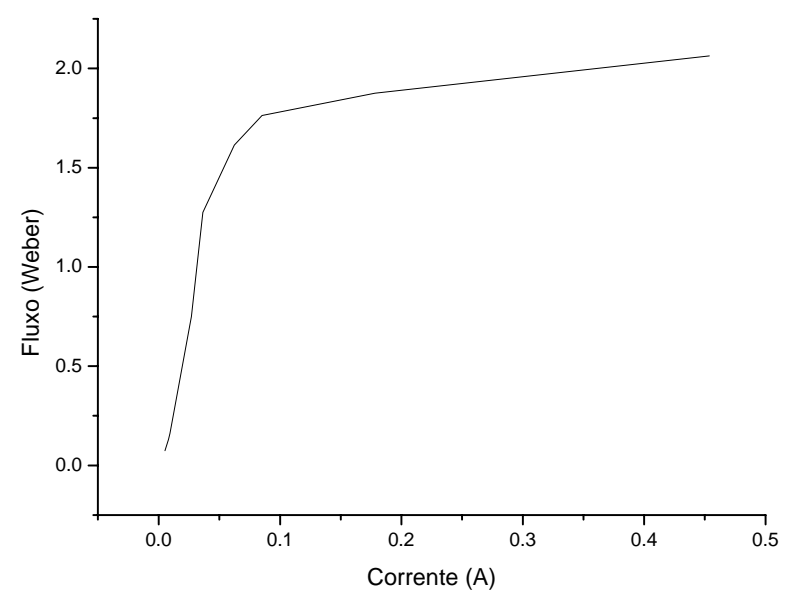

Figura 11. Curva de saturação dos transformadores de corrente do sistema elétrico

Os demais parâmetros para os TC's são listados a seguir:

- Indutância de dispersão do primário: $1,0 \times 10^{-4} H$

- Resistência de dispersão do primário: $0,85 \Omega$

- Indutância de dispersão do secundário: $1,0 \times 10^{-4} \mathrm{H}$

- Resistência de dispersão do secundário: $1,0 \times 10^{-4} \Omega$

- Relação de transformação: 1:40 no primário e 1:400 no secundário.

\subsection{Situações de faltas aplicadas}

Pela formatação do sistema elétrico a ser analisado, considerando a aplicação do software ATP, várias situações operacionais como energização, faltas (internas e externas), condição de sobreexcitação e de saturação dos TC juntos ao transformador de potência foram geradas. 
Para as situações de faltas internas, considerando as conexões do transformador de potência sendo delta-estrela aterrado, houve uma primeira fase de testes onde $o$ enrolamento primário entre as fases A e B foi dividido em porções correspondentes a 10, 50 e $80 \%$ do seu total, para valores de resistência, indutância e tensão relativa a terra (Tabela 4). Este procedimento também foi aplicado ao enrolamento secundário, tendo como referência para a divisão o neutro. Portanto a partir do neutro, tem-se a divisão de 10, 50 e $80 \%$ (Tabela 5). Ainda no tocante a faltas internas, houve uma segunda fase de testes onde somente se dividiu o enrolamento secundário de 5\% até 40\% (Tabela 6), aplicando passos de 5\%, modificando-se ainda o valor da carga conectada a este, qual era considerada média com valor 10 MVA, e permitindo caracterizar carga leve (5\% do carregamento do transformador) e pesada (95\% de carregamento do transformador). Cabe esclarecer que em todos os testes realizados nesta segunda fase, quando da ocorrência de falta interna, considerou-se conexão estrela ou delta para a carga caracterizada.

As faltas externas foram aplicadas na linha de distribuição no ponto indicativo LD da Figura 4, e próximas ao TC secundário indicado pelo ponto NT1 da mesma figura.

A energização do transformador de potência foi realizada considerando-se conexão do tipo delta-estrela aterrado. Cabe comentar que uma situação de falta interna aplicada a partir do momento de energização do transformador também foi considerada.

A condição de sobreexcitação foi considerada com a carga conectada, caracterizando, no entanto, $140 \%$ de tensão na entrada do transformador.

A condição de saturação foi obtida pela aplicação de uma falta externa próxima ao TC do secundário do transformador principal e pela decorrência da mudança de parâmetros no próprio TC.

Tabela 4. Divisão do enrolamento primário, Triângulo, em 10, 50 e $80 \%$ na aplicação de faltas internas com conexão delta-estrela aterrada.

\begin{tabular}{c|c|c|c|c}
\hline $\begin{array}{c}\text { Denominação } \\
\text { dos nós (ATP) }\end{array}$ & $\begin{array}{c}\text { Percentagem do } \\
\text { enrolamento } \\
\text { primário }\end{array}$ & $\begin{array}{c}\text { Resistência } \\
(\Omega)\end{array}$ & $\begin{array}{c}\text { Indutância } \\
(\mathrm{mH})\end{array}$ & $\begin{array}{c}\text { Tensão } \\
(\mathrm{kV})\end{array}$ \\
\hline TPRA-N10TA & $10 \%$ & 0,1048 & 9,083 & 13,80 \\
\hline N10TA-N50TA & $50 \%$ & 0,4192 & 36,332 & 55,20 \\
\hline N50TA-N80TA & $80 \%$ & 0,3144 & 27,249 & 41,40 \\
\hline N80TA-TPRB & $20 \%$ & 0,2096 & 18,166 & 27,60 \\
\hline
\end{tabular}


Tabela 5. Divisão do enrolamento secundário, Estrela, em 80, 50 e 10\% na aplicação de faltas internas com conexão delta-estrela aterrada.

\begin{tabular}{l|c|c|c|c}
\hline $\begin{array}{c}\text { Denominação } \\
\text { dos nós (ATP) }\end{array}$ & $\begin{array}{c}\text { Percentagem do } \\
\text { enrolamento } \\
\text { primário }\end{array}$ & $\begin{array}{c}\text { Resistência } \\
(\Omega)\end{array}$ & $\begin{array}{c}\text { Indutância } \\
(\mathrm{mH})\end{array}$ & $\begin{array}{c}\text { Tensão } \\
(\mathrm{kV})\end{array}$ \\
\hline TSECA-N80EA & $20 \%$ & 0,00350 & 0,3028 & 1,5934 \\
\hline N80EA-N50EA & $80 \%$ & 0,00525 & 0,4542 & 2,3901 \\
\hline N50EA-N10EA & $50 \%$ & 0,00700 & 0,6056 & 3,1868 \\
\hline N10EA-NEUT1 & $10 \%$ & 0,00175 & 0,1514 & 0,7967 \\
\hline
\end{tabular}

Tabela 6. Divisão de enrolamento secundário, Estrela, de 5\% a 40\%, com passos de 5\%, na aplicação de faltas internas com conexão delta-estrela aterrada, para testes em carga leve, média ou pesada na ligação em estrela e delta.

\begin{tabular}{c|c|c|c|c}
\hline $\begin{array}{c}\text { Denominação } \\
\text { dos nós (ATP) }\end{array}$ & $\begin{array}{c}\text { Percentagem do } \\
\text { enrolamento } \\
\text { secundário }\end{array}$ & $\begin{array}{c}\text { Resistência } \\
(\Omega)\end{array}$ & $\begin{array}{c}\text { Indutância } \\
(\mathrm{mH})\end{array}$ & $\begin{array}{c}\text { Tensão } \\
(\mathrm{kV})\end{array}$ \\
\hline TSECA-N40EA & $60 \%$ & 0,010500 & 0,9084 & 4,78020 \\
\hline N40EA-N35EA & $40 \%$ & 0,007000 & 0,6056 & 3,18680 \\
\hline N35EA-N30EA & $35 \%$ & 0,006125 & 0,5299 & 2,78845 \\
\hline N30EA-N25EA & $30 \%$ & 0,005250 & 0,4542 & 2,39010 \\
\hline N25EA-N20EA & $25 \%$ & 0,004375 & 0,3785 & 1,99175 \\
\hline N20EA-N15EA & $20 \%$ & 0,003500 & 0,3028 & 1,59340 \\
\hline N15EA-N10EA & $15 \%$ & 0,002625 & 0,2271 & 1,19505 \\
\hline N10EA-N5EA & $10 \%$ & 0,001750 & 0,1514 & 0,79670 \\
\hline N5EA-NEUT1 & $5 \%$ & 0,000875 & 0,0757 & 0,39835 \\
\hline
\end{tabular}

Para todas as simulações efetuadas e a serem apresentadas neste trabalho, tomaramse como dados de saída representativos das condições do sistema, as correntes dos TC's e do neutro do transformador de potência. No Apêndice A é mostrada a máscara do programa (arquivo fonte), caracterizando uma situação de energização, que servirá como entrada para as situações geradas e simuladas vias ATP. Em função do número de situações geradas e simuladas, será apresentado no que segue alguns casos ilustrativos dos resultados obtidos.

Por pequenas alterações sobre a máscara que descreve o sistema como um todo, serão ilustradas algumas das situações resultantes. Cabe comentar que todas as situações de faltas (internas e ou externas) foram implementadas considerando somente um ângulo de incidência da falta de $0^{\circ}$ (zero grau).

A Figura 12 traz a situação de energização, sob um valor de tensão de $112,7 \mathrm{kV}$ (valor de pico fase-neutro), onde a fase A é fechada no instante $80,52 \mathrm{~ms}$, a fase B em 
$82,52 \mathrm{~ms}$ e a fase $\mathrm{C}$ em $84,52 \mathrm{~ms}$. Observando a Figura 13 notamos as componentes harmônicas obtidas da corrente de inrush da fase C, visto que para esta, observaram-se os valores mais acentuados da magnitude de corrente. Ressalta-se que esses valores foram obtidos considerando-se somente dados de pós-falta, merecendo atenção especial, o forte componente de $2^{\circ}$ harmônico manifestado.

A Figura 14 traz a situação de energização seguida de uma situação de falta, sob um valor de tensão de $112,7 \mathrm{kV}$, onde a fase A é fechada no instante $80,52 \mathrm{~ms}$, sendo aplicada uma falta em 82,52ms. Na figura 15 é obtido o gráfico das componentes harmônicas da mesma condição, observando que não houve praticamente nenhum componente harmônico significante devido ao surgimento da falta.

As Figuras 16 e 17 trazem a situação de falta interna (monofásica) aplicada ao primário do transformador em $10 \%$ do enrolamento A-C (conexão delta), sob tensão de $112,7 \mathrm{kV}$ (valor de pico fase-neutro) e carga de 10 MVA ligada em estrela. A Figura 18 mostra o gráfico das componentes harmônicas da situação ocorrida. Como comprovado na literatura, fica evidenciado que para caso de falta interna não há o aparecimento de componentes harmônicas significativas. Vale chamar a atenção para o componente DC que pode a vir a atrapalhar a leitura e o processo de proteção.

As Figuras 19 e 20 ilustram a situação de falta interna (monofásica) aplicada ao secundário do transformador em 10\% do enrolamento A (conexão estrela), sob tensão de $13,8 \mathrm{kV}$ (valor fase-neutro) e carga de 10 MVA conectada em delta.

As Figuras 21 e 22 mostram a situação de uma falta interna (monofásica) aplicada ao secundário do transformador a $25 \%$ do enrolamento A (conexão estrela), sob tensão de $13,8 \mathrm{kV}$ (valor fase-neutro) com carregamento leve (5\% - carga leve) do transformador e carga conectada em delta.

As Figuras 23 e 24 apresentam a situação de uma falta interna (monofásica) aplicada ao secundário do transformador a $25 \%$ do enrolamento A (conexão estrela), sob tensão de 13,8 kV (valor fase-neutro) com carregamento pesado (95\% - carga pesada) do transformador e carga conectada em delta.

As Figuras 25 e 26 ilustram as correntes obtidas pelos $\mathrm{TC}^{\prime} \mathrm{s}$, no primário e secundário do transformador principal respectivamente, e são referentes a uma condição de 
falta interna (monofásica) a $80 \%$ do enrolamento A (conexão estrela), sendo a carga de 10MVA conectada em estrela.

As Figuras 27, 28 e 29 são referentes à condição de falta externa na linha de distribuição. Podemos notar a variação das correntes em ambos os lados dos secundários dos TC's.

Nas Figuras 30, 31 e 32, têm-se os gráficos de uma condição de saturação do TC, ocorrida devido a uma falta externa próxima ao transformador de potência.

As Figuras 33 e 34 referem-se à condição de sobreexcitação ocorrida no sistema, caracterizada por um índice de $140 \%$ de tensão. É notado pelo gráfico das componentes harmônicas o aparecimento das harmônicas de quinta ordem, de acordo como observado na literatura.

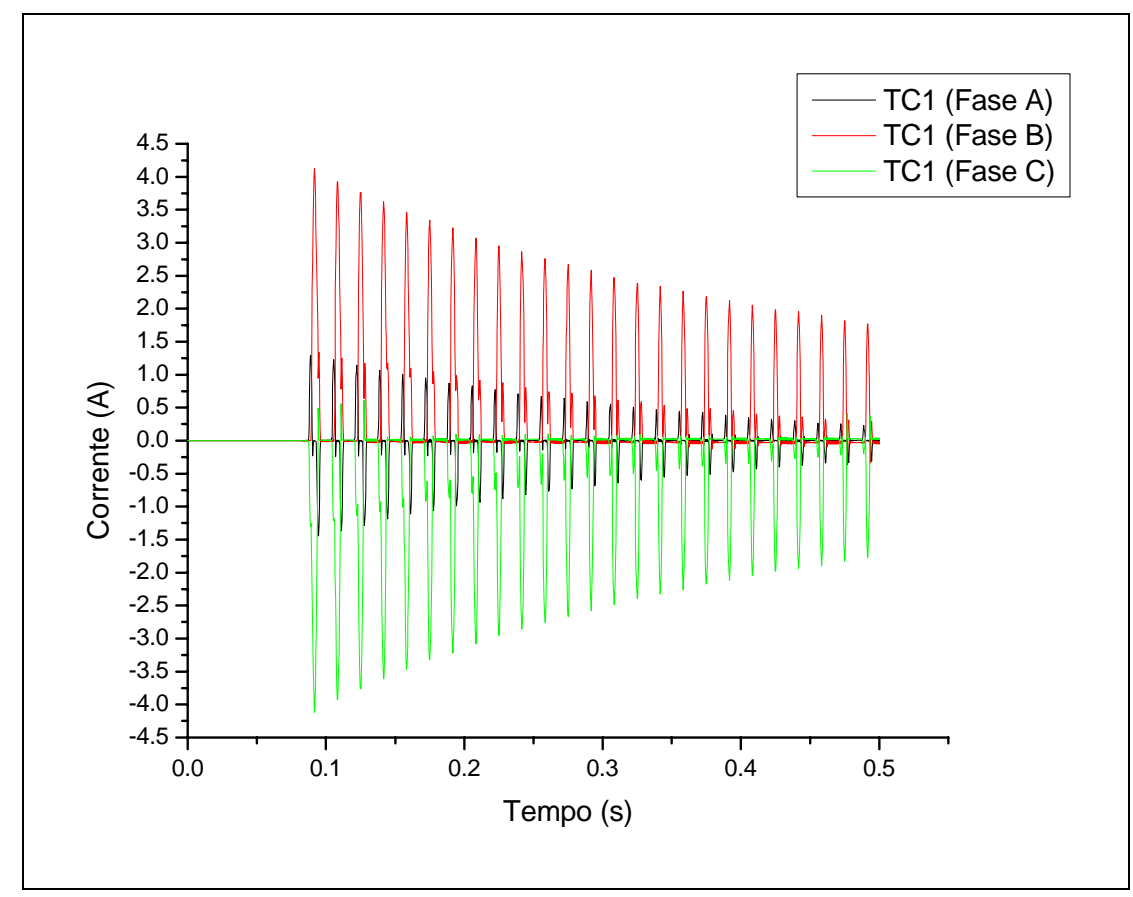

Figura 12. Condição de energização com tensão de $112,7 \mathrm{kV}$ e fechamento em $80,52 \mathrm{~ms}$ na fase $\mathrm{A}$, $82,52 \mathrm{~ms}$ na fase $\mathrm{B}$ e $84,52 \mathrm{~ms}$ na fase $\mathrm{C}$ com ângulo incidência da falta de $0^{\circ}$. 


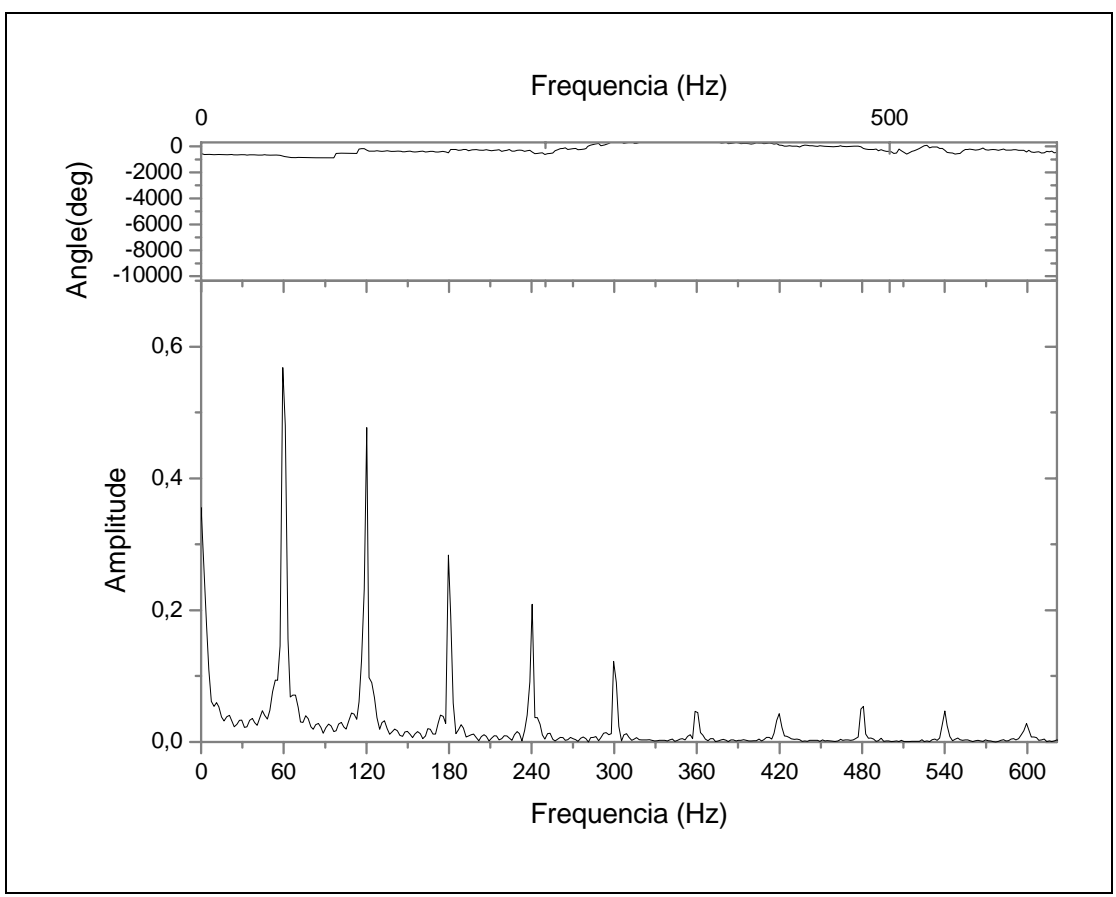

Figura 13. Componentes harmônicas da corrente secundária do TC (fase C), com referência ao primário do transformador de potência, quando da condição de energização.

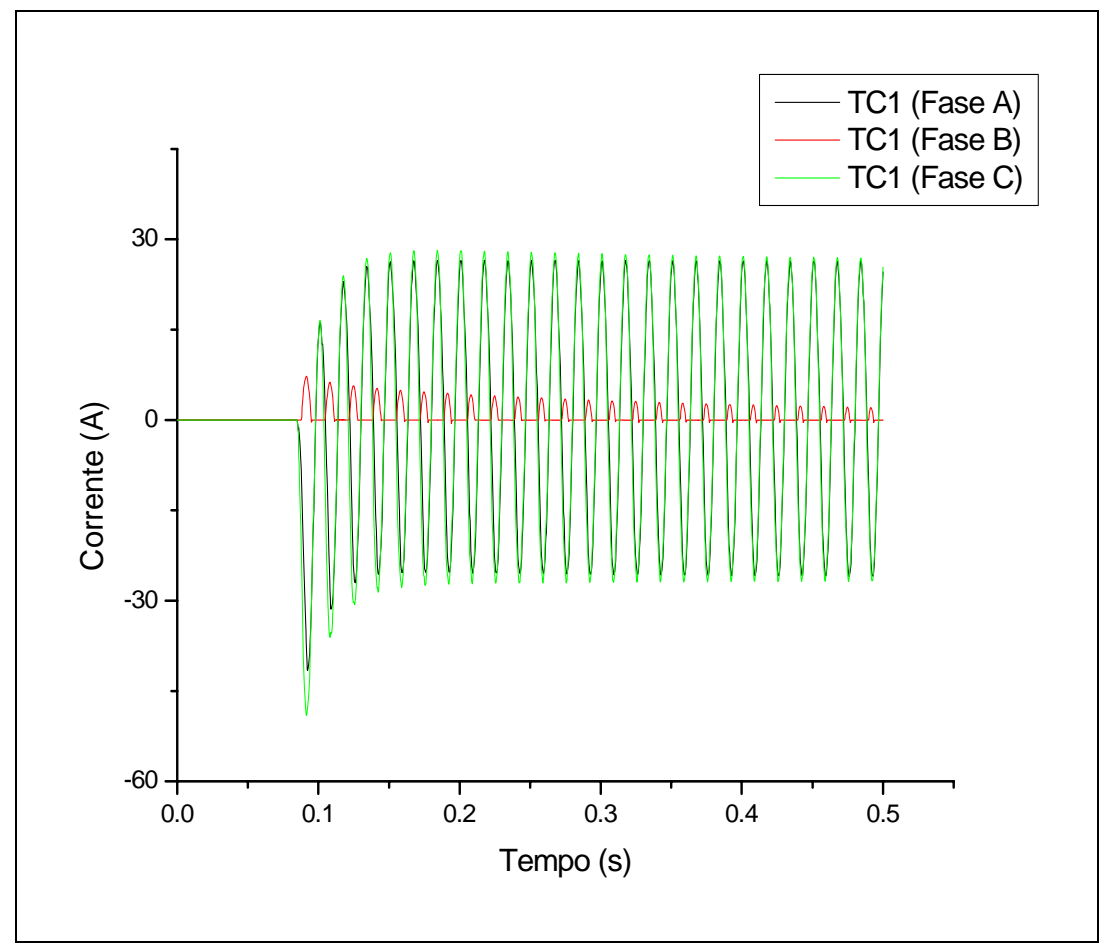

Figura 14. Condição de energização seguida de falta interna, tensão de $112,7 \mathrm{kV}$, fechamento em $80,52 \mathrm{~ms}$ na fase A e falta aplicada a $82,52 \mathrm{~ms}$ com âng. inc. de $0^{\circ}$. 


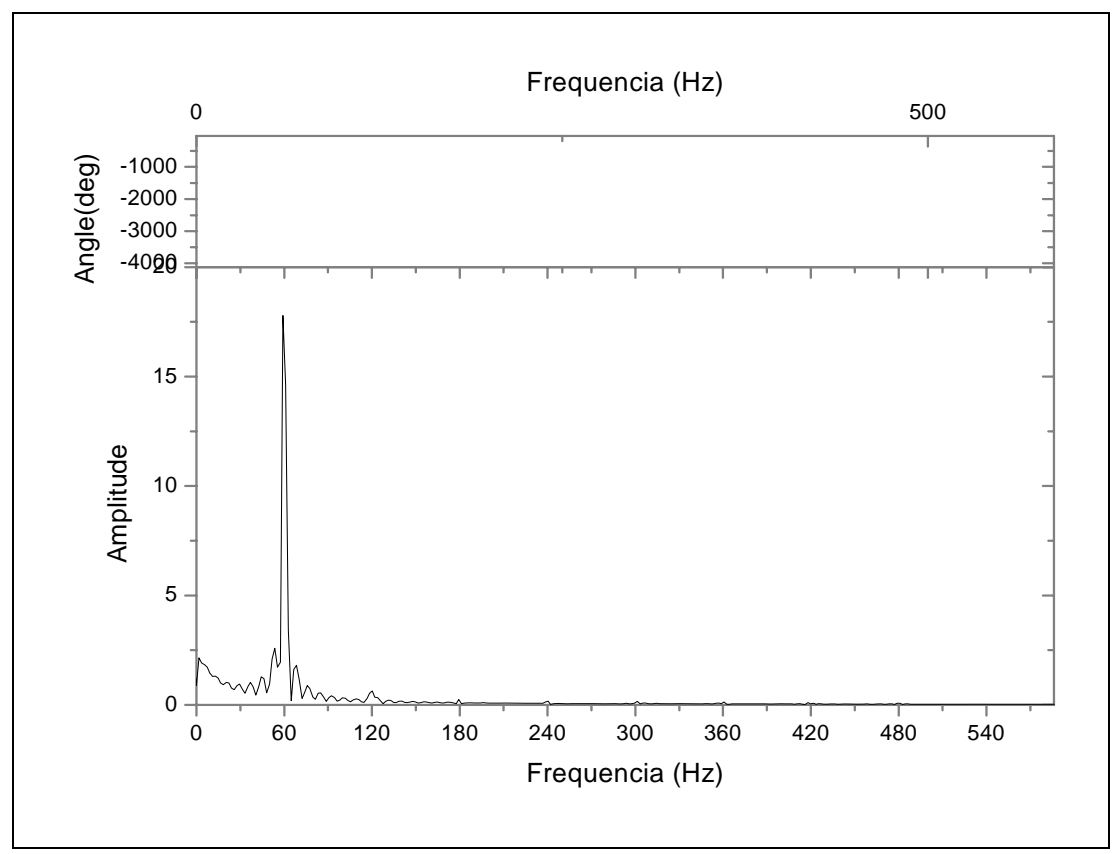

Figura 15. Componentes harmônicas da corrente secundária do TC (fase C), com referência ao primário do transformador de potência, quando da condição de energização seguida de falta.

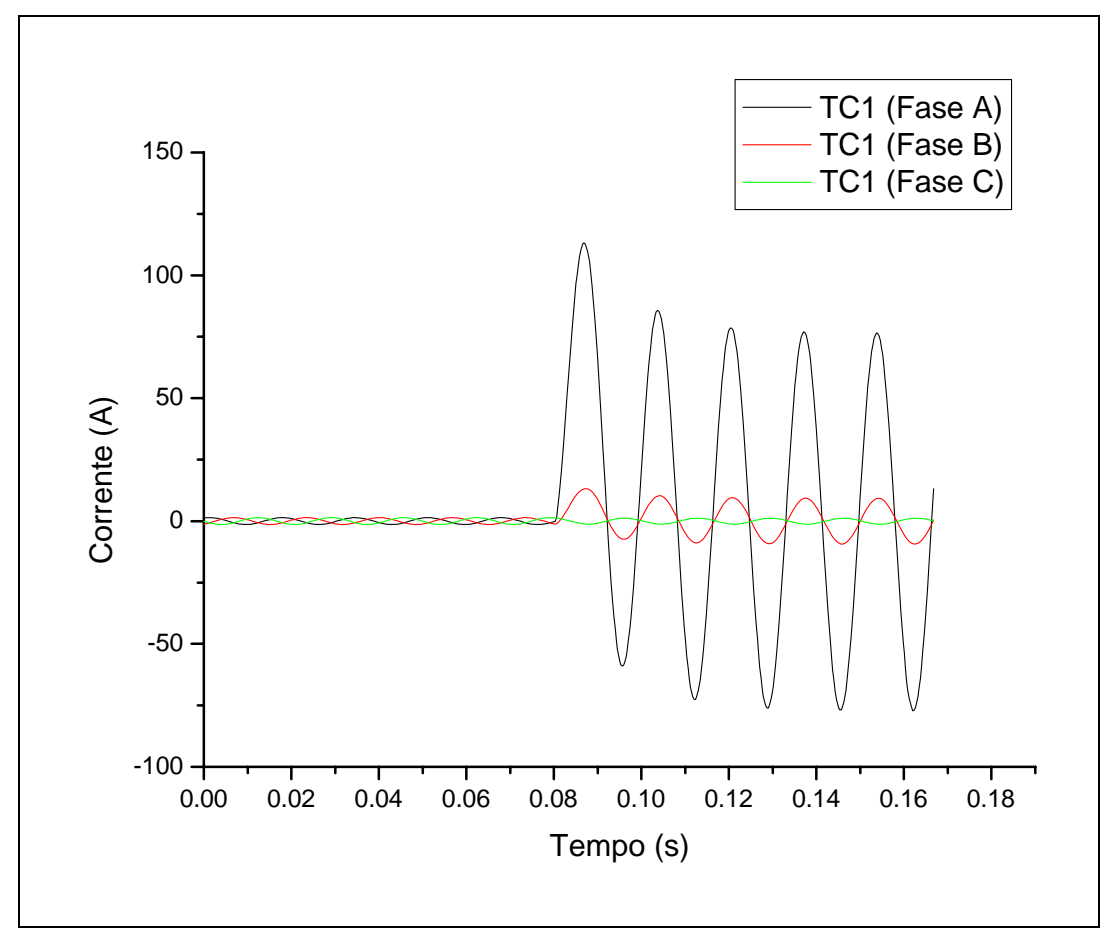

Figura 16. Valores das correntes do secundário do TC, com referência ao primário do transformador de potência, tensão de $112,7 \mathrm{kV}$, sob condição de falta interna em $10 \%$ do enrolamento (delta) e carga de 10 MVA conectada em estrela com âng. inc. da falta de $0^{\circ}$. 


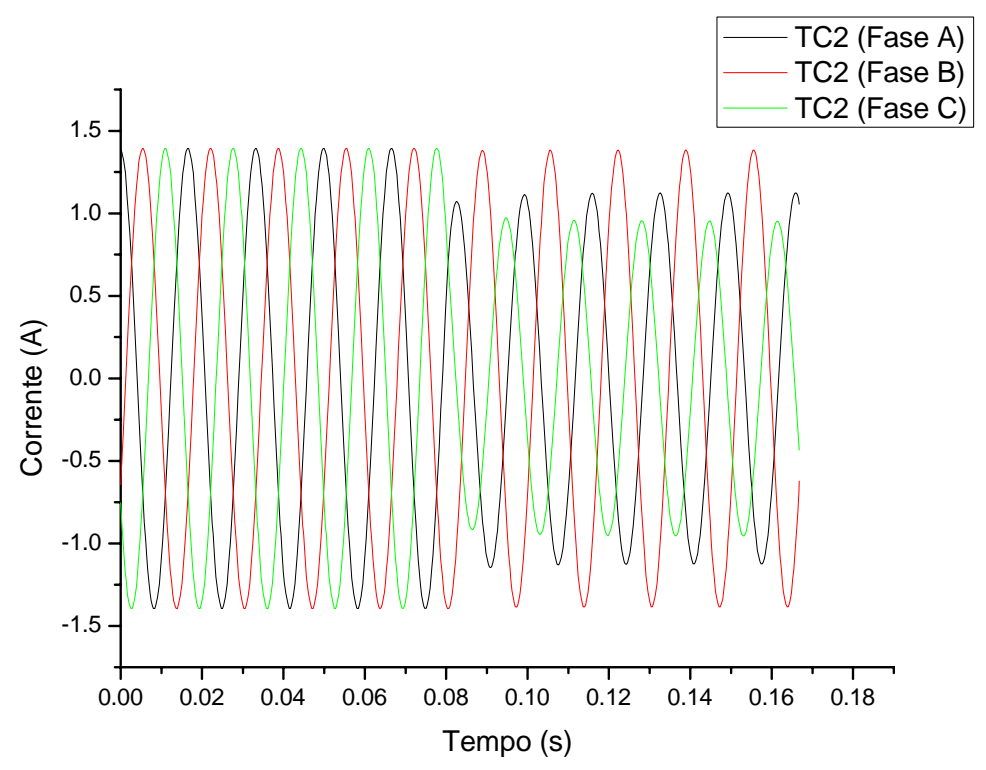

Figura 17. Valores das correntes do secundário do TC, com referência ao secundário do transformador de potência, tensão de $13,8 \mathrm{kV}$, sob condição de falta interna em $10 \%$ do enrolamento (delta) e carga de 10 MVA conectada em estrela com âng. inc. da falta de $0^{\circ}$.

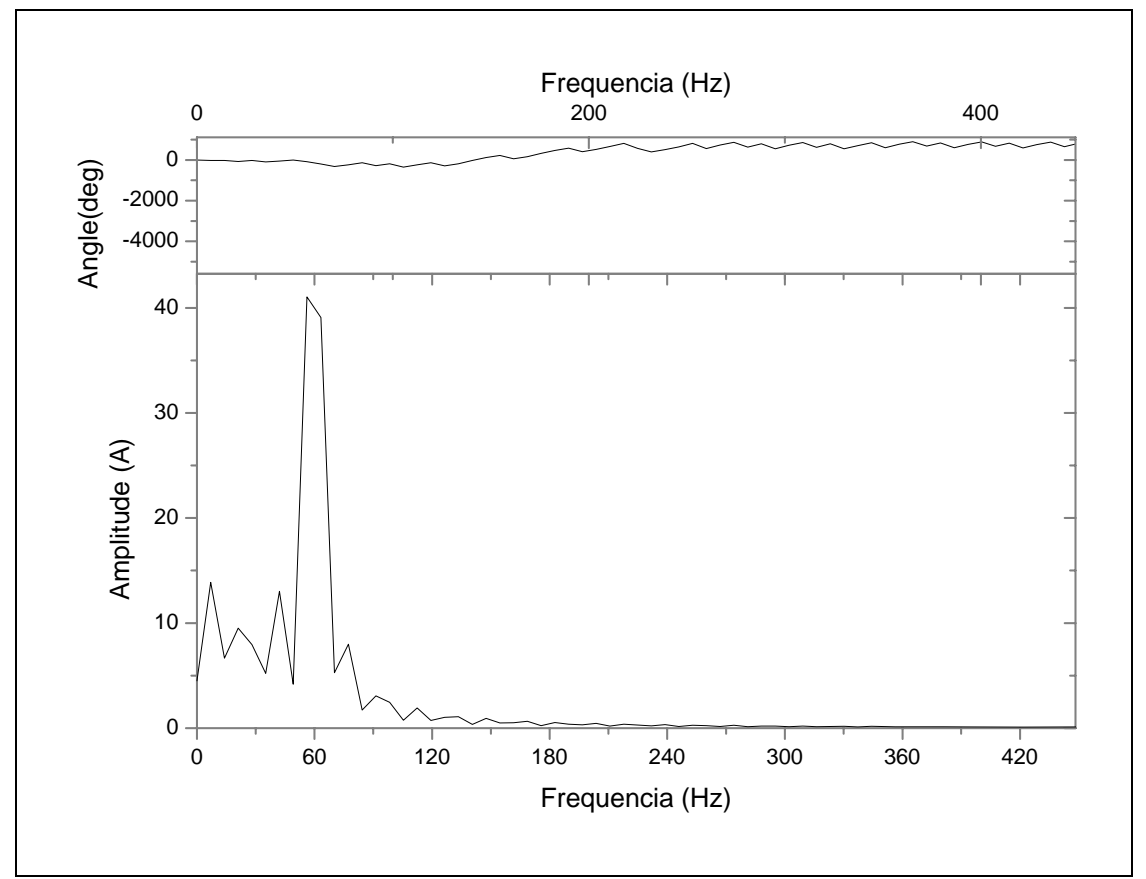

Figura 18. Componentes harmônicas da corrente do secundário do TC, fase A, quando da condição de falta interna em 10\% do enrolamento (delta) e carga de 10MVA conectada em estrela com âng. inc. da falta de $0^{\circ}$. 


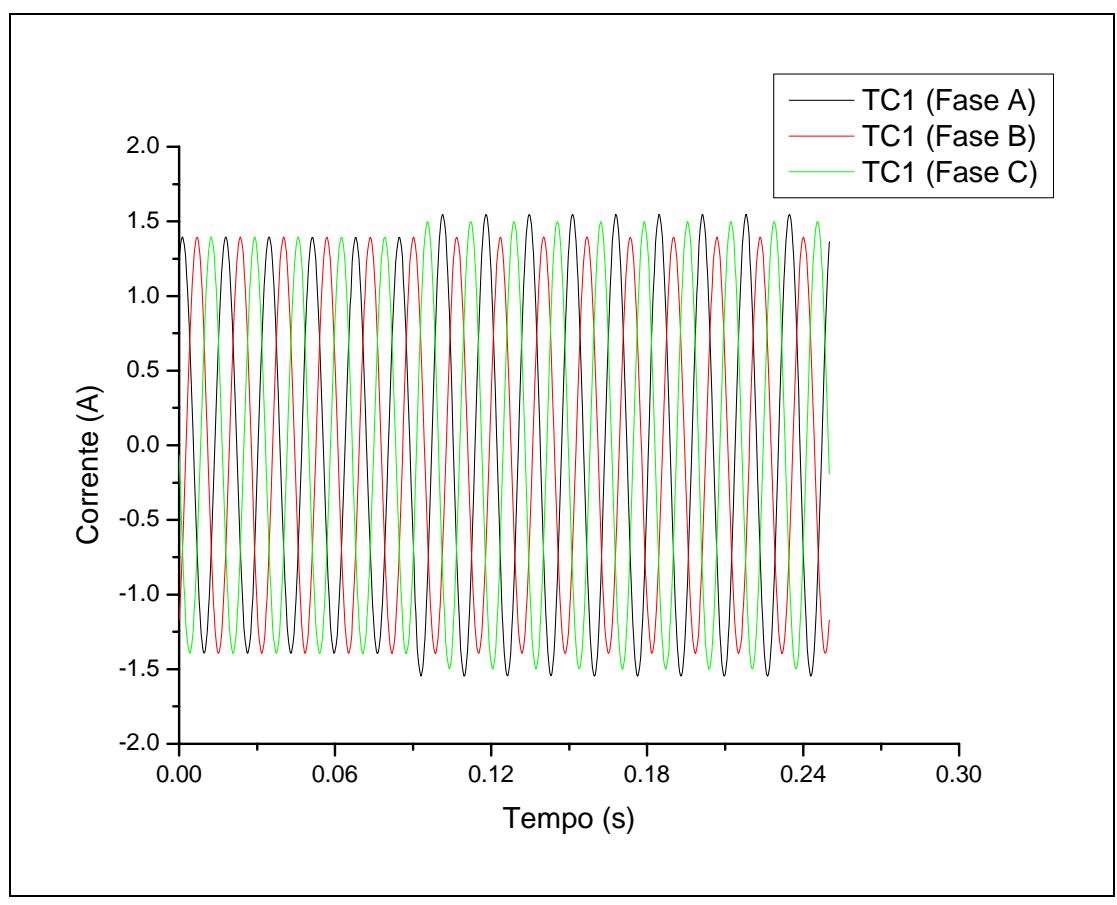

Figura 19. Valores das correntes do secundário do TC, com referência ao primário do transformador de potência $(112,7 \mathrm{kV})$, sob condição de falta interna em $10 \%$ do enrolamento (estrela) e carga média de 10 MVA conectada em delta com âng. inc. da falta de $0^{\circ}$.

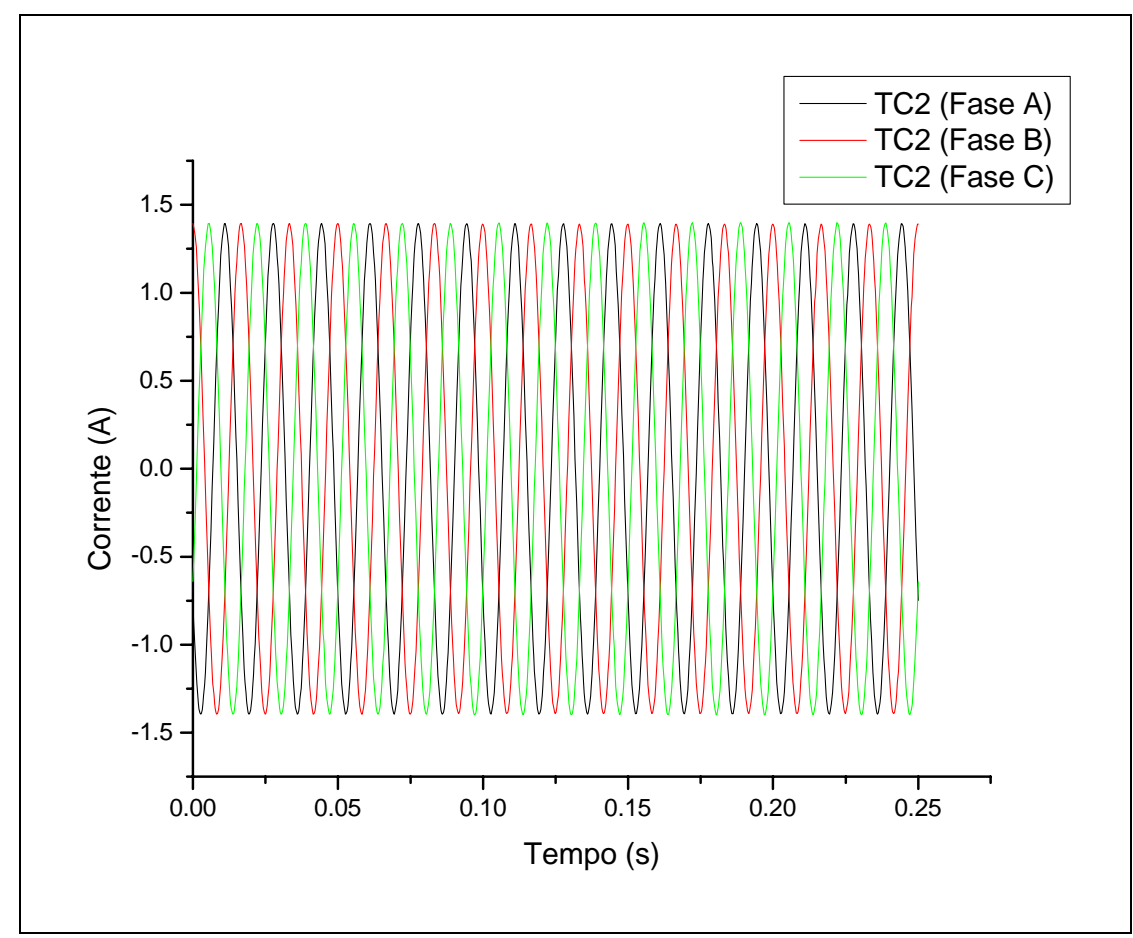

Figura 20. Valores das correntes do secundário do TC, com referência ao secundário do transformador de potência $(13,8 \mathrm{kV})$, condição de falta interna em $10 \%$ do enrolamento (estrela) e carga média de 10 MVA conectada em delta com âng. inc. da falta de $0^{\circ}$. 


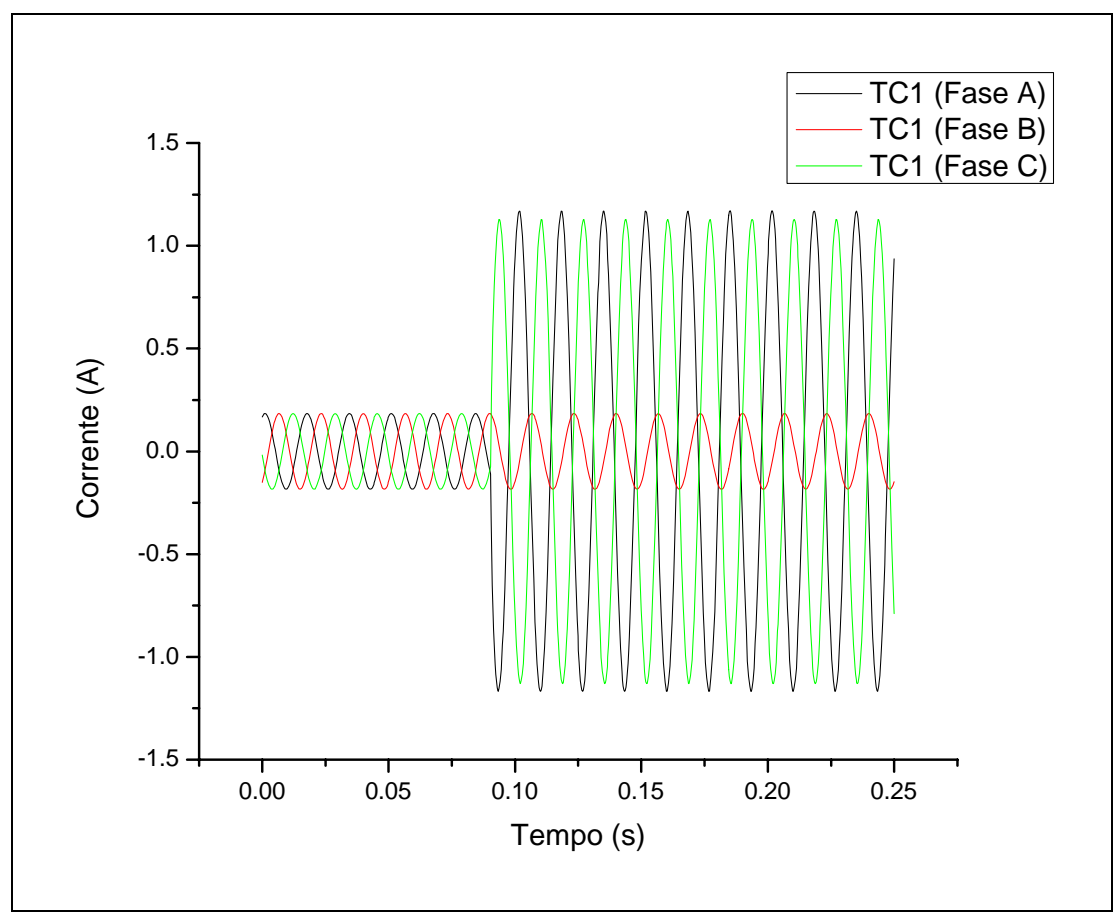

Figura 21. Valores das correntes do secundário do TC, com referência ao primário do transformador de potência $(112,7 \mathrm{kV})$, sob condição de falta interna em $25 \%$ do enrolamento (estrela) e carga leve conectada em delta com âng. inc. da falta de $0^{\circ}$.

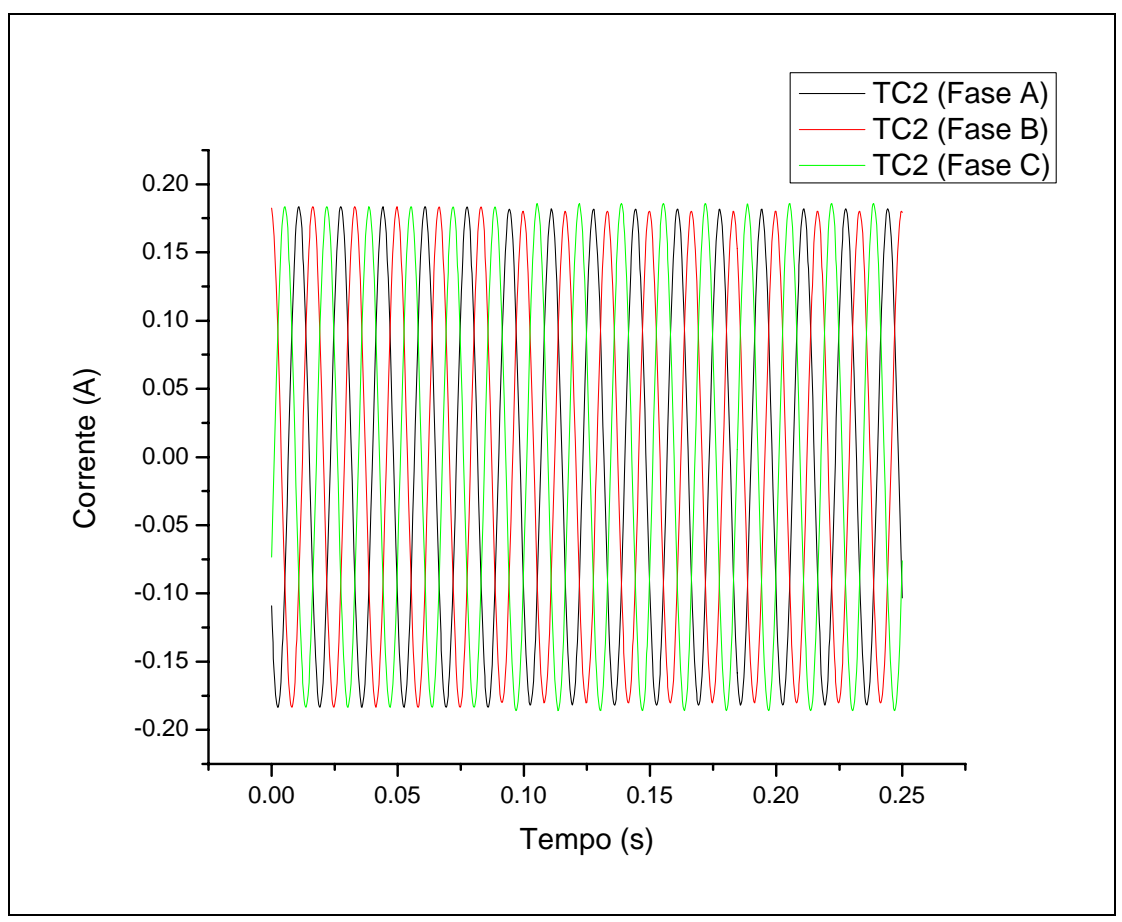

Figura 22. Valores das correntes do secundário do TC, com referência ao secundário do transformador de potência $(13,8 \mathrm{kV})$, sob condição de falta interna em $25 \%$ do enrolamento (estrela) e carga leve conectada em delta com âng. inc. da falta de $0^{\circ}$. 


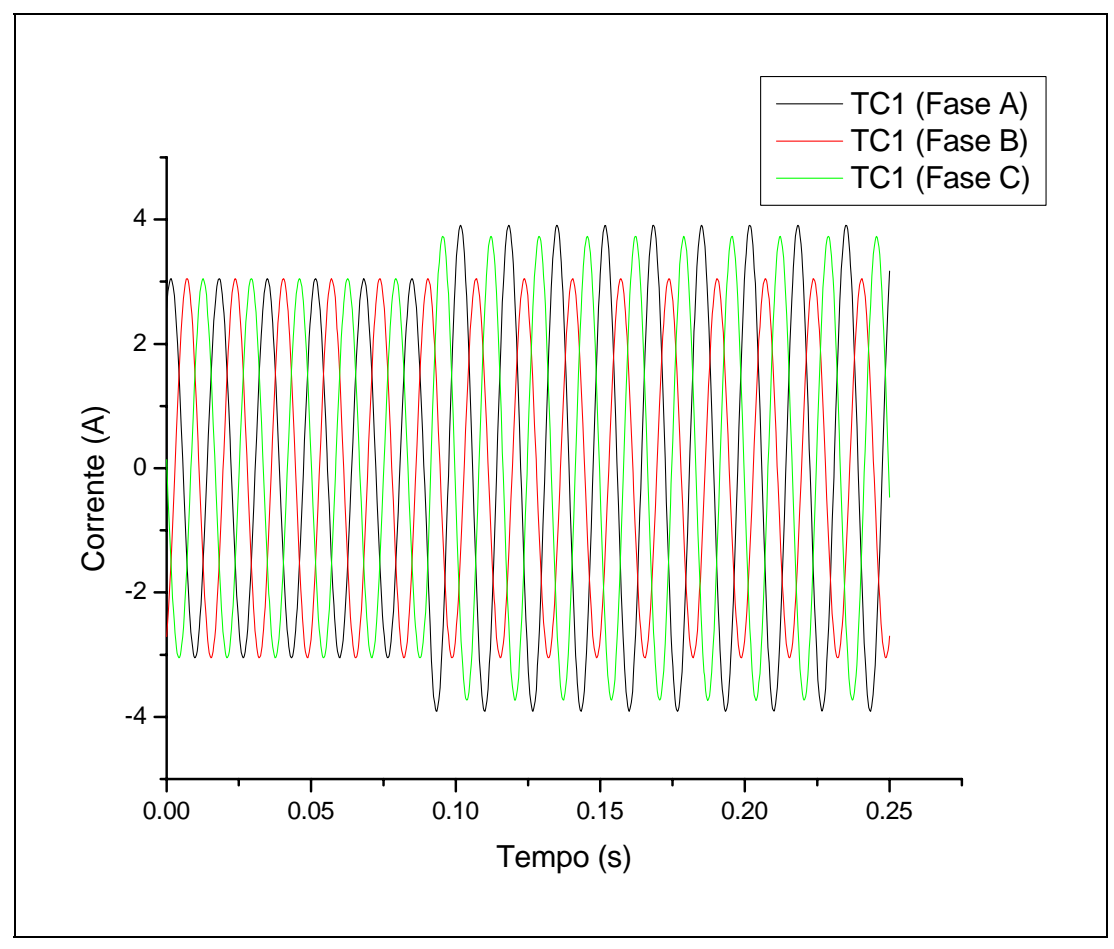

Figura 23. Valores das correntes do secundário do TC, com referência ao primário do transformador de potência $(112,7 \mathrm{kV})$, sob condição de falta interna em $25 \%$ do enrolamento (estrela) e carga pesada conectada em delta com âng. inc. da falta de $0^{\circ}$.

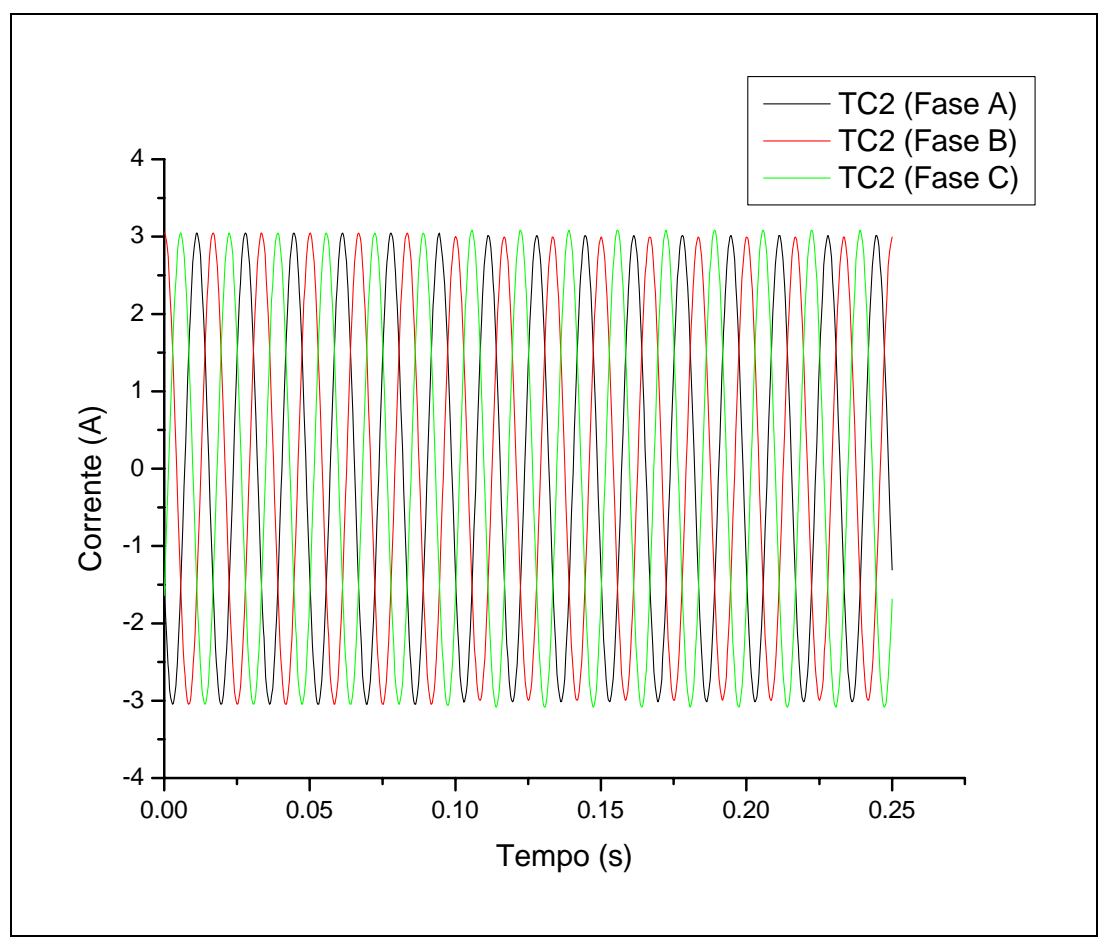

Figura 24. Valores das correntes do secundário do TC, com referência ao secundário do transformador de potência $(13,8 \mathrm{kV})$, sob condição de falta interna em $25 \%$ do enrolamento (estrela) e carga pesada conectada em delta com âng. inc. da falta de $0^{\circ}$. 


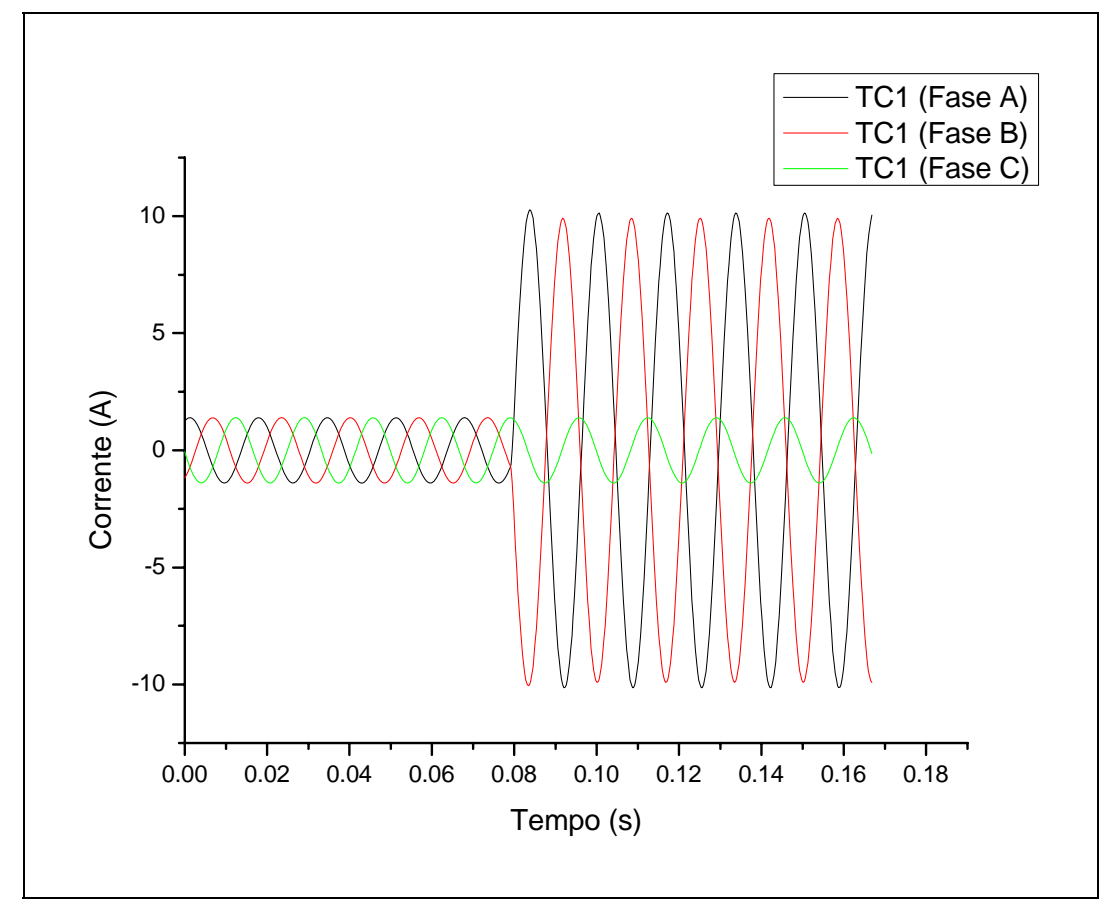

Figura 25. Valores das correntes do secundário do TC, com referência ao primário do transformador de potência $(13,8 \mathrm{kV})$, sob condição de falta interna em $80 \%$ do enrolamento (estrela) e carga de 10MVA conectada em estrela com âng. inc. da falta de $0^{\circ}$.

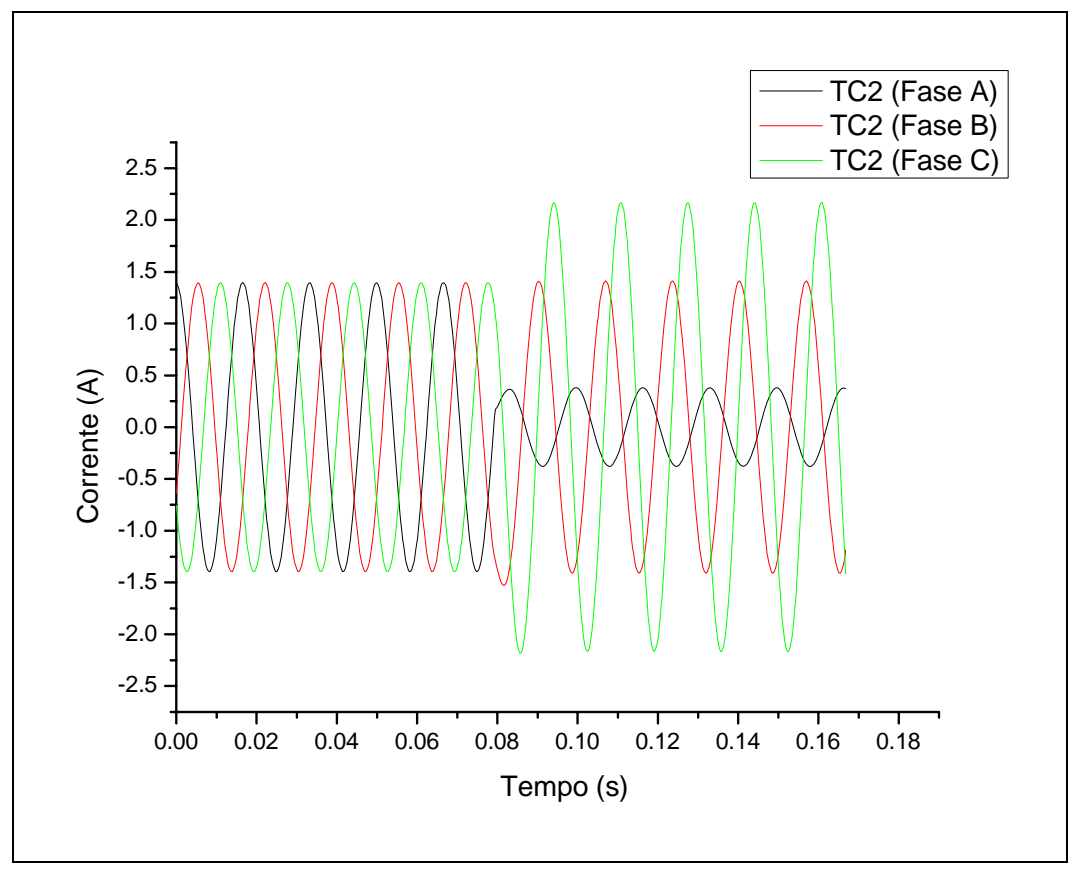

Figura 26. Valores das correntes do secundário do TC, com referência ao secundário do transformador de potência $(13,8 \mathrm{kV})$, sob condição de falta interna em $80 \%$ do enrolamento (estrela) e carga de 10 MVA conectada em estrela com âng. inc. da falta de $0^{\circ}$. 


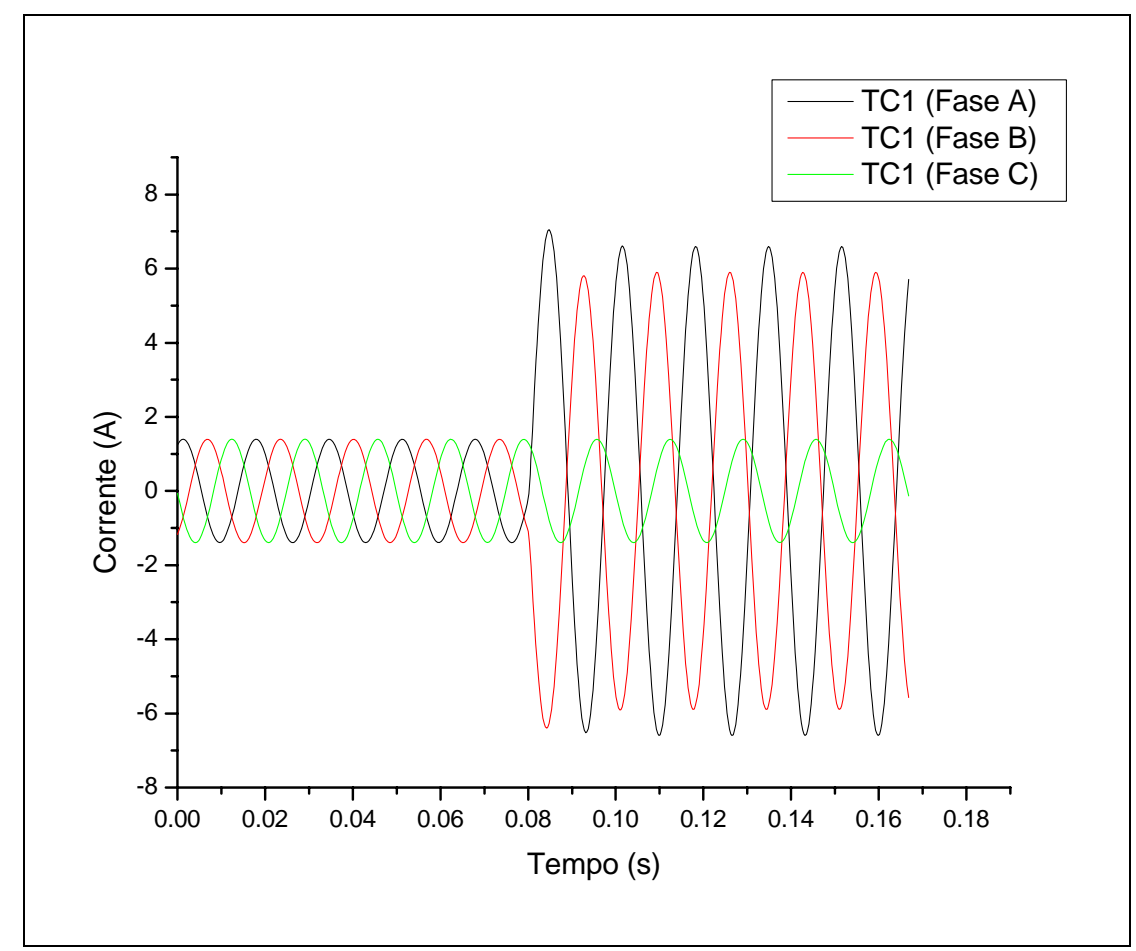

Figura 27. Valores de corrente do secundário do TC, com referência ao primário do transformador de potência sob condição de falta externa na linha de distribuição com âng. inc. da falta de $0^{\circ}$.

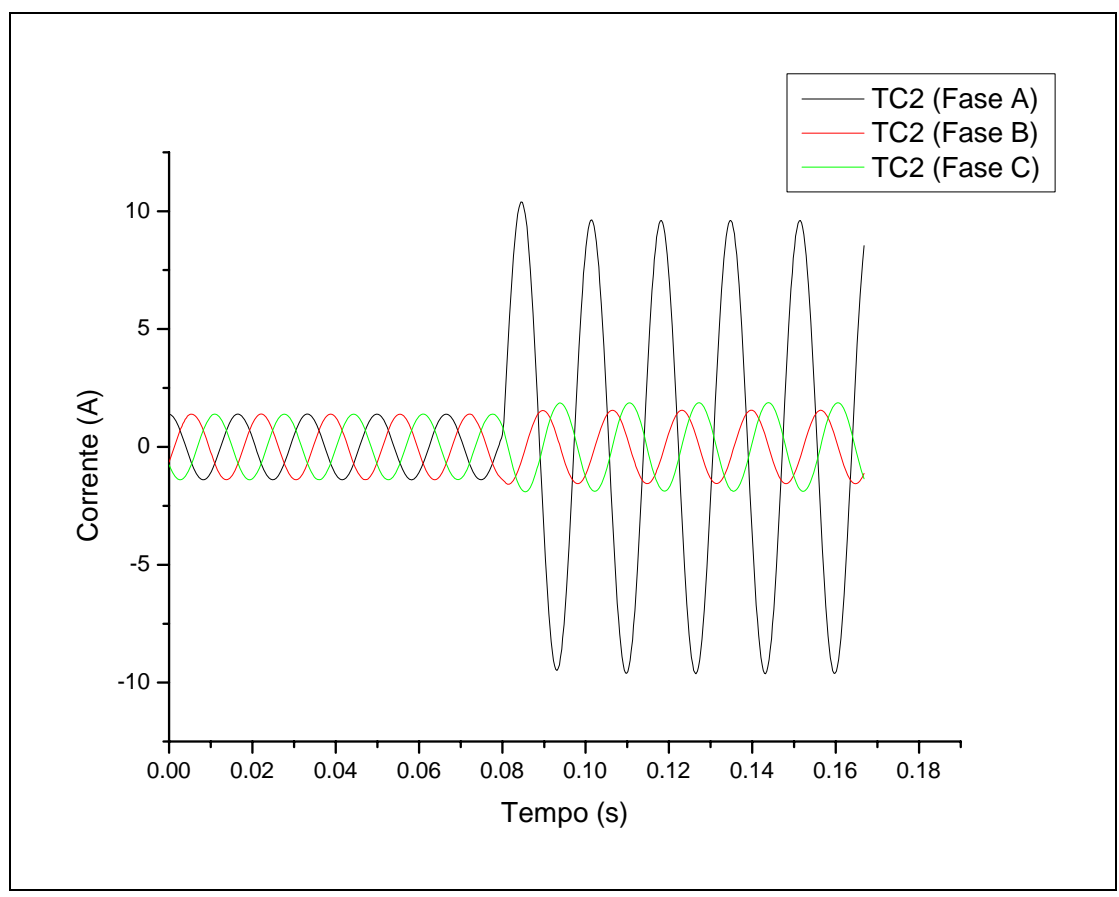

Figura 28. Valores de corrente do secundário do TC, com referência ao secundário do transformador de potência sob condição de falta externa ocorrida na linha de distribuição e âng. inc. da falta de $0^{\circ}$. 


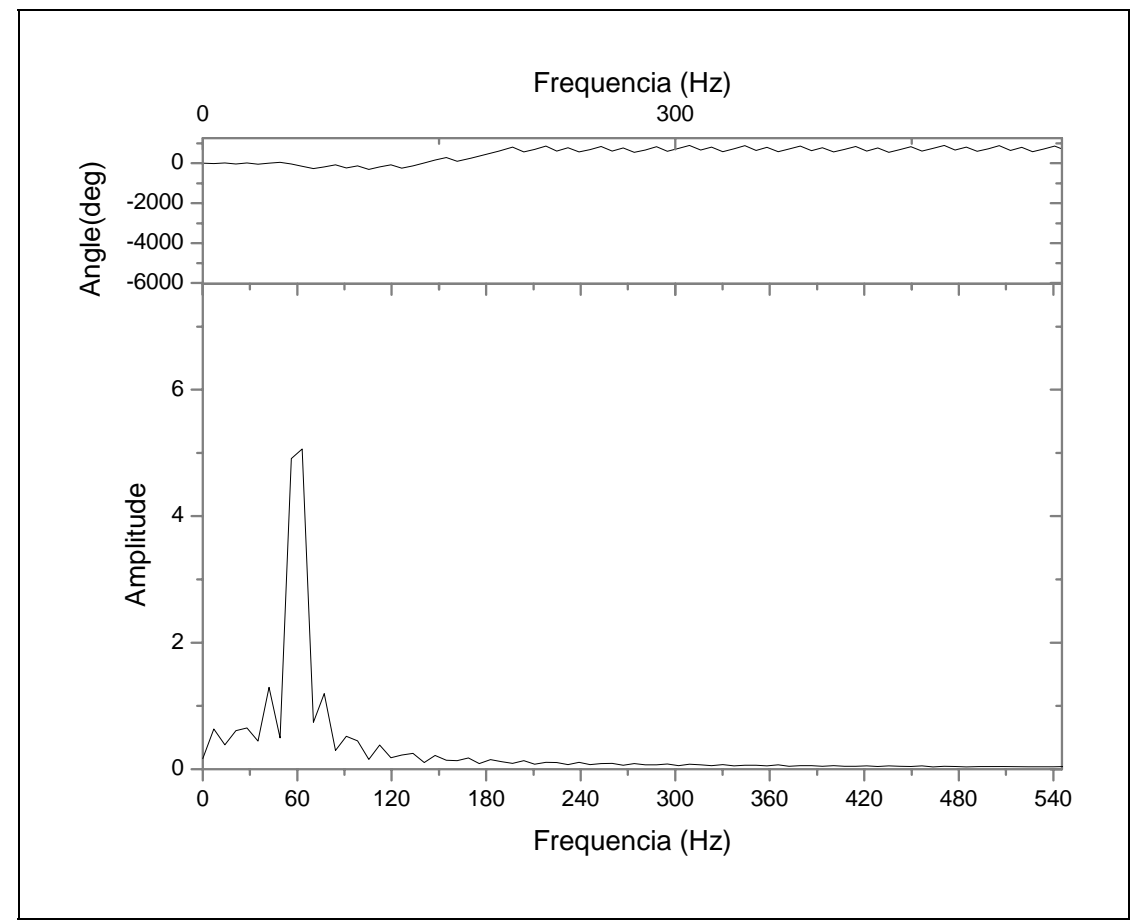

Figura 29. Gráfico das componentes harmônicas da corrente do secundário do TC, com referência ao primário do transformador de potência, fase $\mathrm{A}$, na condição de falta externa à linha de distribuição e âng. inc. da falta de $0^{\circ}$.

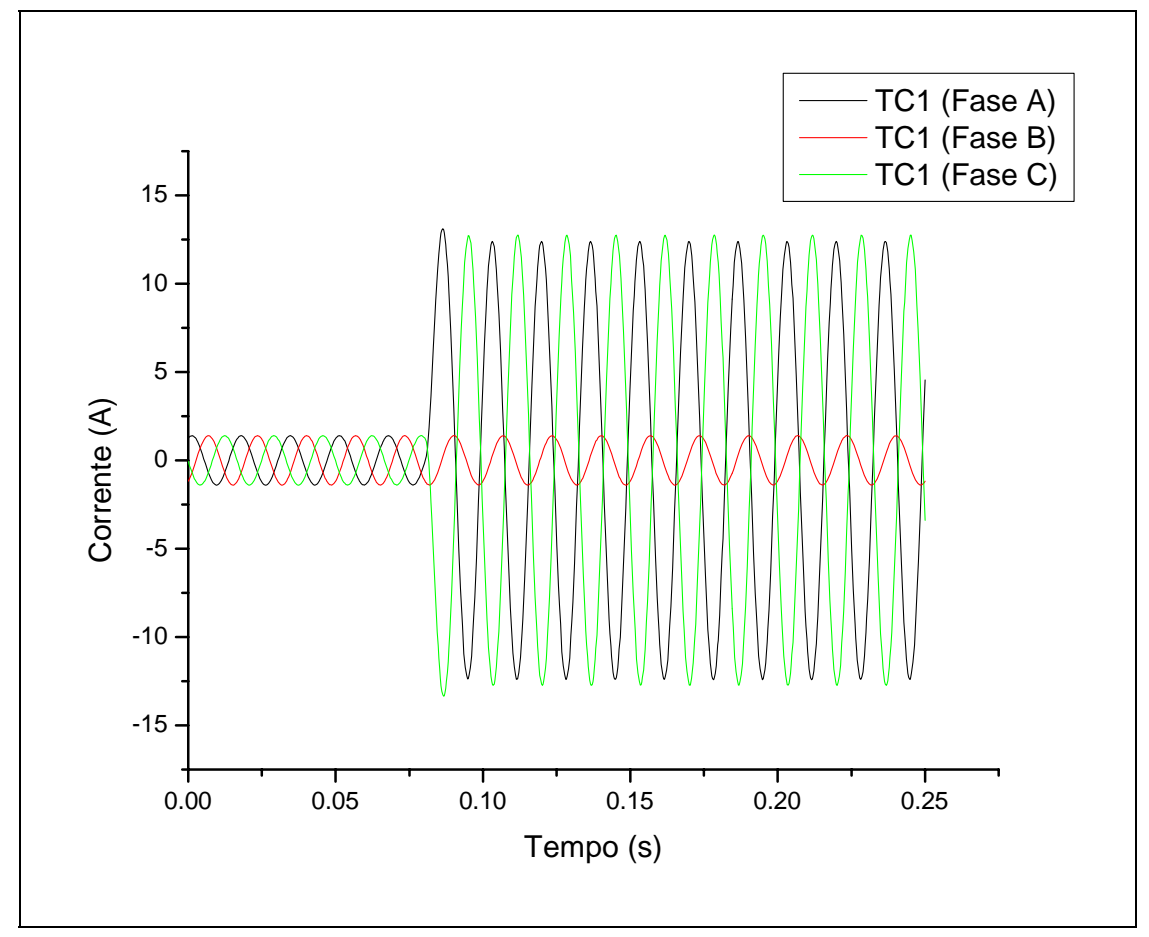

Figura 30. Valores de corrente do secundário do TC, com referência ao primário do transformador de potência, na condição de saturação do TC secundário, ocorrida devido a uma falta externa próxima ao transformador de potência com âng. inc. da falta de $0^{\circ}$. 


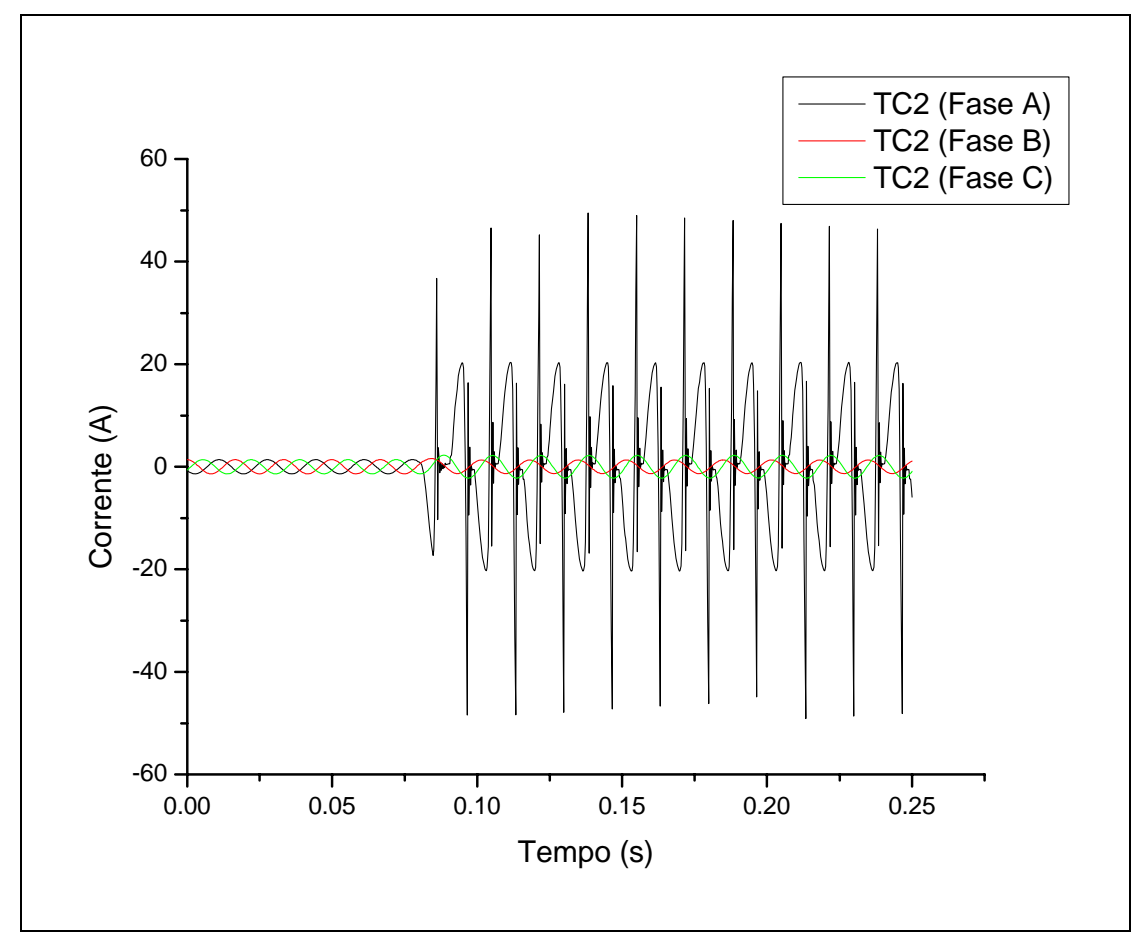

Figura 31. Valores de corrente do secundário do TC, com referência ao secundário do transformador de potência, na condição de saturação do TC secundário, ocorrida devido a uma falta externa próxima ao transformador de potência com âng. inc. da falta de $0^{\circ}$.

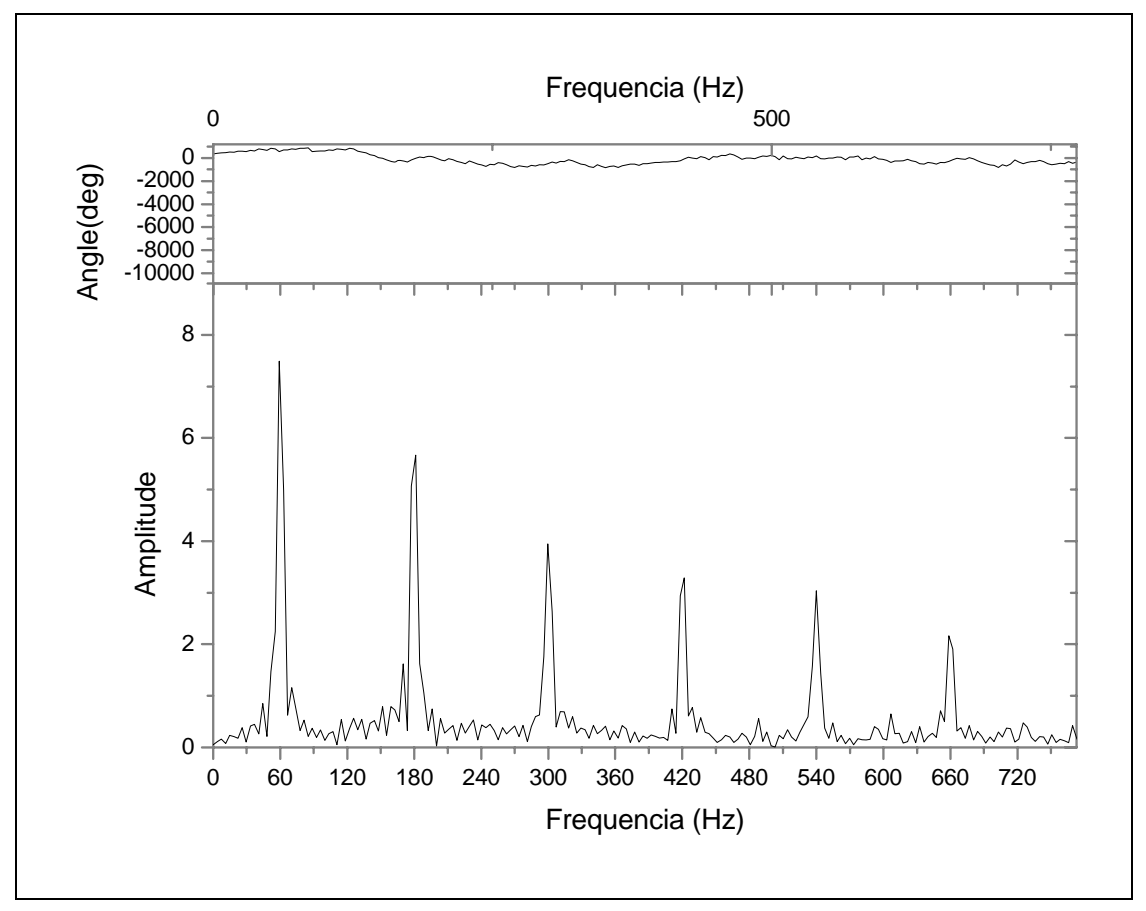

Figura 32. Componentes harmônicas da corrente do secundário do TC com referência ao secundário do transformador de potência, fase A, quando da condição de saturação do TC devido a uma falta externa próxima ao transformador de potência. 


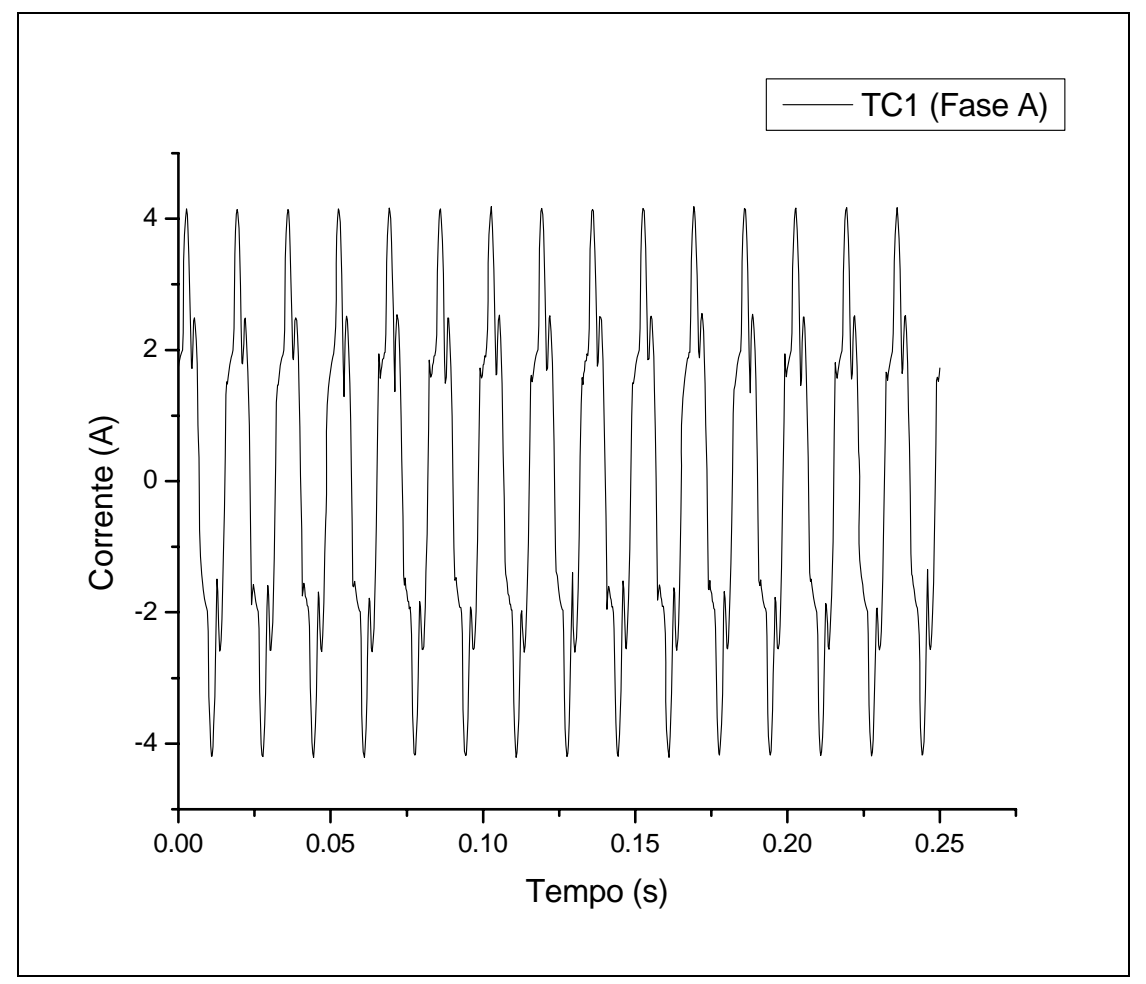

Figura 33. Valores de corrente do secundário do TC, fase A, com referência ao primário do transformador de potência, devido condição de sobreexcitação de $140 \%$ da tensão, estando o sistema em regime com uma carga de 10 MVA.

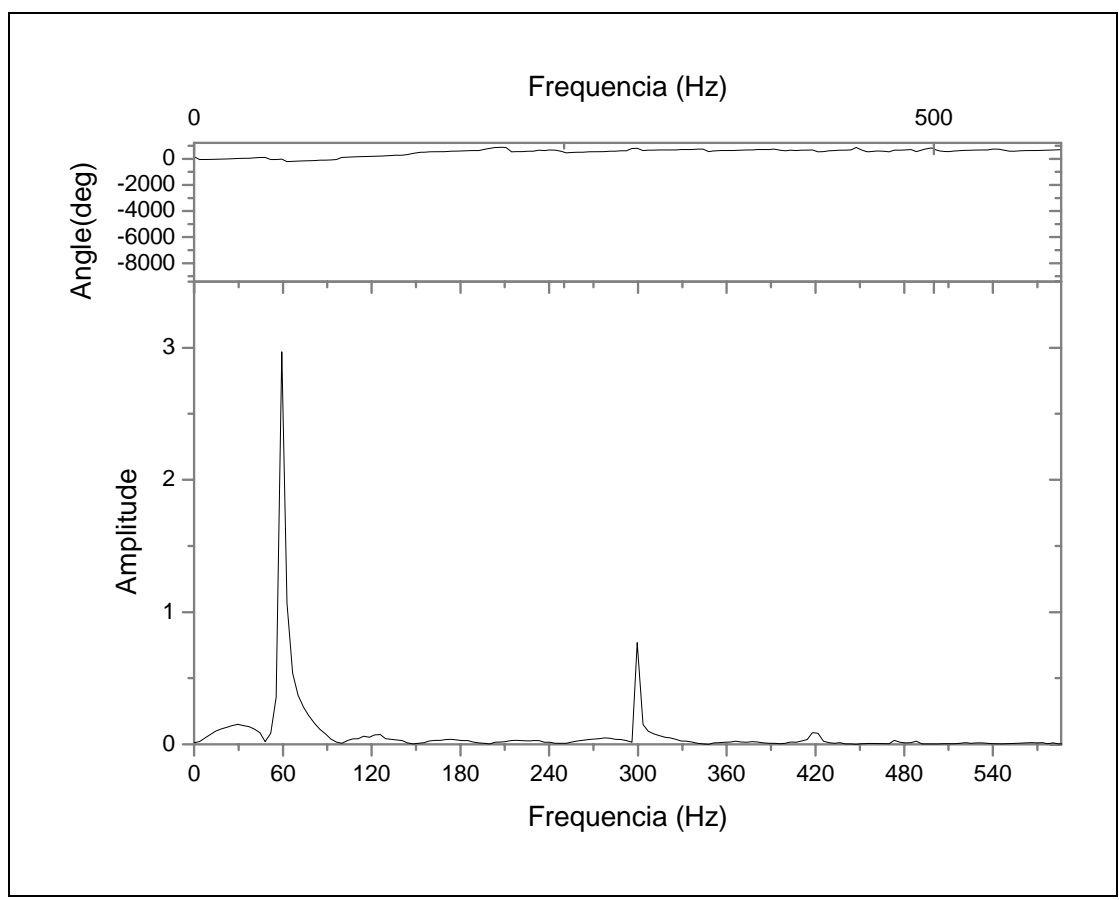

Figura 34. Componentes harmônicas da corrente do secundário do TC, com referência ao primário do transformador de potência, fase A, devido condição de sobreexcitação de $140 \%$ da tensão, estando o sistema em regime com carga de 10 MVA. 


\subsection{O arquivo COMTRADE}

Com o surgimento, desenvolvimento e uso dos relés digitais e registradores de perturbação digitais, além dos softwares de simulação tais como o ATP, entre outros, disponibilizou-se uma grande quantidade de dados digitais para análise do desempenho dos sistemas de potência. Isso trouxe algumas dificuldades para os vários padrões utilizados por cada um dos sistemas de geração, armazenamento e transmissão destes registros. Criou-se então a necessidade de estabelecer um formato padrão para o qual estes dados pudessem ser revertidos e assim usados pelos vários sistemas de análise, teste e simulação ao mesmo tempo, o que facilitaria o trabalho de manipulação destes dados.

Foi desenvolvido pelo IEEE (Institute of Electrical and Electronics Engineers), o padrão "Common Format for Transient Data Exchange (COMTRADE) for Power Systems", (IEEE Standard C37.111-1991, 1991). Este padrão define um formato comum dos arquivos de dados que possibilitam o intercâmbio dos arquivos entre os vários tipos de sistema de análise de dados de falta, teste e simulação. O padrão foi criado em junho de 1991 e recebeu uma nova revisão em 1999 (IEEE Standard C37.111-1999 1999).

Quando manipulamos dados transitórios, é necessário incluir informações que descrevem as circunstâncias ao redor do transitório. Tais informações são usualmente formatadas e armazenadas de formas diferenciadas, sendo que as informações descritas são mais facilmente entendidas e interpretadas em um formato do tipo ASCII (American Standard Code for Information Interchange). Para um determinado evento descrito pelo formato COMTRADE, deve-se ter três tipos de arquivo associados. As informações providas dos arquivos transitórios devem incluir:

1) descrições textuais das circunstâncias ao redor do transitório;

2) a configuração dos transitórios gravados no tempo e

3) os valores dos dados propriamente caracterizados.

Cada um dos três tipos de arquivos possui uma classe de informação: cabeçalho (*.hdr), configuração (*.cfg) e dados (*.dat). A designação dos arquivos possui o seguinte formato: "nome.tip", onde, nome é usado para identificar o arquivo e tip é usado para identificar o tipo de arquivo (hdr, cfg ou dat). As informações são organizadas em linhas e os dados, na mesma linha, são separados por vírgula. A informação deve ser listada na ordem exata fixada pelo padrão. Os desvios deste formato provocarão erros na leitura dos 
dados. As recomendações dos formatos desejáveis são ilustradas pelo artigo do CIGRÈ 34.01 (1989).

Os dados devem ser organizados como:

\section{a) Cabeçalho (nome.hdr):}

O arquivo de "cabeçalho" é criado pelo software conversor como um arquivo de texto. A intenção é que os dados possam ser entendidos e impressos pelo usuário. Este arquivo pode ter qualquer informação desejada, por exemplo, nome da subestação, identificação do equipamento (linha de transmissão, transformador, reator, etc.), comprimento da linha de transmissão, relações de transformação dos transformadores, localização do defeito, etc. Depende apenas do conversor fornecido pelo fabricante do dispositivo do registro.

A pretensão do "cabeçalho" é fornecer informação suplementar de uma maneira narrativa para o usuário entender melhor a condição dos transitórios registrados. $\mathrm{O}$ arquivo “cabeçalho” não será manipulado por um programa de aplicação.

Os seguintes itens devem ser incluídos no arquivo "cabeçalho":

- descrição do sistema de potência em regime permanente;

- nome da subestação;

- identificação dos elementos do sistema sobre efeito do distúrbio (linha, transformador, capacitor ou disjuntor);

- comprimento da linha;

- resistências e reatâncias de seqüência zero e positiva;

- capacitâncias;

- acoplamento mútuo entre linhas paralelas;

- localização e valores dos reatores em derivação (shunt) e capacitores em série;

- relação entre tensão nominal dos enrolamentos dos transformadores;

- relação dos transformadores de potência e conexões dos enrolamentos;

- parâmetros equivalentes do sistema antes dos nós de registros dos dados (por exemplo: seqüência zero e positiva da impedância equivalente das fontes);

- descrições de como as entradas foram obtidas: aquisição em campo ou simulação computacional; 
- descrição dos filtros anti-aliasing usados;

- códigos dos registros onde os dados estarão disponibilizados.

As seguintes informações adicionais devem ser incluídas nesta seção a fim de serem compatíveis com o CIGRE:

- o formato na quais os dados é gravado e

- os "cabeçalhos" das colunas das tabelas de dados.

A Figura 35 caracteriza um exemplo do arquivo "cabeçalho" para uma falta interna aplicada aos enrolamentos do transformador de potência em análise.

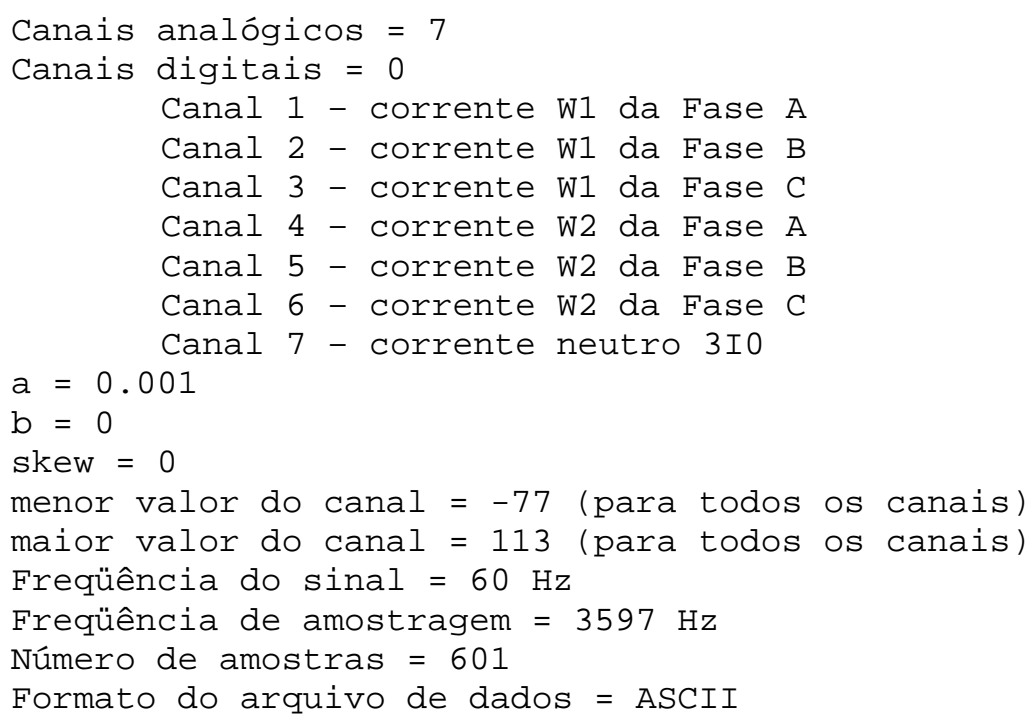

Figura 35. Exemplo do arquivo .HDR referente a uma aplicação de falta interna a $10 \%$ do enrolamento A-B com conexão delta-estrela e âng. inc. da falta de $0^{\circ}$.

\section{b) Configuração (nome.cfg).}

O arquivo de configuração é criado pelo software conversor como um arquivo de texto. Os dados deste arquivo possuem um formato predefinido e fixo de modo que possa ser lido e interpretado pelo software de análise, o qual associará estes dados com os valores armazenados no arquivo nome.dat.

$\mathrm{O}$ arquivo de configuração possui a seguinte organização:

- Nome e identificação da Subestação: Station_name,id

Onde: 
Station_name $=$ Nome da Subestação

id $=$ nome do registrador

- Número e tipos de canais: TT,nnt,nnt

Onde:

$\mathrm{TT}=$ Número total de canais (o número total de grandezas a serem medidas)

$\mathrm{nn}=$ número de canais do tipo $\mathrm{t}$

$\mathrm{t}=$ tipo do canal $(\mathrm{A}=$ analógico $/ \mathrm{D}=$ Digital $)$

- Nome dos canais, unidade e fatores de conversão:

Existe uma linha para informações específicas para cada canal

nn,id,p,ccccc,uu,a,b,skew,min,max

$\cdots$

nn,id,p,ccccc,uu,a,b,skew,min,max

nn,id,m

$\cdots$

nn,id,m

Onde:

$\mathrm{nn}=$ número do canal

$\mathrm{id}=$ nome do canal

$\mathrm{p}=$ identificação da fase $(\mathrm{A}, \mathrm{B}, \mathrm{C}, \mathrm{N})$

$\operatorname{cccccc}=$ circuito/componente sendo monitorado (quase não usado)

$\mathrm{uu}=$ unidade do canal $(\mathrm{V}, \mathrm{A}, \mathrm{kV}$, etc $)$

$\mathrm{a}=$ número real (veja abaixo)

$\mathrm{b}=$ número real. $\mathrm{O}$ fator de conversão do canal é $(\mathrm{ax}+\mathrm{b})$ [o valor de conversão de $\mathrm{x}$, amostra do arquivo .DAT corresponde $\mathrm{a}(\mathrm{ax}+\mathrm{b})$ em unidades uu especificado acima].

skew $=$ número real. Tempo de defasamento $(\mathrm{em} \mu \mathrm{s})$ entre os canais.

min = um inteiro igual ao mínimo valor (menor valor da taxa de amostragem) por amostras deste canal 
$\max =$ um inteiro igual ao máximo valor (maior valor da taxa de amostragem) por amostras deste canal

$\mathrm{m}=(0$ ou 1$)$ estado normal ou de alarme para este canal (só aplicado para canais digitais)

A indicação é repetir a parte “nn,id,p,ccccc,uu,a,b,skew,min,max” para a quantidade de canal existente na gravação na ordem na qual elas ocorram. A parte “nn,id,p,cccccc,uu,a,b,skew,min,max" é representada por canais analógicos e a parte “nn,id,m” é representada por canais digitais.

- Freqüência nominal: If

Onde: if = freqüência nominal em Hz (50 ou 60)

- Taxa de amostragem e número de amostras: Nrates sssss1,endsamp1 sssss2,endsamp2

\section{sssssn,endsampn}

Onde:

nrates $=$ número de taxas de amostragens diferentes no arquivo .DAT sssss $1-\operatorname{sssssn}=$ taxa de amostragem em Hz endsamp1 - endsampn = última amostra nesta taxa

- Data e Hora da primeira amostra: mm/dd/yy,hh:mm:ss.ssssss

Onde:

$$
\begin{aligned}
& \mathrm{mm}=\text { mês }(01-12) \\
& \mathrm{dd}=\text { dia }(01-31) \\
& \mathrm{yy}=\text { últimos dois dígitos do ano } \\
& \mathrm{hh}=\text { hora }(00-23) \\
& \mathrm{mm}=\text { minutos }(00-59)
\end{aligned}
$$


ss.ssssss $=$ segundos (de 0 seg. até 59,999999 seg.)

- Data e Hora do momento do Trigger: mm/dd/yy,hh:mm:ss.ssssss

Onde:

$$
\begin{aligned}
& \mathrm{mm}=\text { mês }(01-12) \\
& \mathrm{dd}=\text { dia }(01-31) \\
& \mathrm{yy}=\text { últimos dois dígitos do ano } \\
& \mathrm{hh}=\text { hora }(00-23) \\
& \mathrm{mm}=\text { minutos }(00-59)
\end{aligned}
$$

ss.ssssss $=$ segundos (de 0 seg. até 59,999999 seg.)

- Tipo do arquivo .DAT (Binário ou ASCII): ft

Onde:

$$
\mathrm{ft}=\text { tipo do arquivo .DAT (ASCII ou Binário) }
$$

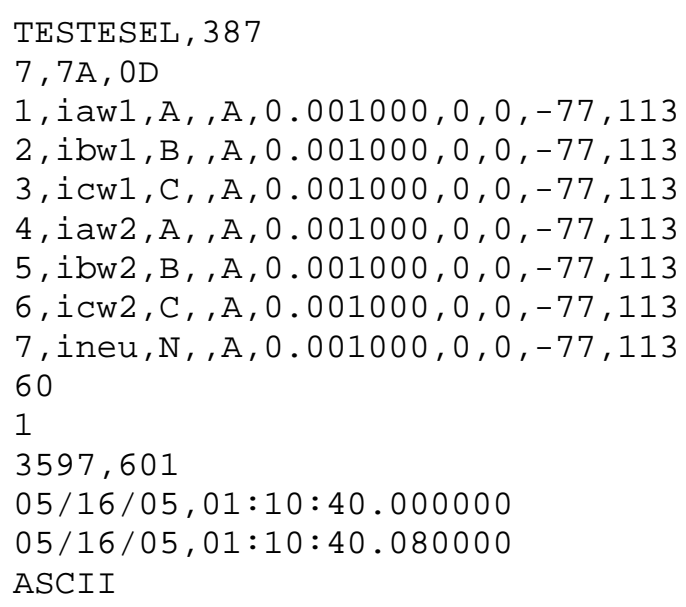

Figura 36. Exemplo do arquivo .CFG de uma aplicação de falta interna com conexão delta-estrela em $10 \%$ do enrolamento A-B com âng. inc. da falta de $0^{\circ}$. 


\section{c) Dados (nome.dat)}

$\mathrm{O}$ arquivo de dados é criado pelo software conversor como um arquivo do tipo ASCII ou Binário. Os dados deste arquivo possuem um formato pré-definido e fixo de modo que possa ser lido e interpretado pelo software de análise o qual associará estes dados com os dados do arquivo .CFG. A Figura 37 mostra a estrutura do arquivo de dados (.DAT).

$\mathrm{O}$ arquivo de dados deve conter os valores organizados em linhas e colunas, onde cada linha corresponde a um conjunto de valores da primeira amostra de cada canal precedido de um número seqüencial e o tempo do conjunto de amostras. Cada linha possui $\mathrm{n}+2$ colunas onde $n$ é o número de canais do registro. $\mathrm{O}$ número de linhas varia de acordo com o número de amostras do arquivo e isto define o tamanho do arquivo. O número de colunas é dependente do sistema de gravação e também afeta o tamanho do arquivo.

A primeira coluna deve conter o número da amostra. A segunda coluna deve conter o tempo da amostra, em $\mu$ s, do início do registro. A terceira e demais colunas contém o valor da amostra que corresponde aos valores da tensão, corrente e estado. Os valores das amostras devem ser representados no formato inteiro com seis dígitos e separados por vírgula. Valores não existentes devem ser representados por 999999. As informações de estado (canais digitais) devem ser representadas por zeros e uns. Nenhuma outra informação deve existir no arquivo .DAT.

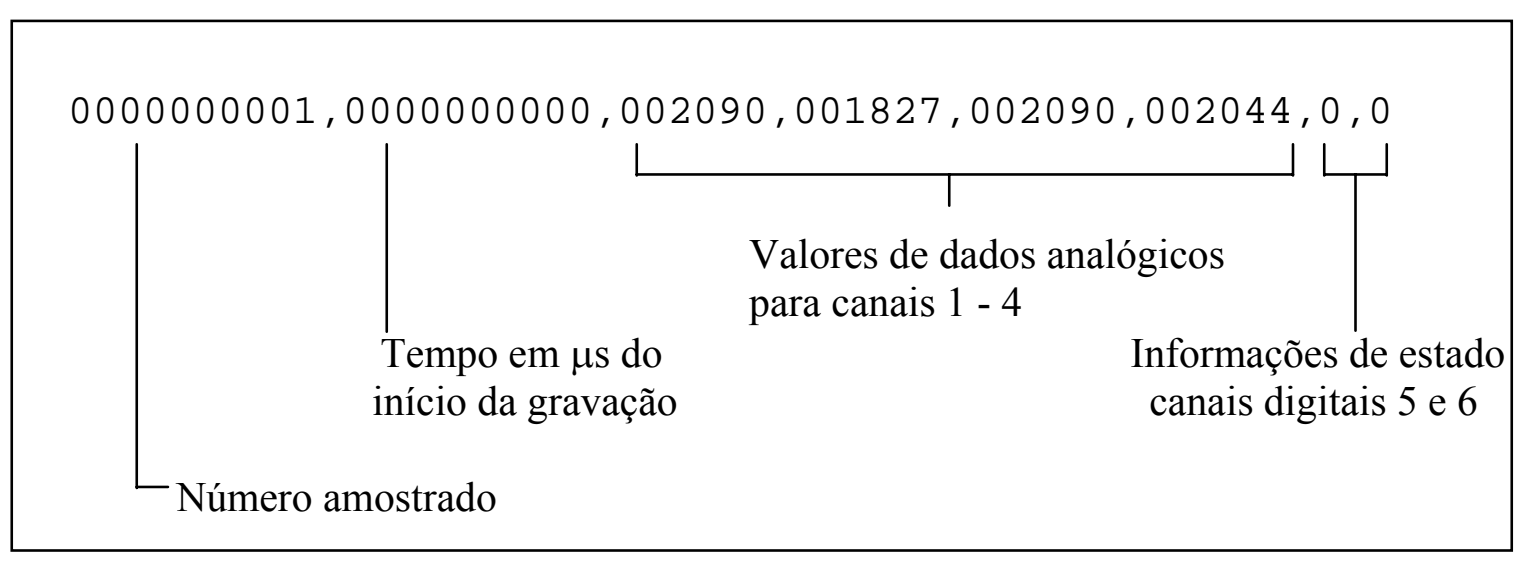

Figura 37. Estrutura do arquivo .DAT. 


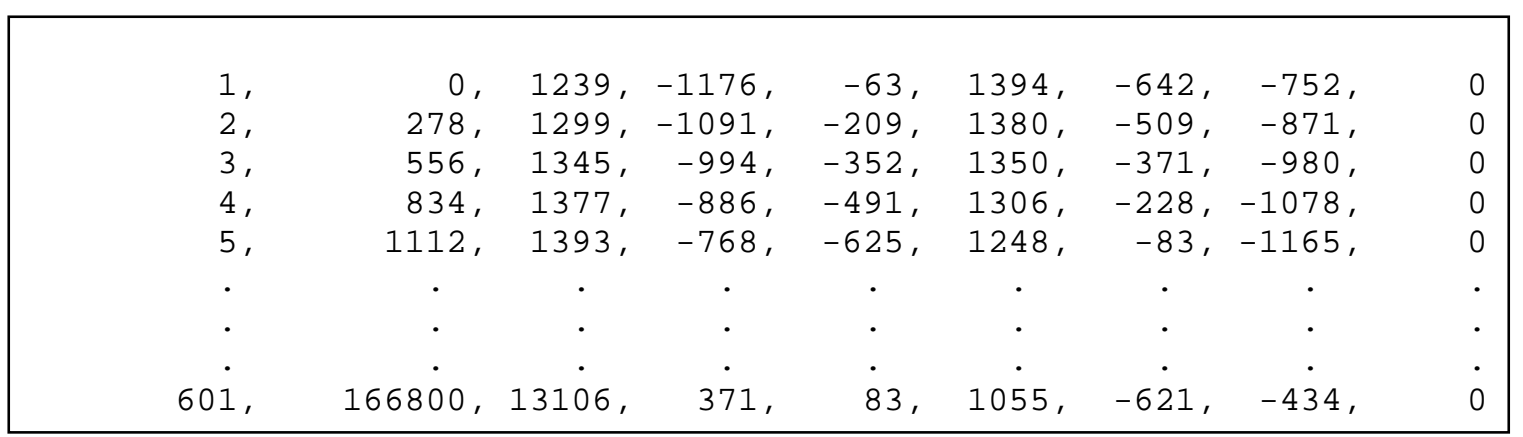

Figura 38. Exemplo do arquivo .DAT de uma aplicação de falta interna com conexão delta-estrela em $10 \%$ do enrolamento A-B com âng. inc. da falta de $0^{\circ}$. 


\section{METODOLOGIA E RESULTADOS OBSERVADOS}

Este capítulo abordará a descrição da metodologia aplicada ao esquema prático e funcional montado, passo a passo, evidenciando todas as etapas envolvidas. O principal objetivo será o de apresentar os testes caracterizados com relação ao esquema desenvolvido para a proteção diferencial de transformadores, denotando os benefícios esperados e oferecidos de tal abordagem.

\subsection{Metodologia aplicada}

Para a caracterização do sistema como um todo pela Figura 4, tem-se como primeiro passo (Figura 39), a modelagem do mesmo dispondo do software ATP, com a conseqüente aplicação de situações desejáveis ao trabalho. Afirma-se que foi simulado e testado um considerável número de casos frente às situações desejadas. Contudo, para a ilustração deste trabalho, algumas condições receberão destaque, a saber:

- condição de energização do transformador principal (Figuras 12 e 13);

- condição de energização com falta interna do transformador principal (Figuras 14 e 15);

- situação de falta monofásica interna (envolvendo a fase A com conexão a terra), aplicada a 10\% do enrolamento primário (delta) do transformador de potência, sendo ilustrada e caracterizada pelas Figuras 16, 17 e 18 com carga de 10 MVA conectada em estrela;

- situação de falta monofásica interna, aplicada a 10\% do enrolamento (estrela), carga de 10 MVA sendo conectada em delta, caracterizada pelas Figuras 19 e 20;

- situação de falta interna aplicada a 25\% do enrolamento (estrela), carga conectada em delta, carregamento pesado, ilustrado pelas Figuras 23 e 24; 
- situação de falta monofásica interna (caracterizada sobre a fase A), aplicada a $80 \%$ do enrolamento secundário do transformador de potência (Figuras 25 e 26);

- situação de falta externa, aplicada ao final da linha de distribuição (Figuras 27, 28 e 29);

- situação de falta externa aplicada próxima ao TC secundário com saturação do mesmo (Figuras 30, 31 e 32) e

- condição de sobreexcitação (Figuras 33 e 34).

As situações ilustradas foram originadas da aplicação do software ATP, considerando-se uma freqüência de amostragem de $3840 \mathrm{~Hz}$ e serão devidamente comentadas no que segue.

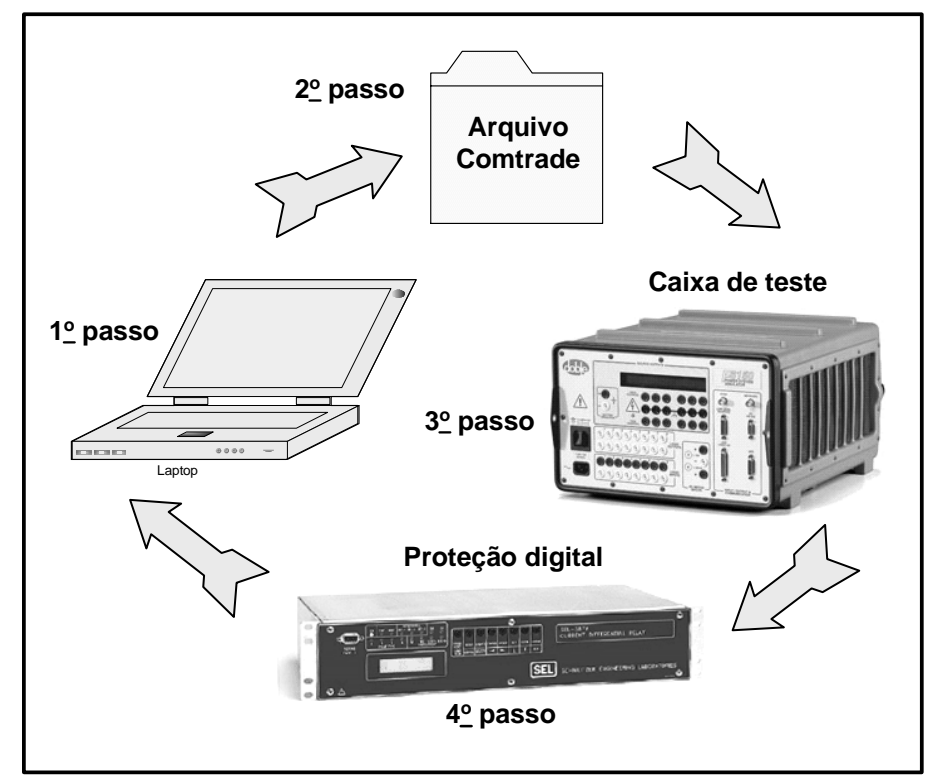

Figura 39. Seqüência de eventos caracterizando a metodologia aplicada.

Na seqüência dos eventos, dispondo-se das saídas discretas geradas pelo software

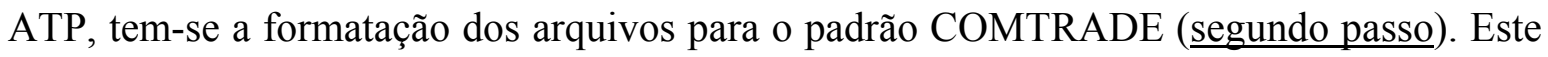
padrão define um formato comum dos arquivos de dados conforme padronização do IEEE Standard C37_111_1991, o qual possibilita o intercâmbio dos arquivos entre os vários tipos de sistemas de análise de dados de falta, testes e simulações. 
No terceiro passo, as situações desejáveis para a análise, já no formato padrão COMTRADE, são disponibilizadas à caixa de testes. Esta por sua vez, é empregada para caracterizar determinadas situações de testes sobre as lógicas de proteção digitais aplicadas aos relés comerciais. A caixa de testes é útil para validar e levantar as curvas características de operação dos relés associados, principalmente na definição e implementação das lógicas de proteção para as linhas de transmissão e de distribuição ou à faltas internas e externas em transformadores, como é o caso. Por esta caixa é possível avaliar os arquivos COMTRADE provenientes das inúmeras situações de testes implementadas computacionalmente, bem como as registradas junto às concessionárias locais. A mesma possibilita conexão com a internet para atualização, acompanhamento e atuação dos sistemas de proteção, sincronização via satélite (GPS - Global Positioning Satellite) e configuração interna, de forma independente via microcomputadores, essenciais aos testes e aplicações práticas comentadas.

Como evidenciado pela Figura 39, caracteriza-se o quarto passo como a avaliação do comportamento da operação dos relés desejados frente às situações apresentadas.

Voltando ao passo um da seqüência, têm-se as análises das oscilografias registradas pelo relé SEL-387A direcionado à proteção diferencial de transformadores, quando da apresentação de alguns distúrbios em formato COMTRADE. Estas oscilografias representam os sinais de corrente observadas em ambos os $\mathrm{TC}^{\prime} \mathrm{s}$, bem como as correntes diferenciais. Todos os valores observáveis passam por filtros passa-baixas anti-aliasing (filtro Butterworth), os quais servem para remover os componentes de alta freqüência dos sinais, e por filtros digitais (Fourier de Onda Completa) para se extrair principalmente os componentes fundamentais, de segunda, quarta e quinta harmônica. Após esse processo de filtragem, quando necessário, faz-se via relé, uma correção das escalas dos tapes dos TC's, a remoção de componentes de seqüência zero e a compensação da defasagem do transformador, em função das conexões caracterizadas.

Devido o uso de um equipamento programável (digital), devem-se fazer alguns ajustes do elemento diferencial utilizado para avaliação dos testes, sendo que estes foram condicionados aos valores normalmente encontrados na prática. Estes ajustes serão relacionados a seguir, a fim de um melhor entendimento dos parâmetros necessários:

Relação do TC de alta - CTR1 $=40$ 
Relação do TC de baixa - CTR2 $=400$

Tap da alta - TAP1 $=2,61 \mathrm{~A}$

Tap da baixa - TAP2 $=2,61 \mathrm{~A}$

Pick-up do elemento diferencial - O87P=0,30 (p.u. do tap)

Primeira inclinação - SLP1 $=25 \%$

Segunda inclinação - SLP2 $=50 \%$

Ponto de transição inclinação - IRS1 = 3,0 (p.u. do tap)

Elemento diferencial instantâneo - U87P $=8,00$ (p.u. do tap)

Bloqueio $2^{\circ}$ harmônico - PCT2 $=15 \%$

Bloqueio $4^{\circ}$ harmônico - PCT4 $=15 \%$

Bloqueio $5^{\circ}$ harmônico - PCT5 = 35\%

\subsection{Resultados observados}

Antes de analisarmos as oscilografias propriamente ditas, vamos elucidar sobre o significado da nomenclatura empregada. Nas oscilografias que serão apresentadas, na parte superior, acima das formas de onda, estão representadas as saídas analógicas, as quais ilustram os sinais filtrados de corrente em ambos os lados, de alta (IAW1, IBW2 e ICW1 fases $\mathrm{A}, \mathrm{B}$ e $\mathrm{C}$ respectivamente) e de baixa (IAW2, IBW2 e ICW2), do transformador principal. Na parte inferior, abaixo às formas de onda, são caracterizadas as saídas digitais que denotam a resposta de operação do relé diferencial por meio de diferentes variáveis intrínsecas à lógica do relé SEL-387A. Estas são representadas por sinais de 0 ou 1, demarcados por uma linha normal (sinal 0), ou por uma linha em destaque (sinal 1). Dentre as variáveis caracterizadas podemos destacar as seguintes:

$87 \mathrm{O} 1$ - Partida (pickup) individual do elemento diferencial da fase A;

87R - Elemento diferencial com restrição;

87U - Elemento diferencial sem restrição (instantâneo);

TRIP1 - Comando individual de disparo (87R ou 87U) da fase A;

87BL1 - Bloqueio individual da proteção diferencial da fase A;

2HB1 - Bloqueio individual por $2^{\circ}$ harmônica da fase A;

$4 \mathrm{HBL}$ - Bloqueio comum por $4^{\circ}$ harmônica;

5HB1 - Bloqueio individual por $5^{\circ}$ harmônica da fase A; 
IOP1 - Corrente diferencial de operação da fase A;

IRT1 - Corrente diferencial de restrição da fase A;

I1F2 - Corrente diferencial de $2^{\circ}$ harmônica da fase A;

I1F5 - Corrente diferencial de $5^{\circ}$ harmônica da fase A.

32IF1 - Corrente residual de neutro.

Cabe comentar que a linha pontilhada em vermelho sobre as ilustrações a serem apresentadas, denota o início da marcação do trigger, o qual indica o disparo da oscilografia. Todas as oscilografias foram realizadas utilizando-se de 5 ciclos de pré e 10 ciclos de pós-falta, com uma taxa amostral de 8 pontos por ciclo. Ressalta-se que, os sinais foram injetados ao relé a uma freqüência de amostragem de $3840 \mathrm{~Hz}$.

Para efeito meramente ilustrativo, apresenta-se em anexo, a lógica do elemento de proteção do relé SEL-387A (Schweitzer Engineering Laboratories).

A seguir serão apresentadas e discutidas as oscilografias obtidas e analisadas pelo relé, modelo SEL-387A.

A Figura 40 ilustra uma oscilografia referente a uma situação de energização com o secundário do transformador de potência a vazio. Para esta situação, a proteção é habilitada como bloqueio comum das componentes harmônicas, onde se visualiza a forma de onda já filtrada e se constata que o relé logo de início verifica a alteração do valor da corrente de operação (IOP2 e IOP3), a qual ultrapassa o valor mínimo pré-estabelecido (pickup O87P), habilitando então o elemento diferencial instantâneo (87U) e/ou de restrição (87R). Mediante tal situação, o relé também monitora desde o início as componentes harmônicas de $2^{\mathrm{a}}(2 \mathrm{HB} 1,2,3), 4^{\mathrm{a}}(4 \mathrm{HBL})$ e $5^{\mathrm{a}}(5 \mathrm{BH} 1)$ ordem nas três fases, fazendo com que haja o bloqueio da operação (87BL). Pode ser observado que a partir do momento que aparece a componente harmônica de $2^{\mathrm{a}}$ ordem, em qualquer fase, há um bloqueio comum sobre a atuação do relé.

A Figura 41 ilustra a oscilografia do mesmo caso de energização. Contudo, a proteção esta habilitada como sendo por bloqueio independente das componentes harmônicas. A diferença é que o bloqueio será individual a cada fase e não comum a todas, como anteriormente comentado. Neste caso também se garante a não operação por energização. 
A Figura 42 mostra a oscilografia para o mesmo caso de energização, porém, a proteção foi habilitada por restrição das componentes harmônicas. Quando esta função esta habilitada o relé eleva a curva de operação agregando um dado valor calculado a partir da corrente diferencial de $2^{\mathrm{a}}$ e $4^{\mathrm{a}}$ harmônica. Percebe-se então que, como houve uma elevação da curva, o ponto de operação caiu fora da região de operação, caracterizado pela não atuação dos elementos de restrição $(87 \mathrm{R} 1,2,3$,). Logo o relé não irá operar garantindo a perfeita energização do transformador.

$\mathrm{Na}$ Figura 43 temos a ilustração da oscilografia caracterizando as correntes diferenciais de operação, onde as fases A, B e C são representadas pelos números 1, 2 e 3 respectivamente. Percebe-se que a corrente de operação na fase A não é sensibilizada, devido ao não alcance do valor mínimo (pickup). Porém, observa-se que nas demais fases esse limiar é alcançado, demonstrando que existe uma corrente de operação. Observa-se também que existem correntes de restrição, que poderiam habilitar a operação do relé pelo elemento de restrição. Todavia não há atuação do relé, devido ao bloqueio por harmônicos, caracterizado pelas curvas I1F2, I2F2 e I3F2.

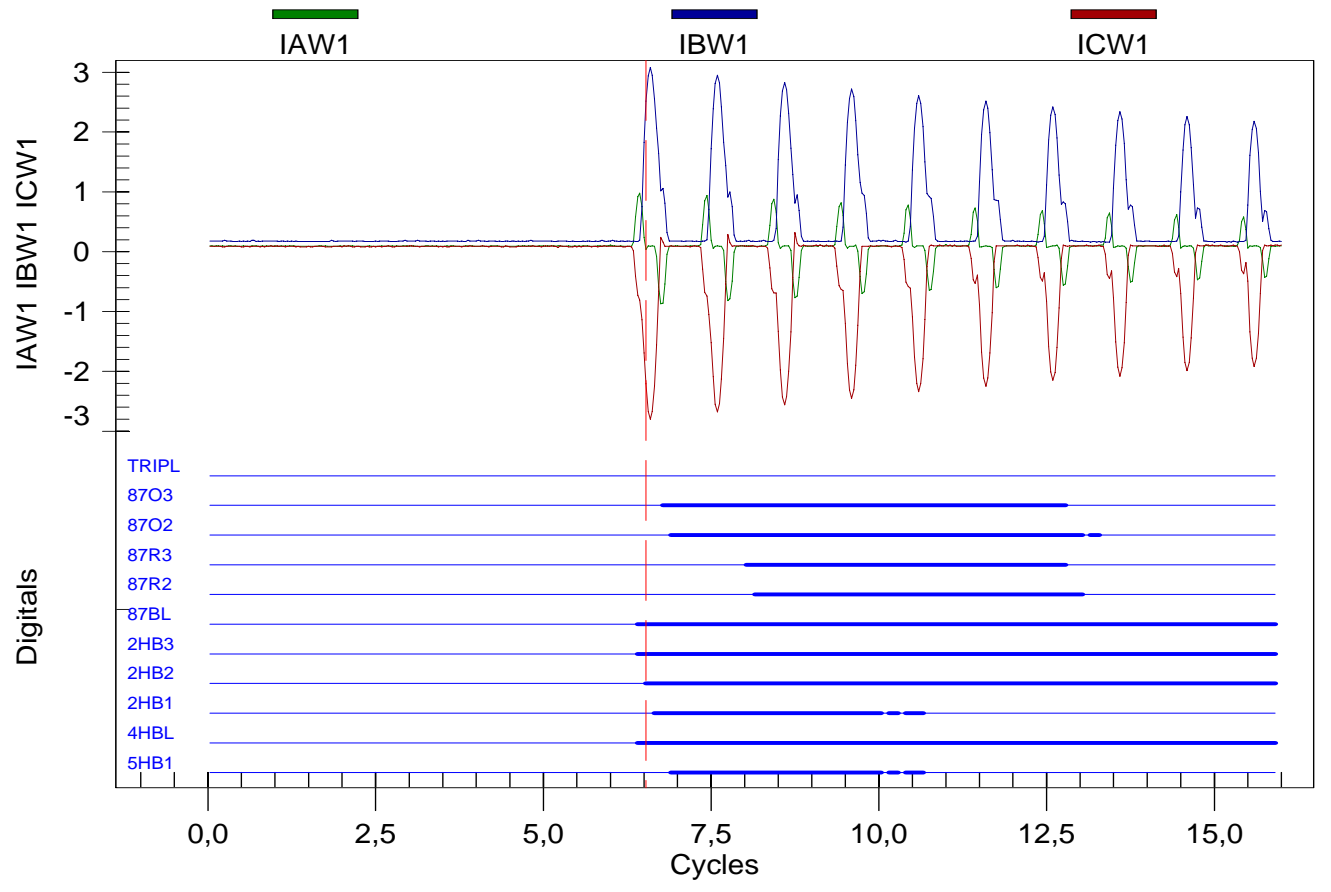

Figura 40. Correntes observadas nos transformadores de medição com a conseqüente posição do sistema de proteção para a situação de energização do transformador principal a vazio, com proteção por bloqueio comum das componentes de $2^{\mathrm{a}}$ harmônica. 


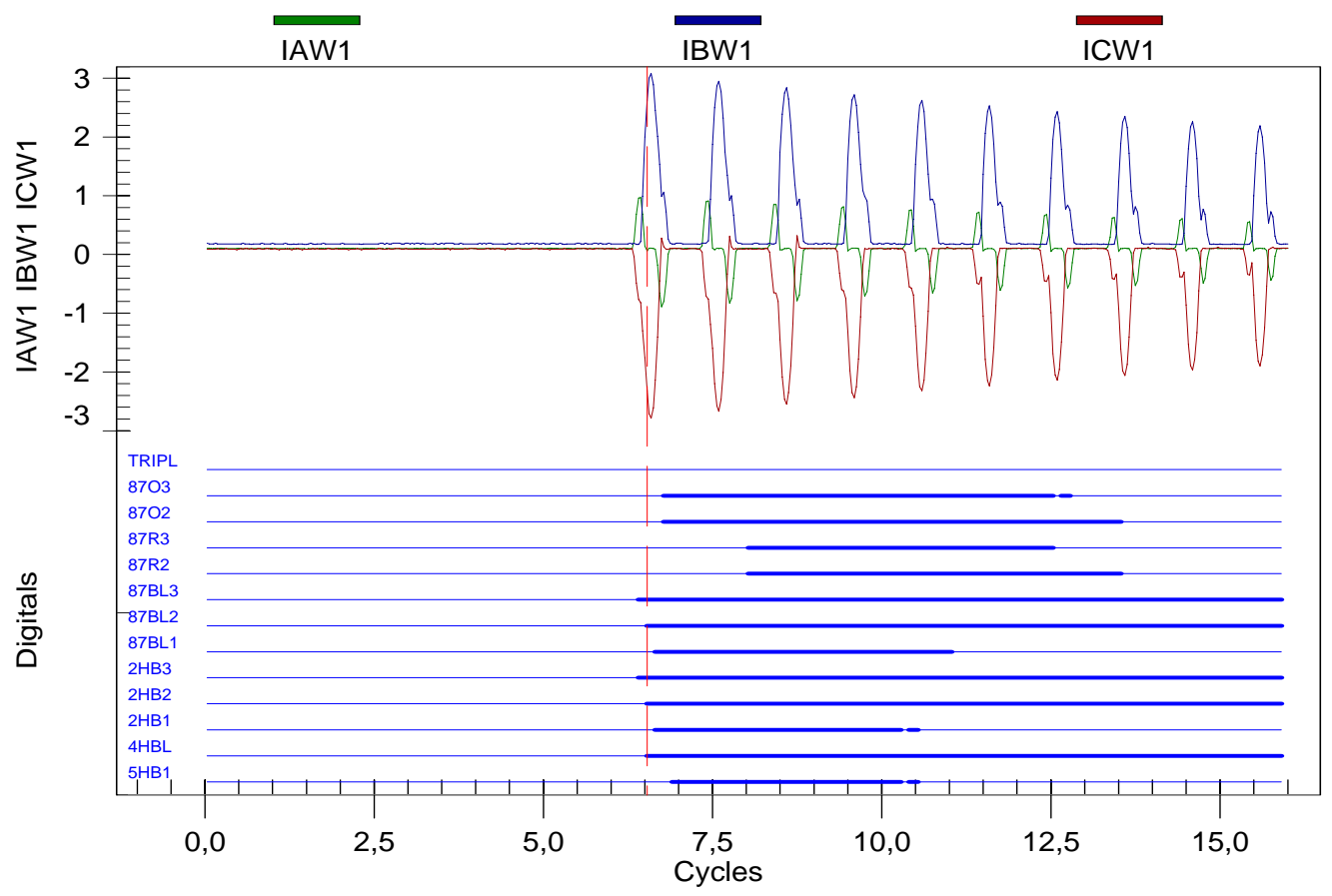

Figura 41. Correntes observadas nos transformadores de medição com a conseqüente posição do sistema de proteção para a situação de energização do transformador principal a vazio, com proteção por bloqueio independente das componentes harmônicas de segunda ordem.

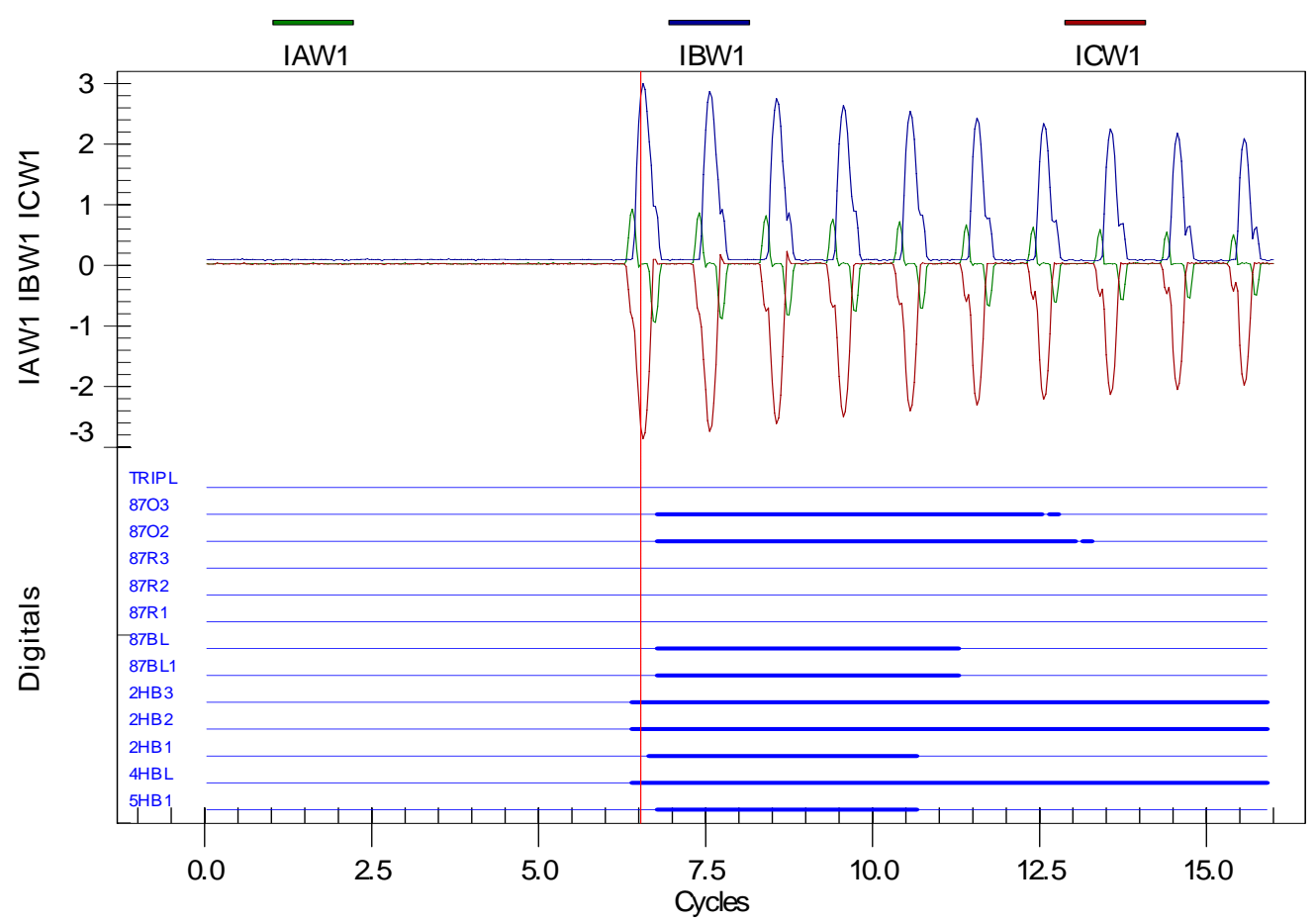

Figura 42. Correntes observadas nos transformadores de medição com a conseqüente posição do sistema de proteção para a situação de energização do transformador principal a vazio, com proteção por restrição. 


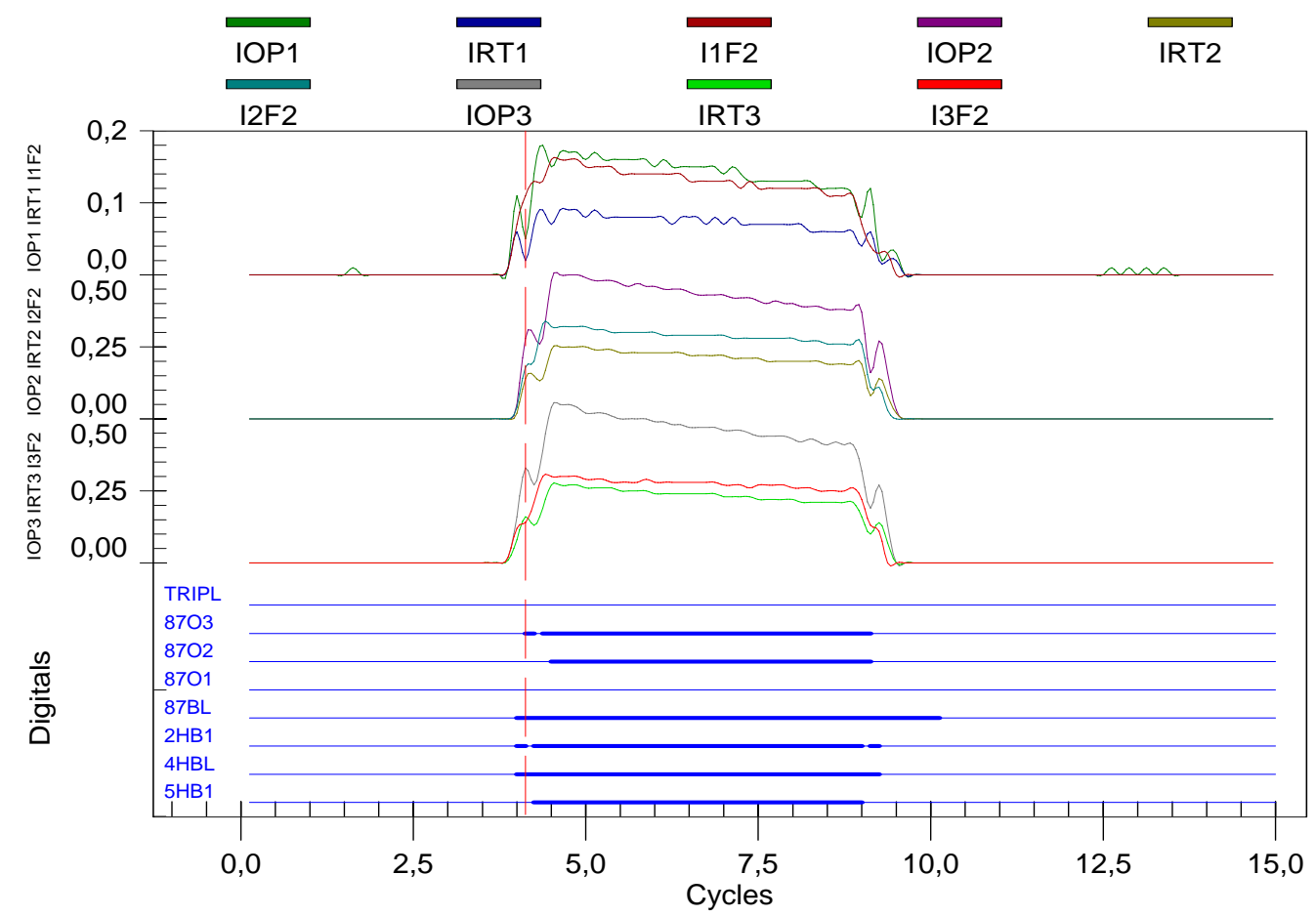

Figura 43. Correntes diferenciais observadas pelos TC's com a conseqüente posição do sistema de proteção para a situação de energização do transformador principal a vazio.

As oscilografias das Figuras 44, 45 e 46 representam uma situação de energização do transformador de potência quando da ocorrência de uma falta interna monofásica (faseterra), diferenciando-se somente pela função de proteção habilitada: por bloqueio comum, independente e por restrição em cada uma das situações.

Apenas para um melhor entendimento às funções mencionadas e das suas conseqüências sobre a filosofia de proteção empregada, no que segue, será comentado quando da situação de energização seguida de uma situação de falta interna.

Para o caso de bloqueio comum, o relé irá observar as componentes harmônicas independente da(s) fase(s) envolvida(s), bloqueando a sua operação quando da manifestação em qualquer uma da(s) fase(s). Já para a função de bloqueio independente, o relé irá observar cada fase individualmente. Por esta função, por exemplo, quando da não observância da restrição harmônica em duas das fases do sistema e mediante a uma situação de falta caracterizada, o relé irá operar. E para o caso de função de proteção por restrição, o relé irá observar somente os valores das correntes através do cálculo do ponto de operação na característica de atuação da proteção diferencial, apresentado pela Figura 2. Deve-se 
ressaltar que para este caso, quando há o surgimento de harmônicas de $2^{\mathrm{a}}$ e $4^{\mathrm{a}}$ ordem, o processo digital faz com que a curva se eleve, aumentando a região de bloqueio e acrescentando uma maior segurança para a não atuação do relé.

A Figura 44 ilustra a oscilografia referente à energização com falta quando se utilizou a função para proteção com bloqueio comum por componentes harmônicos. Notase logo de início o aparecimento da componente harmônica de $2^{\mathrm{a}}$ ordem nas três fases. Porém, decorrido um dado instante, caracterizou-se a componente apenas na fase 2 (B). Sendo assim, como o bloqueio comum estava habilitado, houve o bloqueio errôneo da operação do relé, ou seja, embora o relé tenha percebido a falta pelo elemento de restrição $(87 \mathrm{R} 1,2,3)$ a atuação do mesmo (TRIPL) foi restringida pelo bloqueio comum da $2^{\mathrm{a}}$ harmônica.

$\mathrm{Na}$ Figura 45 aplica-se o método para proteção com bloqueio independente das componentes harmônicas. Nota-se que o relé observa as fases 1 e 3 (A e C), as quais são bloqueadas $(87 \mathrm{BL} 1,3)$ por apresentarem uma $2^{\mathrm{a}}$ harmônica temporária $(2 \mathrm{HB} 1,3)$. A partir do momento da não existência das harmônicas, o relé calcula e compara os valores das correntes lidas com as calculadas e então delibera a atuação (TRIPL), mesmo havendo bloqueio da fase 2 (B), pois se percebe que o valor ultrapassa o adotado para a restrição $(87 \mathrm{R} 1,3)$, que é de $15 \%$. Vale a pena observar que a falta foi detectada após 1,375 ciclos.

A Figura 46 mostra o método para proteção por restrição. O relé observa os harmônicos envolvidos no início da energização (5HB1, 4HBL, 2HB1,2,3) e qual logo são bloqueados (87BL), mas como a função bloqueio não esta habilitada, não influenciará na tomada de decisão. Neste método a restrição é calculada desde o início da detecção da condição adotada, e após 2,375 ciclos é observada a atuação do relé (TRIPL). Este é um método um pouco mais demorado para observação dos resultados, mas que melhor abrange todos os problemas relacionados. 


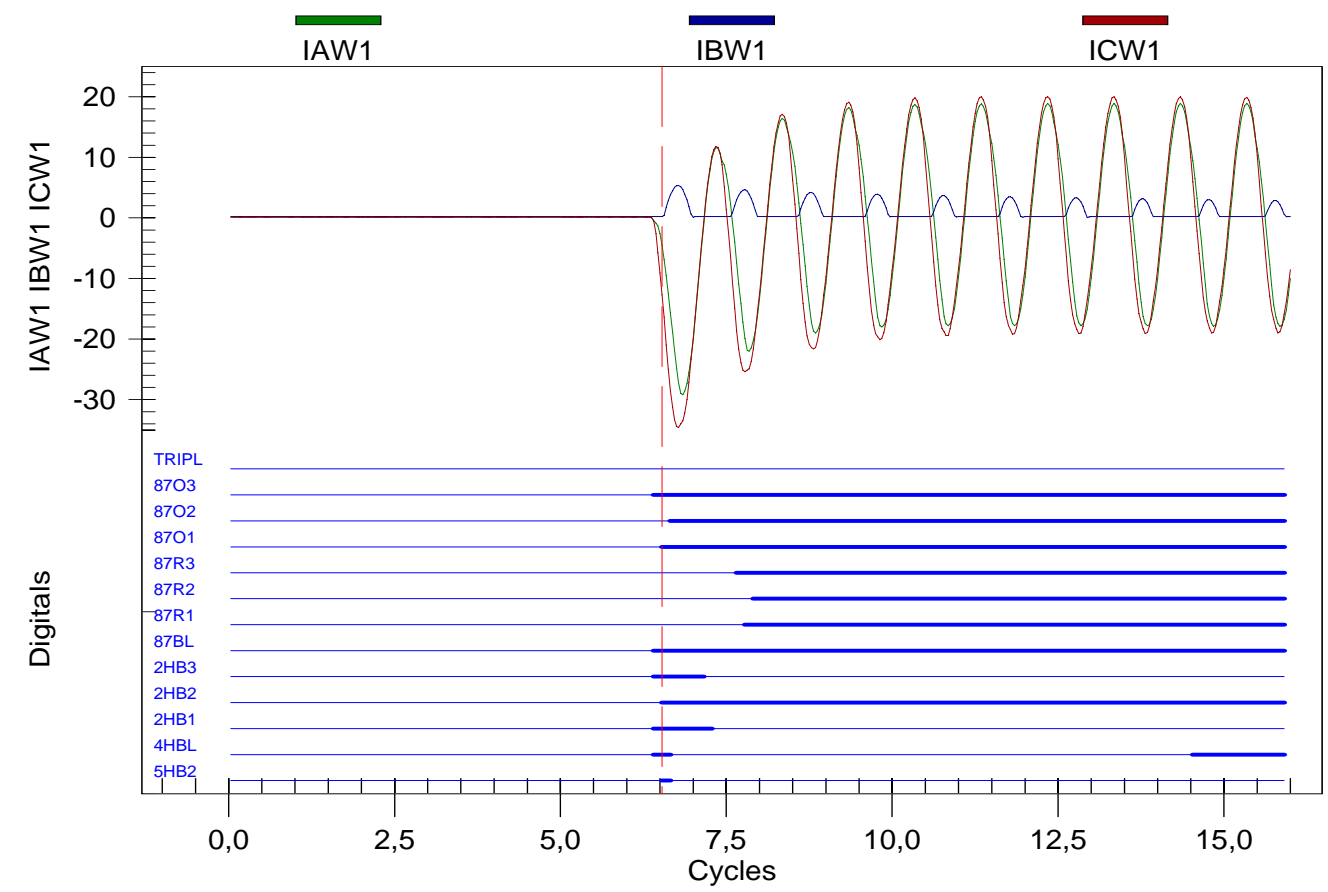

Figura 44. Correntes observadas nos transformadores de medição com a conseqüente posição do sistema de proteção para a situação de energização com falta no secundário (estrela) do transformador, com proteção por bloqueio comum das componentes de segunda harmônica.

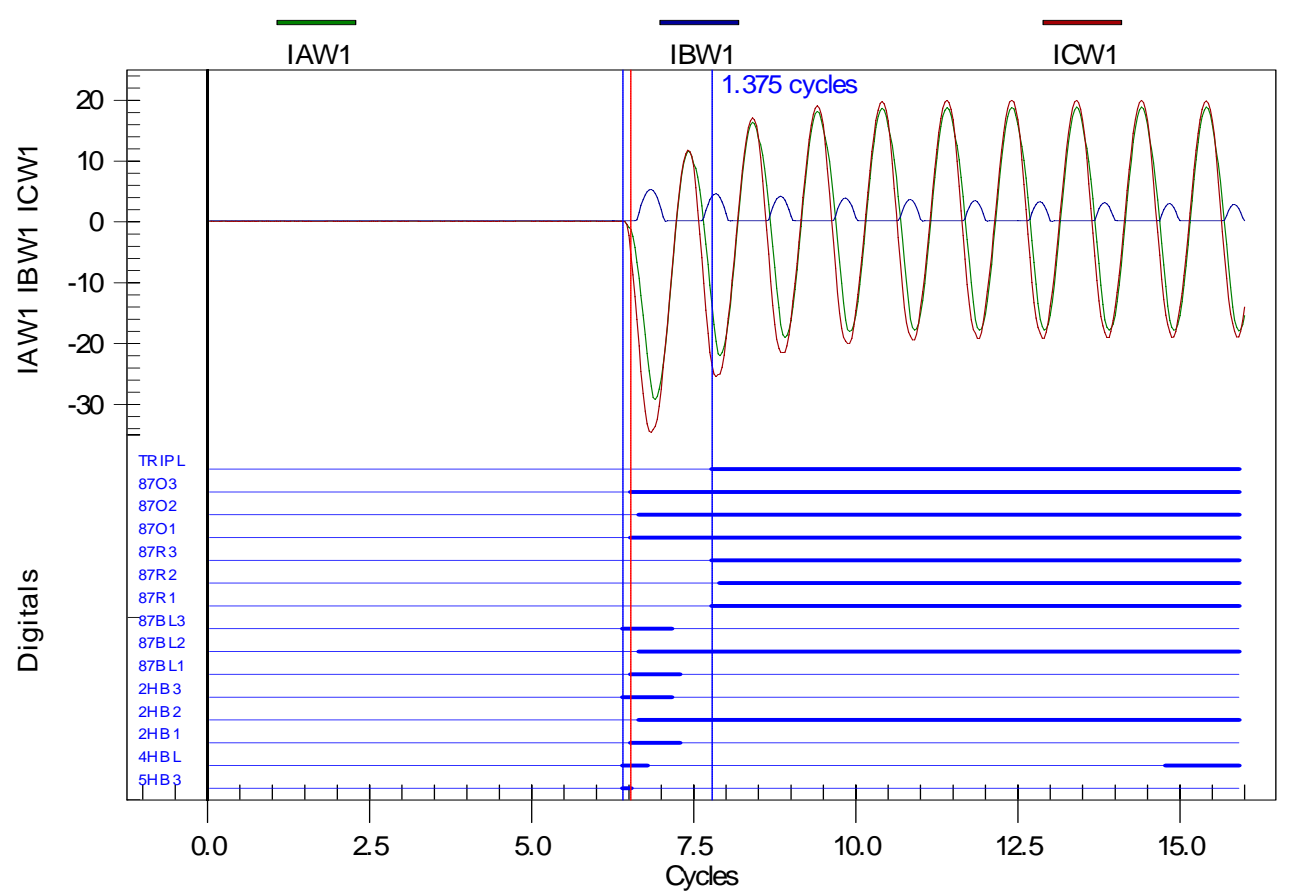

Figura 45. Correntes observadas nos transformadores de medição com a conseqüente posição do sistema de proteção para a situação de energização com falta no secundário (estrela) do transformador principal a vazio, com proteção por bloqueio independente das componentes de segunda harmônica. 


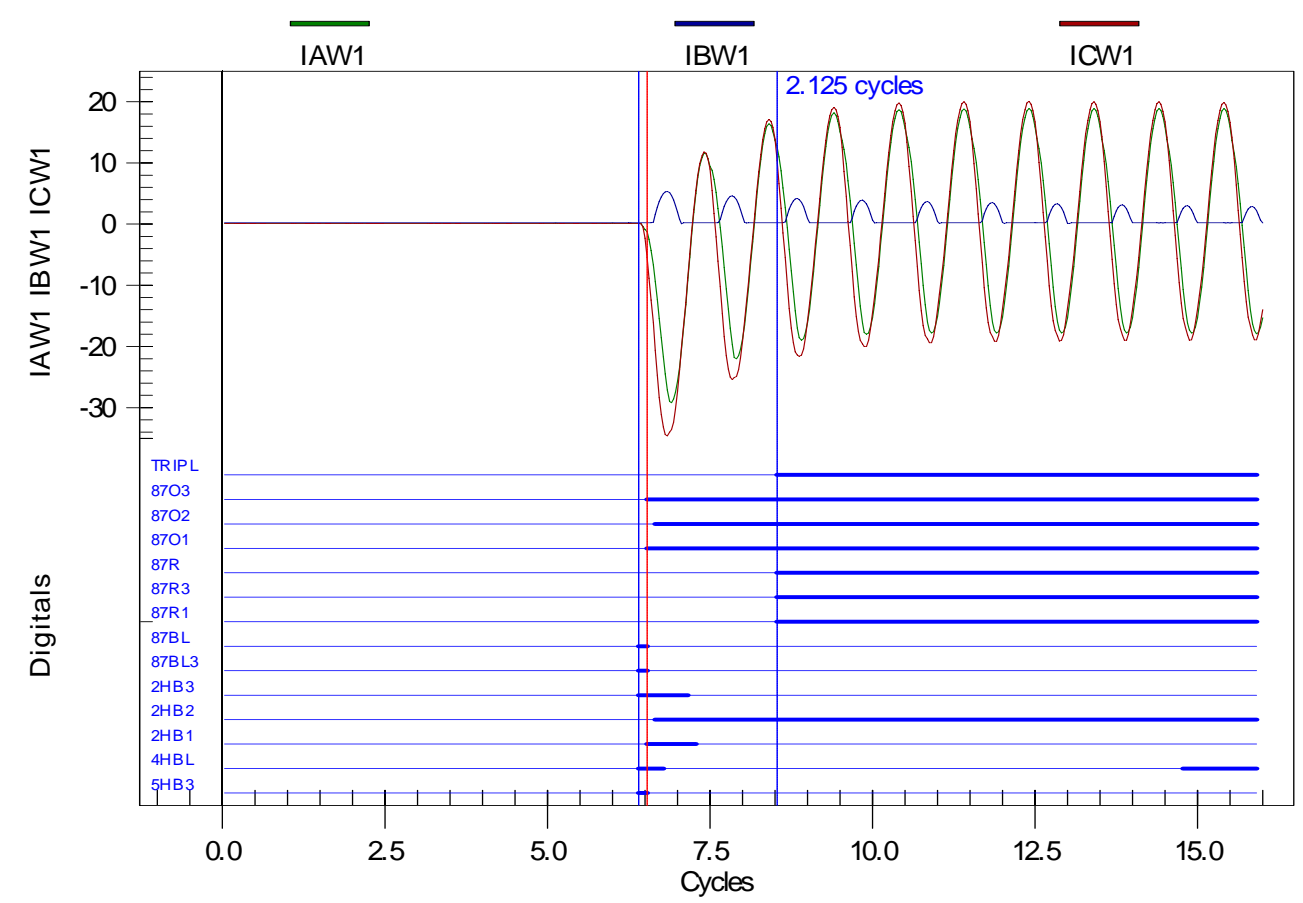

Figura 46. Correntes observadas nos transformadores de medição com a conseqüente posição do sistema de proteção para a situação de energização com falta no secundário (estrela) do transformador principal a vazio, com proteção por restrição.

A Figura 47 ilustra uma oscilografia referente a uma situação de falta interna (faseterra) no enrolamento primário (delta), ramo $\mathrm{AB}$, a $10 \%$ da fase $\mathrm{A}$ do transformador de potência, carga de 10 MVA conectada em estrela. Para esta situação, nota-se a sensibilização da operação do elemento da proteção diferencial (8701) logo no início do distúrbio, uma vez que o valor mínimo parametrizado (pickup - O87P) foi alcançado, habilitando assim, a operação de restrição harmônica e instantânea. No início do distúrbio há a operação por bloqueio de $2^{\circ}, 4^{\circ}$ e $5^{\circ}$ harmônico (detecção de alguns componentes), restringindo a operação por restrição harmônica. Contudo, após 1 ciclo de pós-falta, o relé emite o comando de disparo (TRIP1) através do elemento instantâneo da proteção diferencial (87U), uma vez que a corrente de operação diferencial (IOP) excede o valor de ajuste do elemento instantâneo (U87P) parametrizado no relé.

A Figura 48 representa as correntes diferenciais processadas pelo relé, pelas quais se percebe a atuação do elemento instantâneo $(87 \mathrm{U})$, devido a corrente de operação ultrapassar o limiar adotado de 8,0 p.u. 


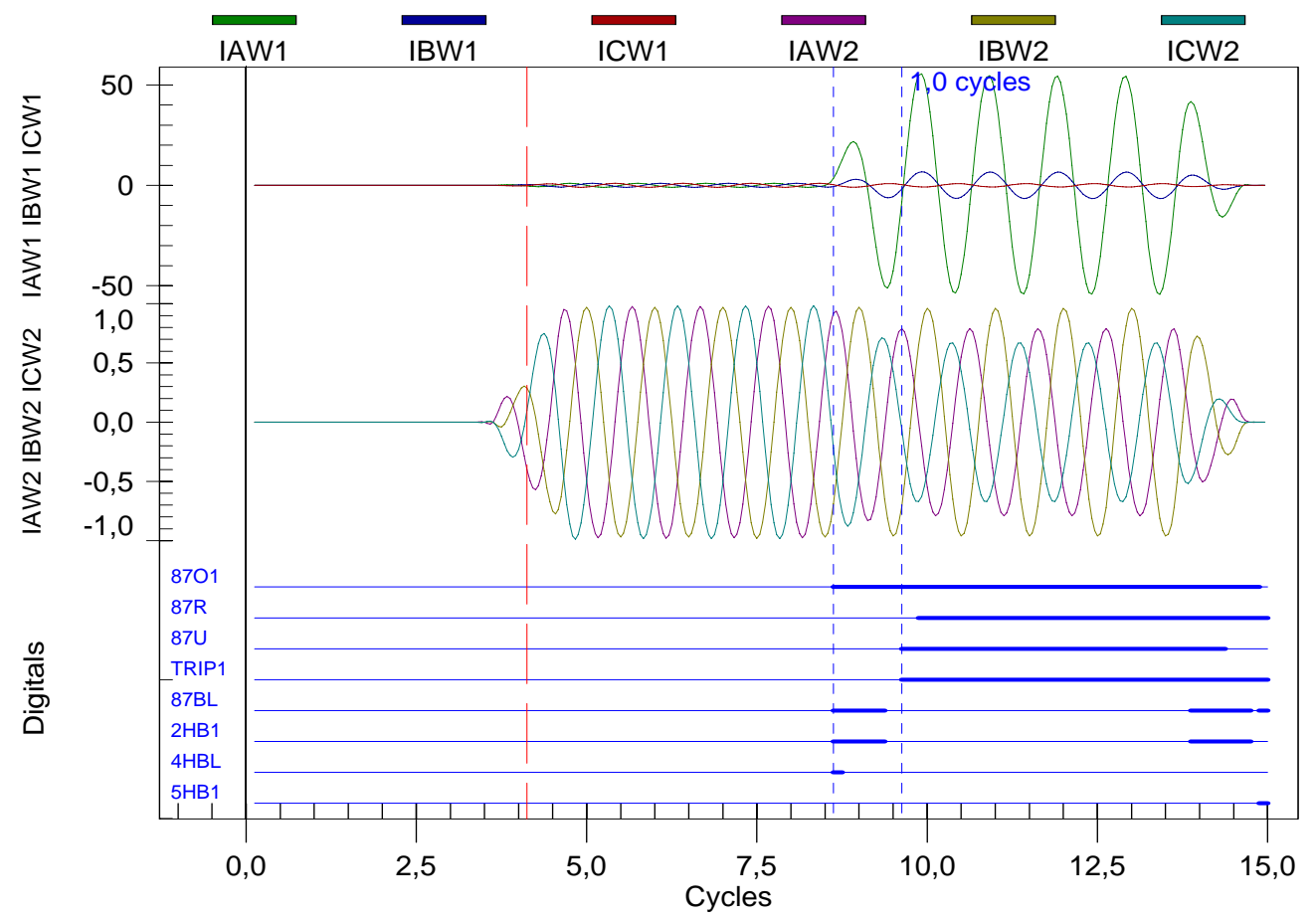

Figura 47. Oscilografia das correntes observadas nos TC's com a conseqüente posição do sistema de proteção para uma falta interna, aplicada a $10 \%$ do enrolamento (delta), carga média de 10 MVA sendo conectada em estrela.

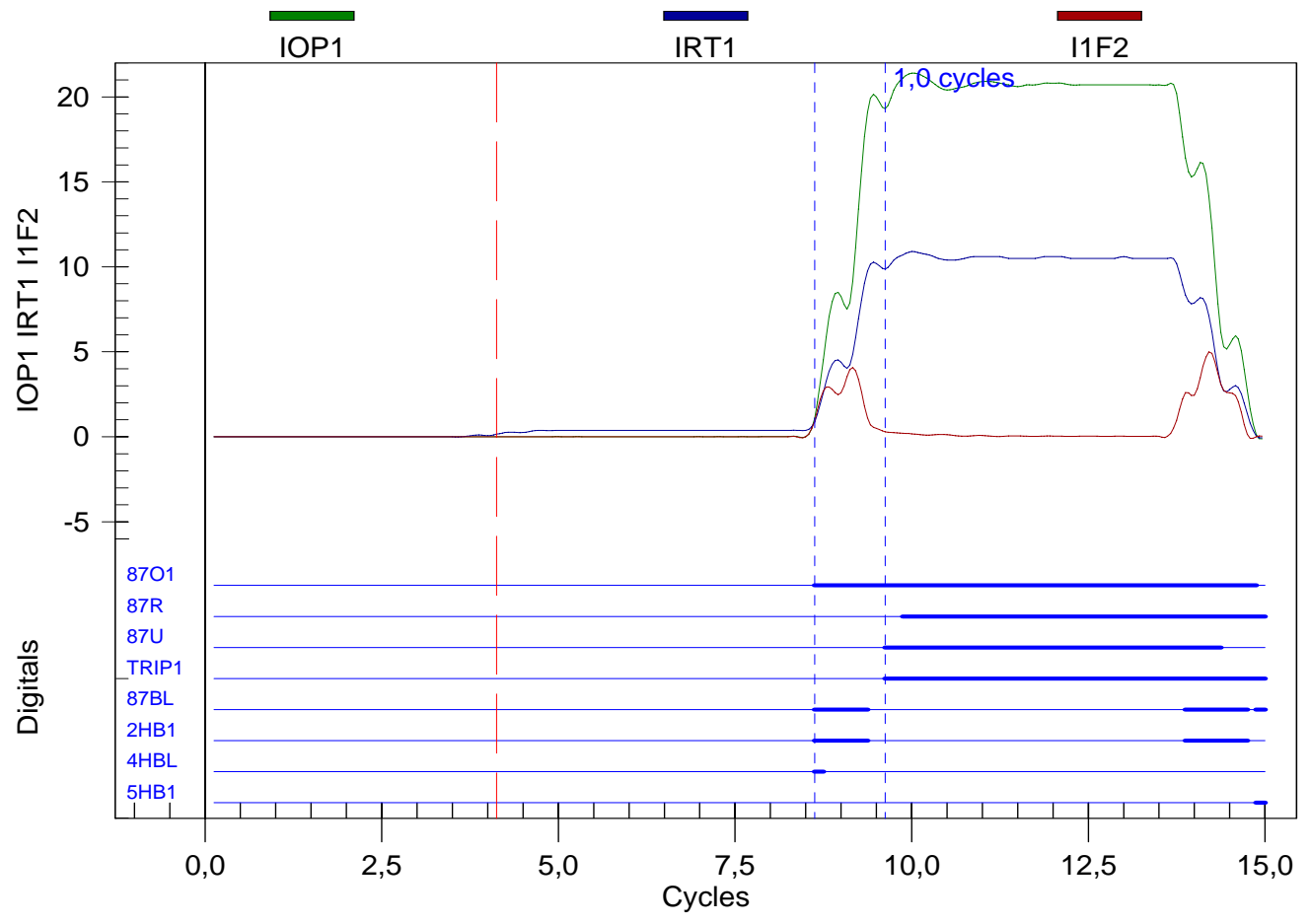

Figura 48. Oscilografia das correntes diferenciais observadas nos TC's com a conseqüente posição do sistema de proteção para uma falta interna, aplicada a 10\% do enrolamento (delta), carga média de 10MVA sendo conectada em estrela. 
A Figura 49 ilustra uma oscilografia referente a uma situação de falta interna (faseterra) no enrolamento secundário (estrela), ramo A, a 10\%, carga de 10 MVA sendo conectada em delta. Para esta situação, nota-se que nenhuma característica foi sensibilizada. Apesar de ser uma falta interna o relé não conseguiu distinguir a falta de uma operação normal. Em casos como este, onde a falta ocorre próxima do neutro, não há um grande desbalanceamento das correntes do primário e do secundário, conseqüentemente a corrente de operação não atingiu o valor mínimo (pickup - O87P), conforme ilustra a Figura 50. Uma solução para este problema foi então habilitar uma função chamada "falta terra restrita" (REF - Restrict Earth Fault), cujo equacionamento é baseado no cálculo da corrente diferencial de neutro, utilizando para isto, a corrente de neutro medida (In) e a corrente de neutro calculada $((\mathrm{Ia}+\mathrm{Ib}+\mathrm{Ic}) / 3)$. Uma vez utilizada esta função, é possível contornar o problema para este tipo de situação, o que pode ser constatado na Figura 50, onde, agregado desta função (32IF1), houve a atuação do relé.

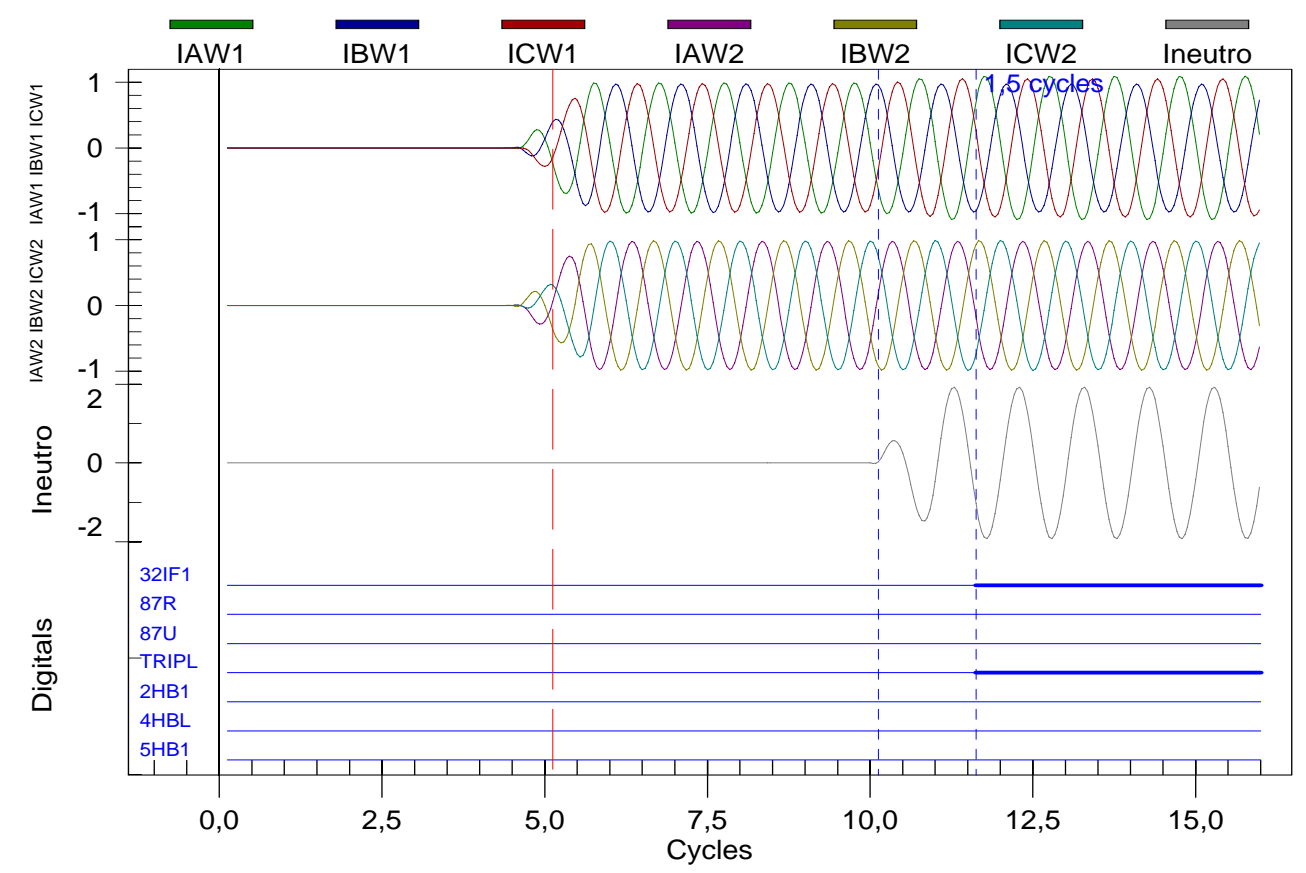

Figura 49. Oscilografia das correntes observadas nos TC's na proteção para uma falta interna, aplicada a $10 \%$ do enrolamento (estrela), carga média de 10 MVA sendo conectada em delta e função "falta terra restrita" habilitada. 


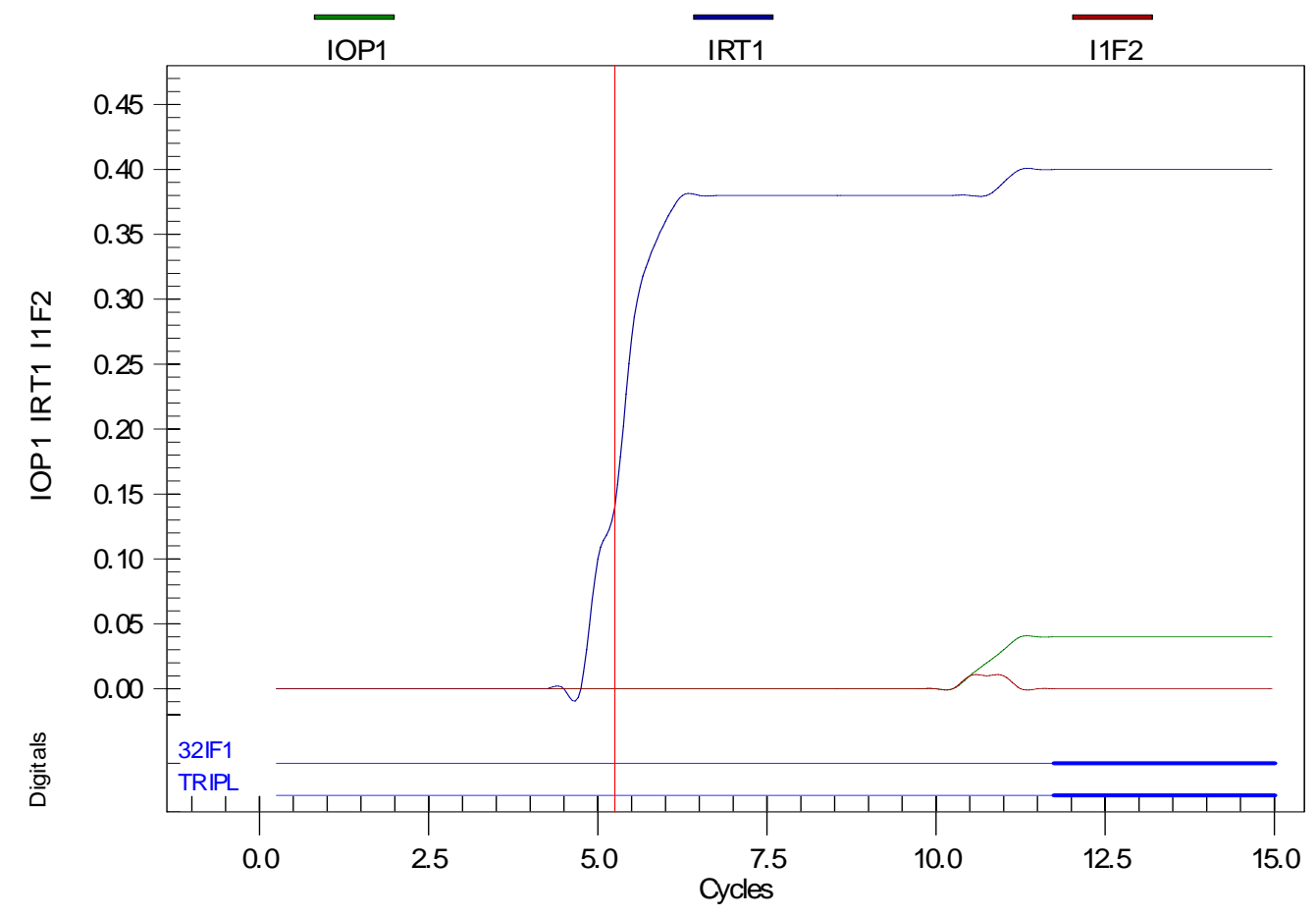

Figura 50. Oscilografia das correntes diferenciais observadas nos TC's com a conseqüente posição do sistema de proteção para uma falta interna, aplicada a 10\% do enrolamento (estrela), carga média de 10 MVA sendo conectada em delta e função "falta terra restrita" habilitada.

Na Figura 51 tem-se a oscilografia de uma situação de falta interna aplicada a 25\% do enrolamento (estrela), carga conectada em delta, com carga pesada e função "falta terra restrita" habilitada. Neste caso o relé também não consegue distinguir dentre uma situação de falta interna de uma situação normal utilizando a proteção diferencial percentual convencional. Entretanto, o mesmo atua pela função REF, protegendo o transformador. Ressalta-se que mesmo para uma falta a $25 \%$ do enrolamento estrela com referência ao neutro e carga pesada, a proteção diferencial convencional não foi sensibilizada, necessitando que outra função fosse habilitada para garantir a proteção.

Cabe comentar que durante o desenvolvimento dos testes, observou-se que a proteção diferencial por restrição começa a atuar somente para situações de falta acima de $30 \%$ do enrolamento secundário em estrela, mesmo assim, com um tempo de atuação um pouco elevado (maior que 2 ciclos) (conforme Figuras 65, 66 e 67, apêndice B). Tal constatação vem a valorizar a metodologia empregada, pois, a partir desta, pôde-se ativar outras funções para garantir o correto funcionamento do relé. 


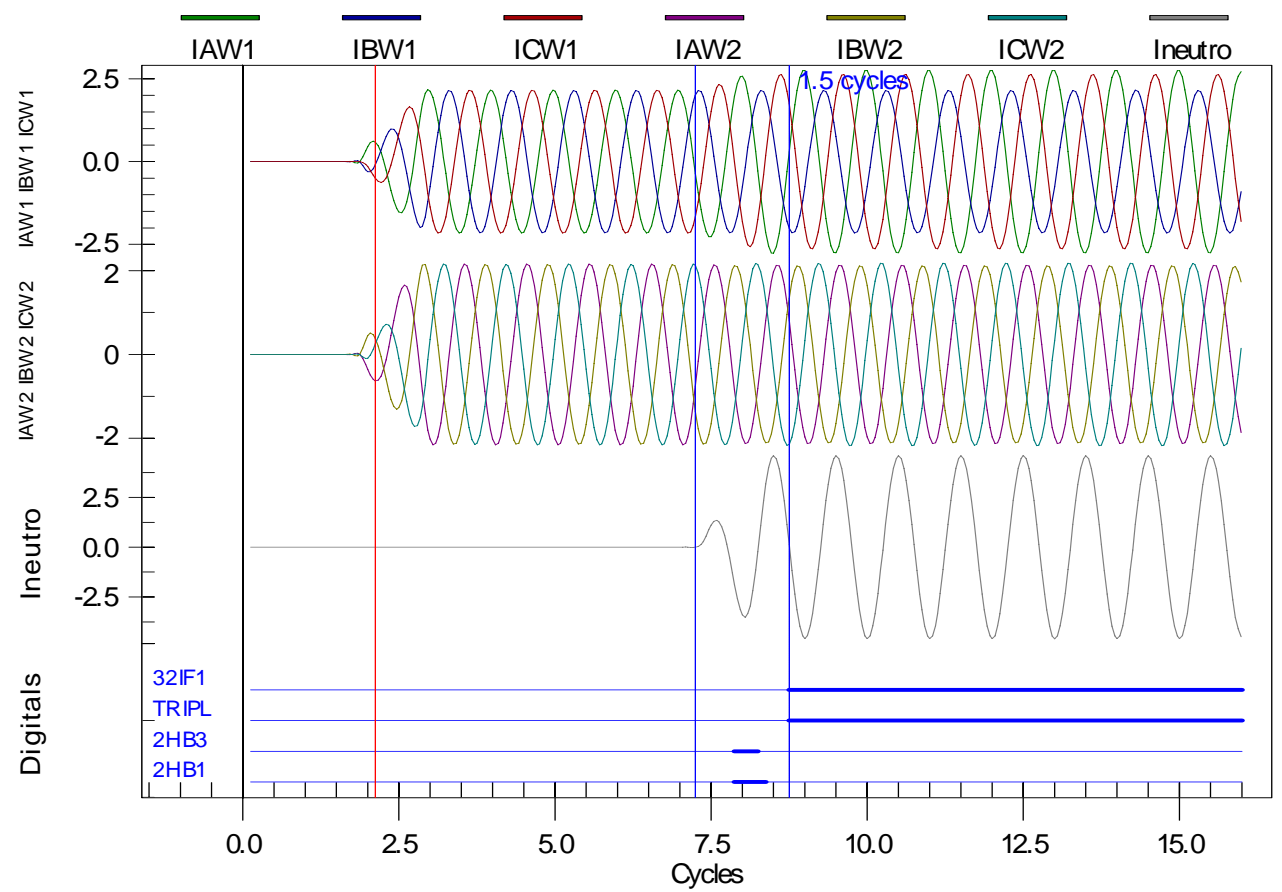

Figura 51. Oscilografia das correntes observadas nos TC's na proteção para uma falta interna, aplicada a $25 \%$ do enrolamento (estrela), carga conectada em delta, carga pesada e função falta terra restrita habilitada.

A Figura 52 ilustra a resposta de operação do relé frente a uma situação de falta interna aplicada a $80 \%$ do enrolamento secundário (estrela) do transformador principal, carga média de 10MVA conectada em estrela. Pode-se notar que no início a lógica de operação do relé (8701) é sensibilizada, pois esta ultrapassa o valor inicial de 0,3 p.u. parametrizado. Vemos também que há a detecção da $2^{\mathrm{a}}, 4^{\mathrm{a}}$ e $5^{\mathrm{a}}$ harmônica e, conseqüentemente, o bloqueio comum da lógica (87BL). Em seguida há o amortecimento da corrente de $2^{\mathrm{a}}$ harmônica, desabilitando o bloqueio da operação devido à mesma. Uma vez que não há bloqueio da operação, e a relação entre a corrente diferencial de operação e a corrente de restrição excede uma das curvas características do relé, o mesmo atua (TRIPL) pelo elemento de restrição (87R).

$\mathrm{Na}$ figura seguinte (Figura 53), podemos visualizar as correntes diferenciais de operação, restrição e $2^{\mathrm{a}}$ harmônica. Percebe-se que nesta situação houve um tempo maior na extinção da falta, em torno de 1,375 ciclos, esperando que a relação entre a corrente de operação (IOP1) e de restrição (IRT1) exceda uma das inclinações ajustadas caindo na região de operação do relé. Nesta situação o programa aguarda a tomada de novos valores para uma decisão confiável sobre o ocorrido. 


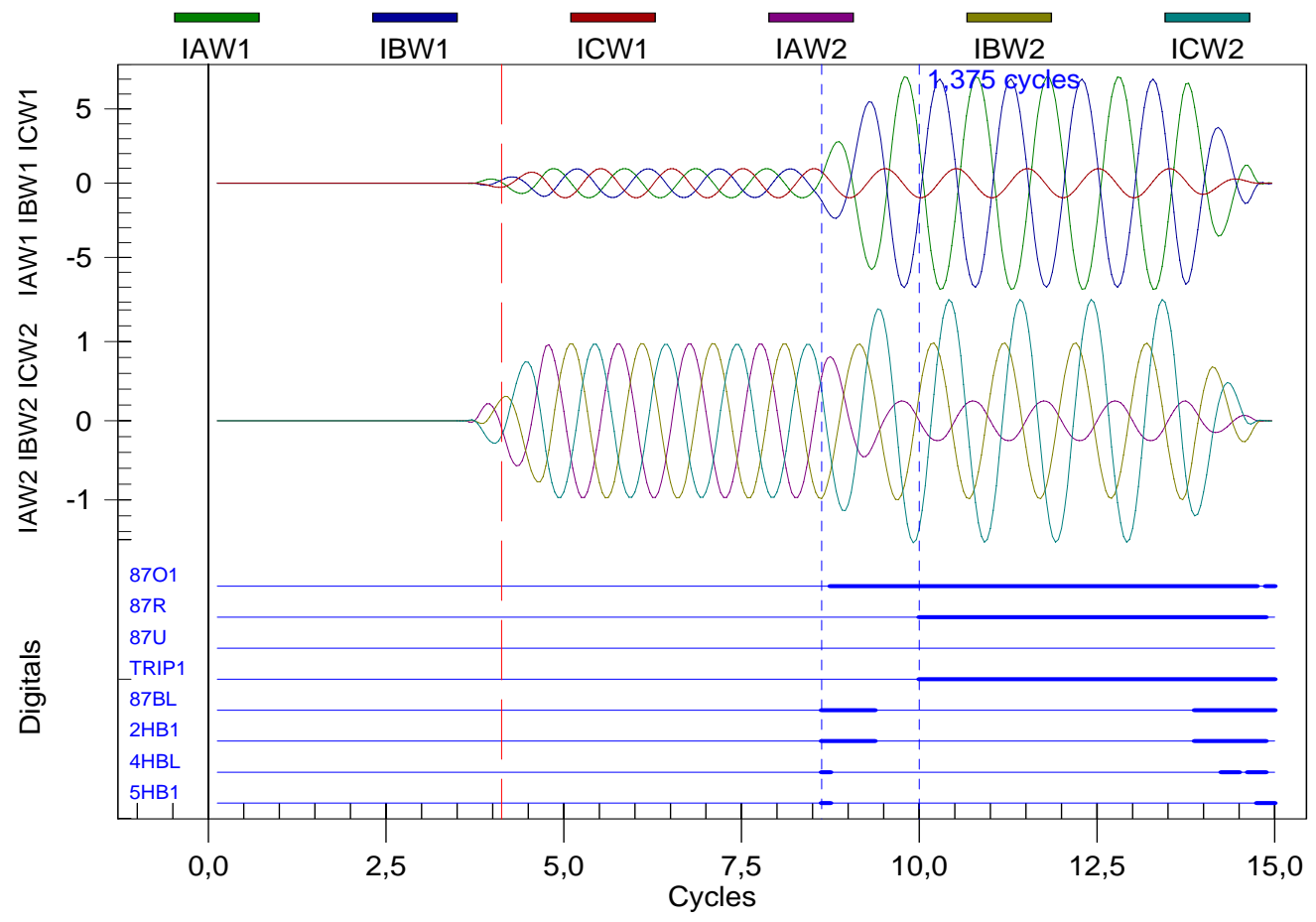

Figura 52. Correntes observadas nos TC's com a conseqüente posição do sistema de proteção para uma falta interna, aplicada a $80 \%$ do enrolamento (estrela) do transformador carga média de 10MVA conectada em estrela.

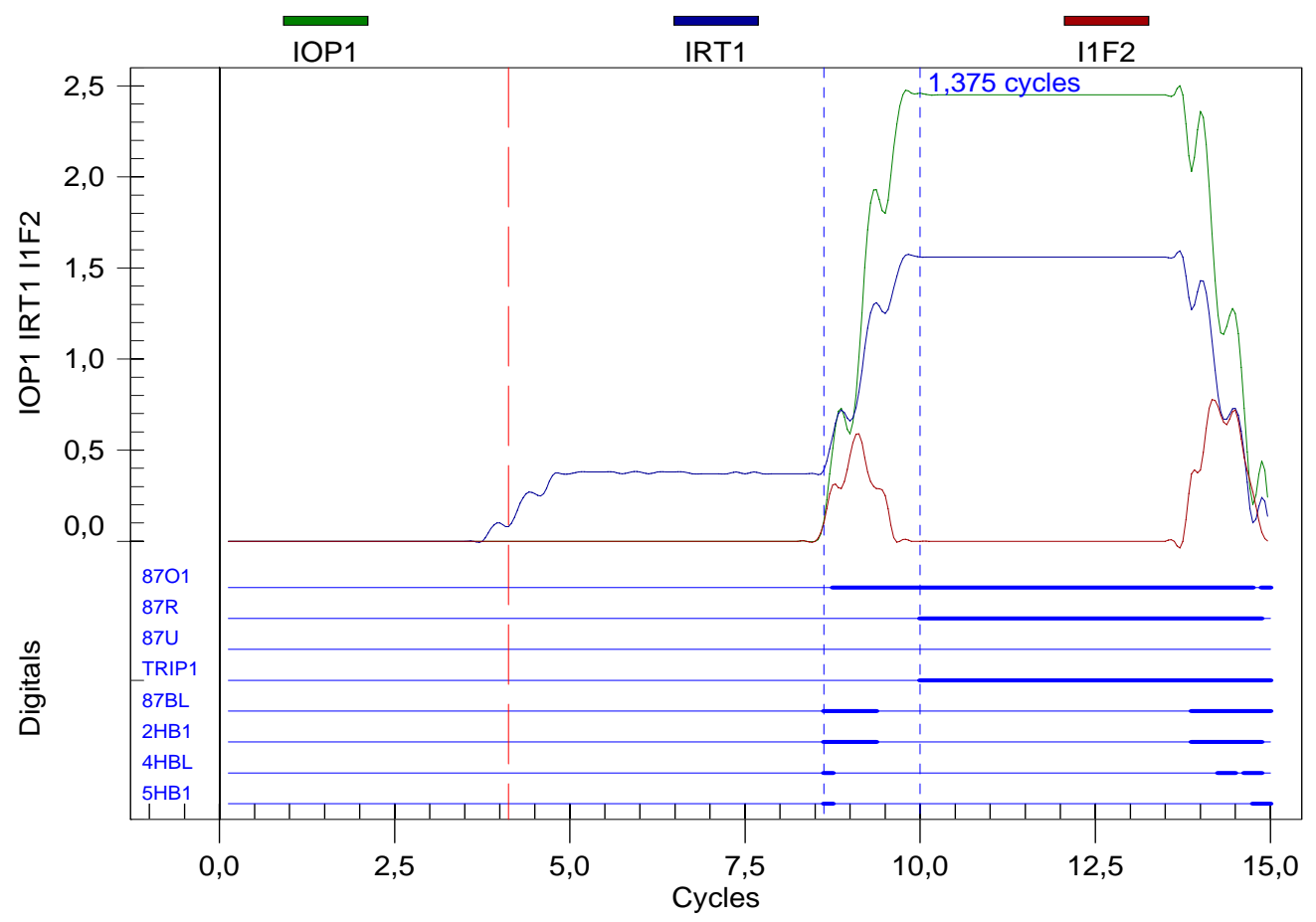

Figura 53. Correntes diferenciais observadas nos $\mathrm{TC}^{\prime}$ s com a conseqüente posição do sistema de proteção para uma falta interna, aplicada a $80 \%$ de um enrolamento (estrela) do transformador. 
Abaixo, temos a Figura 54, a qual ilustra a situação de uma falta externa aplicada ao final da linha de distribuição, onde se observa a alteração nas correntes, tanto do lado delta como do estrela.

$\mathrm{Na}$ Figura 55, têm-se as correntes diferenciais de operação e restrição $\left(2^{\mathrm{a}}\right.$ e $5^{\mathrm{a}}$ harmônicas), de todas as fases do sistema. Percebe-se pela mesma que não há uma corrente de operação (IOP1,2,3) considerável frente à corrente mínima ajustada (O87P), caracterizando dessa forma uma falta externa, como era esperado. Nota-se também que os valores das correntes diferenciais de $2^{\mathrm{a}}$ e $5^{\mathrm{a}}$ harmônica não excederam seus ajustes, porém, observa-se à presença de corrente de restrição.

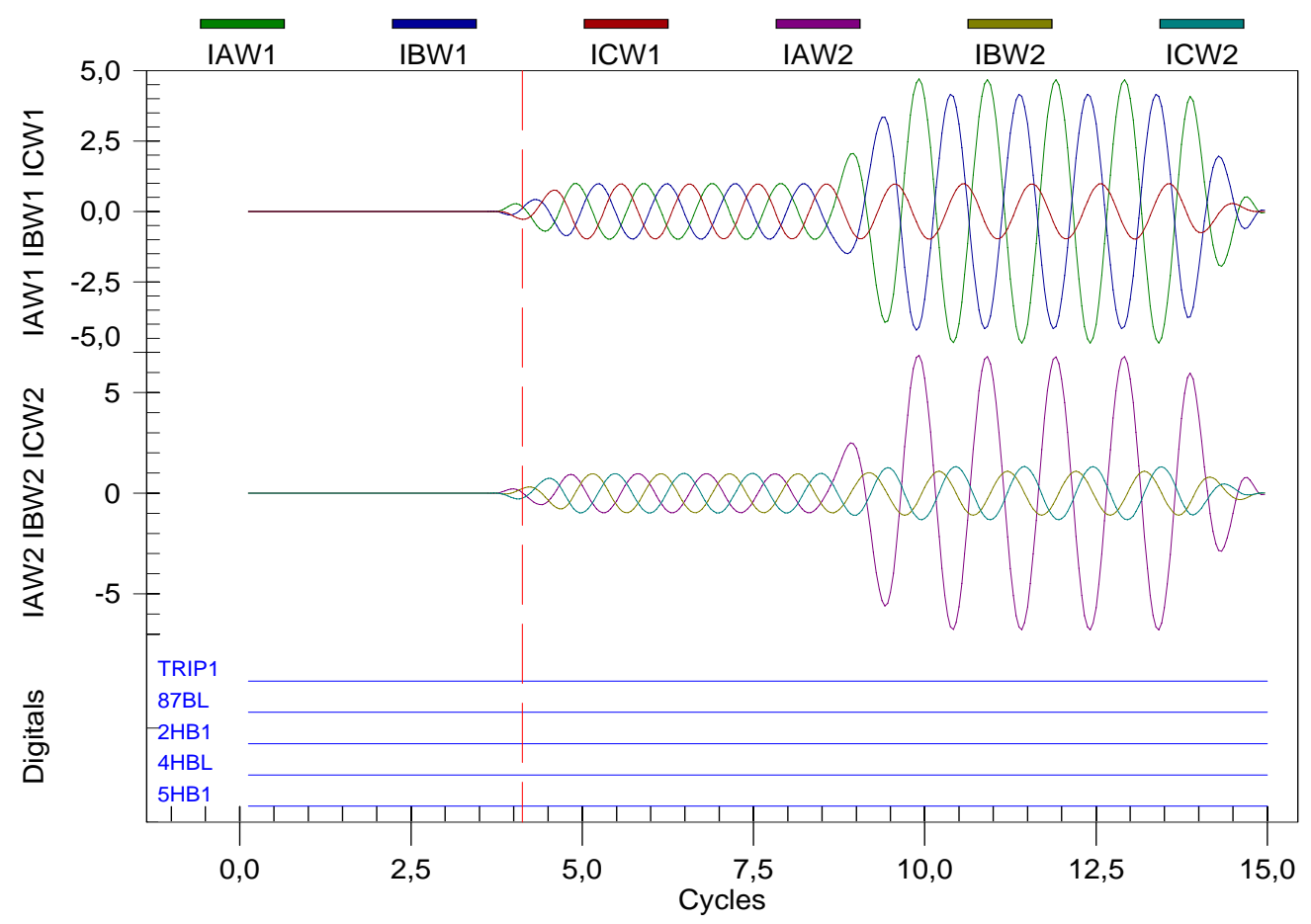

Figura 54. Correntes observadas nos TC's com a conseqüente posição do sistema de proteção para uma falta externa, caracterizada na linha de distribuição. 


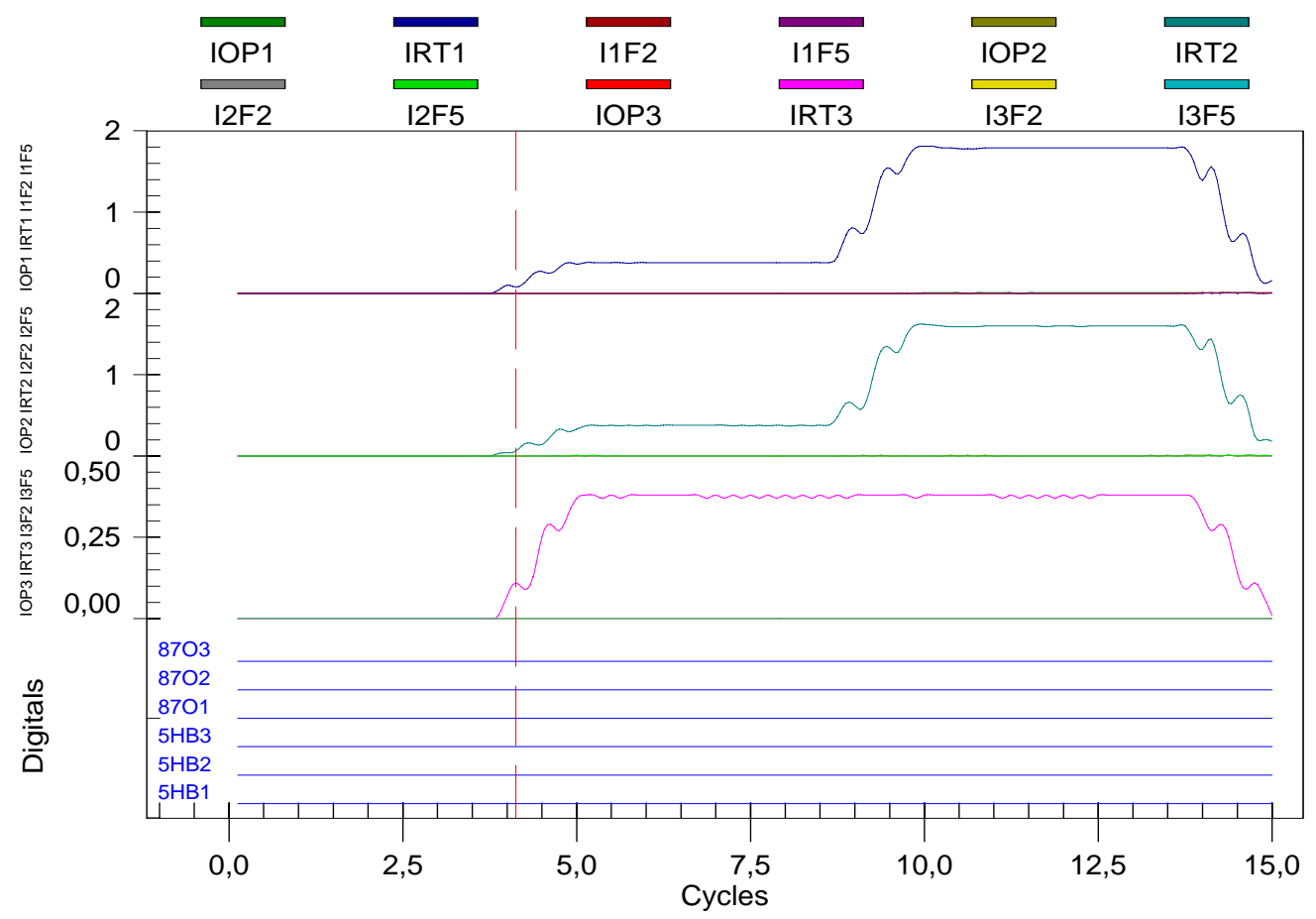

Figura 55. Correntes diferenciais observadas nos TC's com a conseqüente posição do sistema de proteção para uma falta externa, aplicada na linha de distribuição.

A Figura 56 mostra a oscilografia referente a uma situação de falta externa ocorrida próxima ao TC secundário com saturação do mesmo. Para uma melhor caracterização das formas de onda da corrente em saturação, apresenta-se esta oscilografia antes da filtragem digital.

Analisando este caso em particular, observou-se a sensibilização do relé pela corrente de operação diferencial $(8701,3)$, o que, normalmente, para um caso ideal de falta externa não deveria ocorrer. Houve a operação errônea do relé, devido à função REF estar habilitada e não-ajustada de forma correta para este tipo de falta. Podemos observar que estando o relé ajustado pela função de restrição, a qual eleva a curva de operação, dado os níveis de $2^{\mathrm{a}}$ e $4^{\mathrm{a}}$ harmônica, esta garantiria a esperada não atuação do relé para uma falta externa. Além disso, nesta situação haveria o bloqueio por $5^{\text {a }}$ harmônica $(5 \mathrm{HB} 1,3)$, a qual também garantiria a não atuação do relé. Contudo, caso a função REF esteja habilitada, como foi o caso, haverá a operação errônea por parte do relé, como pôde ser observado na figura. Logo, para esta situação, a função REF poderia estar habilitada, desde que ajustada de forma correta. 
Por outro lado, analisando as correntes diferenciais para esta situação (Figura 57), caso a função de restrição por harmônica não estivesse habilitada e o nível de $2^{\mathrm{a}}, 4^{\mathrm{a}}$ e $5^{\mathrm{a}}$ harmônica não ultrapassasse o valor ajustado, também poderia haver operação errônea do relé.

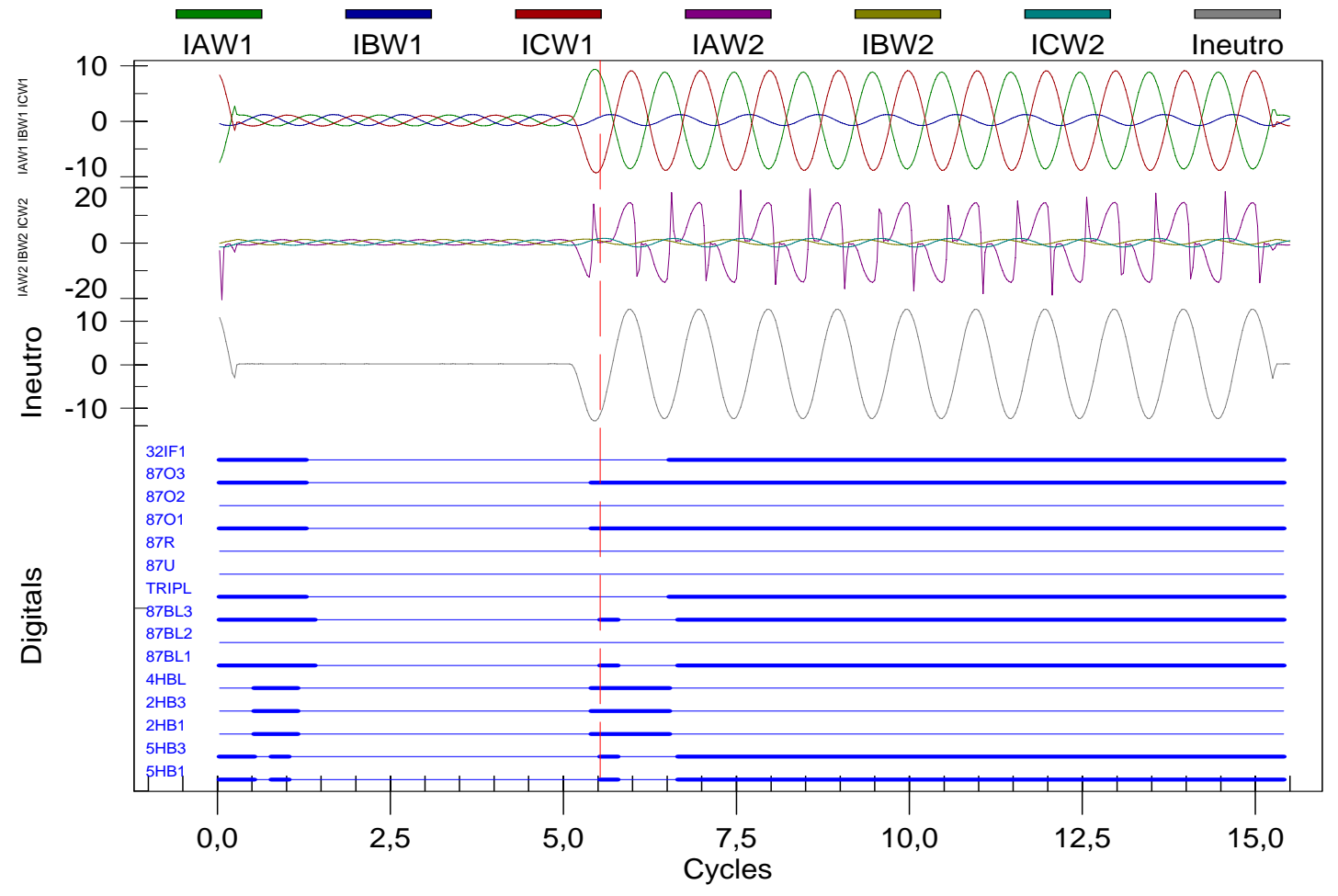

Figura 56. Oscilografia de uma falta externa aplicada próxima ao TC do lado secundário do transformador de potência com saturação do mesmo. 


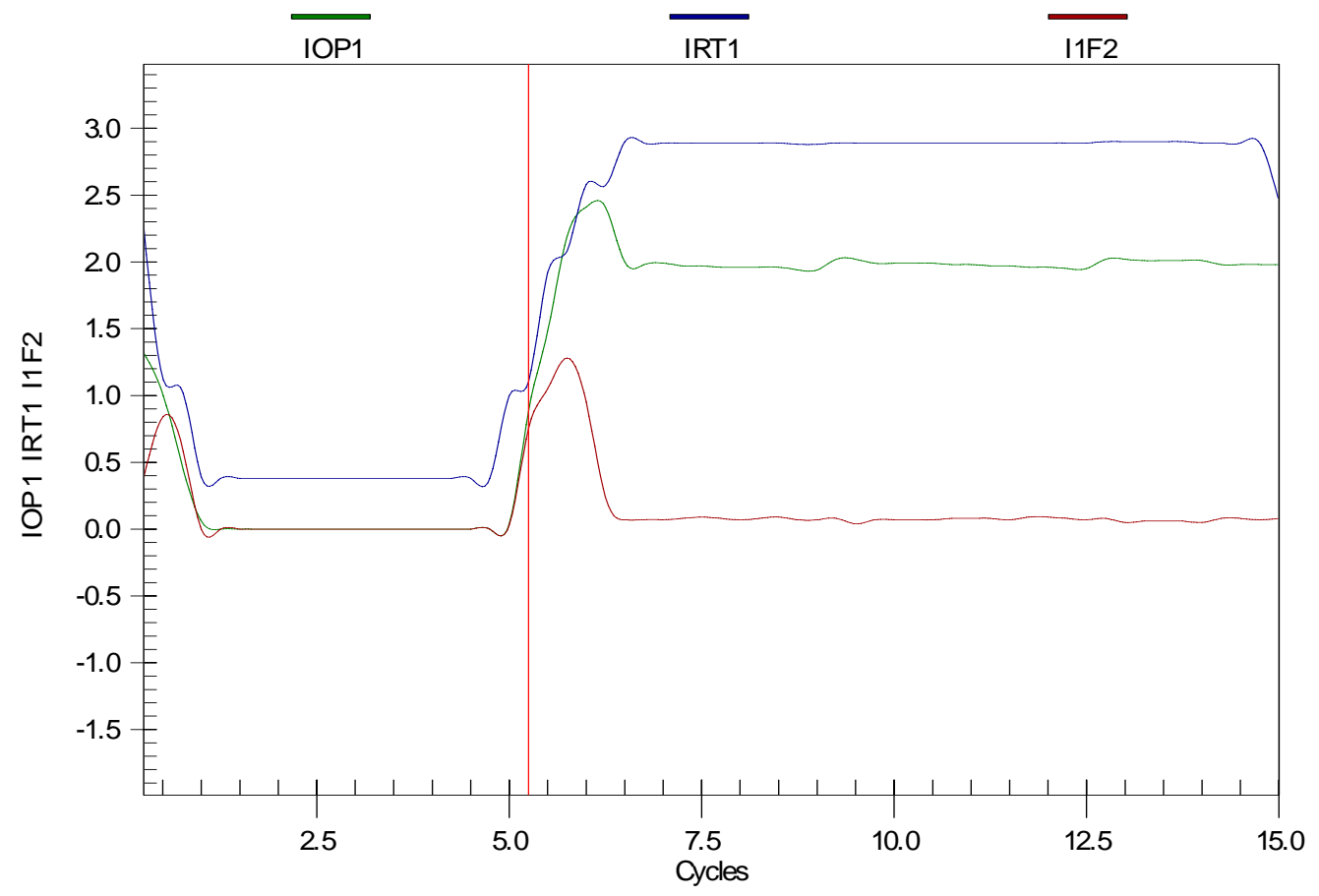

Figura 57. Correntes diferenciais observadas nos TC's de uma falta externa aplicada próxima ao TC do lado secundário do transformador de potência com saturação do mesmo.

A Figura 58 ilustra a oscilografia referente a uma situação de sobreexcitação, ocorrida no sistema em regime, com carga de 10 MVA, sendo de 140\% de sobretensão.

Em virtude da sobretensão aplicada ao primário do transformador há uma sobreexcitação do mesmo e, conseqüente, deformação das ondas de corrente. Essa deformação leva ao aparecimento de correntes diferenciais de operação $(87 \mathrm{O} 1,2,3)$, sensibilizando o relé. Em um dado instante após essa sensibilização, ocorre a atuação do elemento de restrição $(87 \mathrm{R} 1,2,3)$, porém a operação do relé (trip) é impedida devido à função de bloqueio por $5^{\circ}$ harmônico $(5 \mathrm{HB} 1,2.3)$, garantindo uma resposta correta por parte do relé frente à situação de sobreexcitação. Através dessa simulação pode-se comprovar que no caso de sobreexcitação há o predomínio da componente de $5^{\circ}$ harmônico, como observado pelos apontamentos teóricos levantados. 


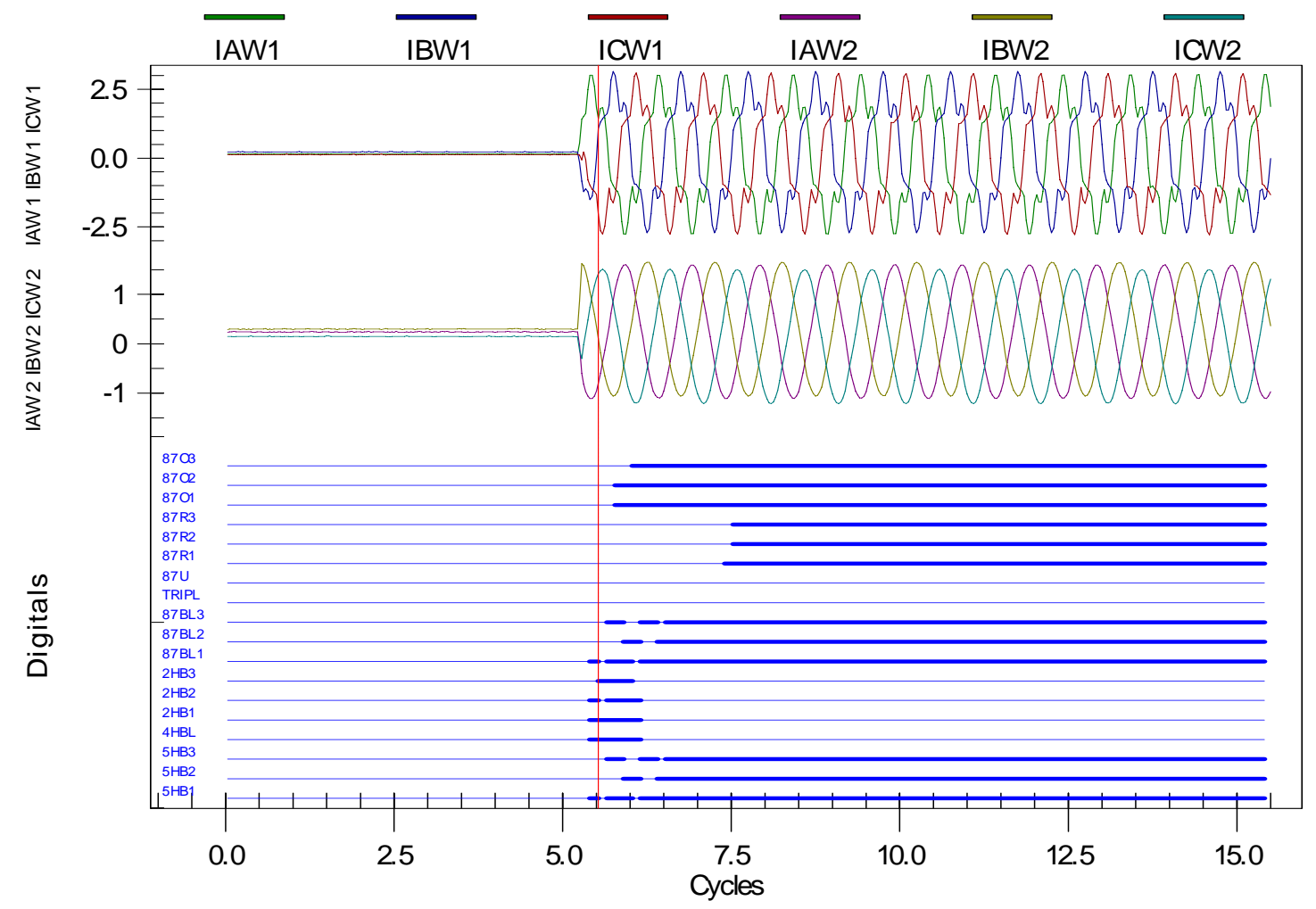

Figura 58. Oscilografia de uma condição de sobreexcitação, com 140\% de tensão e sistema em regime normal.

A Tabela 7 abaixo mostra uma compilação de todas as situações analisadas frente às funções de proteção por bloqueio comum, independente e por restrição, comentadas anteriormente.

Lembra-se que somente deverá estar habilitada uma única função. Logo, caso a proteção por bloqueio comum esteja habilitada, devem ser desconsideradas as outras duas funções, de bloqueio independente e de restrição. 
Tabela 7. Resumo das situações aplicadas no trabalho.

\begin{tabular}{|c|c|c|c|c|}
\hline & Casos Aplicados & $\begin{array}{c}\text { Proteção por } \\
\text { bloqueio comum }\end{array}$ & $\begin{array}{l}\text { Proteção por } \\
\text { bloqueio } \\
\text { independente }\end{array}$ & $\begin{array}{l}\text { Proteção por } \\
\text { restrição }\end{array}$ \\
\hline & Energização & $\begin{array}{c}\text { habilitado } \\
\text { relé não opera, } \\
\text { "REF" } \\
\text { desabilitado }\end{array}$ & $\begin{array}{c}\text { habilitado } \\
\text { relé não opera, } \\
\text { "REF" } \\
\text { desabilitado }\end{array}$ & $\begin{array}{c}\text { habilitado } \\
\text { relé não opera, } \\
\text { "REF" } \\
\text { desabilitado }\end{array}$ \\
\hline & $\begin{array}{l}\text { Energização } \\
\text { com falta interna }\end{array}$ & $\begin{array}{l}\text { habilitado } \\
\text { relé não opera, } \\
\text { "REF" } \\
\text { desabilitado }\end{array}$ & $\begin{array}{l}\text { habilitado } \\
\text { relé opera, } \\
\text { "REF" } \\
\text { desabilitado }\end{array}$ & $\begin{array}{l}\text { habilitado } \\
\text { relé opera, } \\
\text { "REF" } \\
\text { desabilitado }\end{array}$ \\
\hline 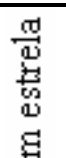 & $\begin{array}{l}\text { Falta interna } \\
10 \% \text { delta } \\
\text { carga média }\end{array}$ & 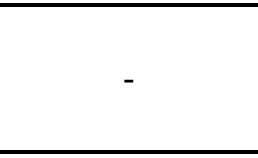 & 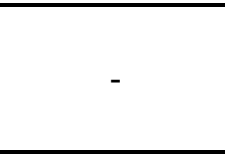 & $\begin{array}{c}\text { relé opera pelo } \\
\text { instantâneo, } \\
\text { "REF" } \\
\text { desabilitado } \\
\end{array}$ \\
\hline 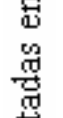 & $\begin{array}{c}\text { Falta interna } \\
20 \% \text { estrela } \\
\text { carga pesada }\end{array}$ & - & - & $\begin{array}{l}\text { relé opera pela } \\
\text { "REF" }\end{array}$ \\
\hline 总 & $\begin{array}{c}\text { Falta interna } \\
25 \% \text { estrela } \\
\text { carga leve }\end{array}$ & - & - & $\begin{array}{l}\text { relé opera pela } \\
\text { "REF" }\end{array}$ \\
\hline $\begin{array}{l}9 \\
0 \\
0 \\
0\end{array}$ & $\begin{array}{l}\text { Falta interna } \\
80 \% \text { estrela } \\
\text { carga média }\end{array}$ & - & - & $\begin{array}{l}\text { relé opera pela } \\
\text { restrição }\end{array}$ \\
\hline \multirow{8}{*}{ 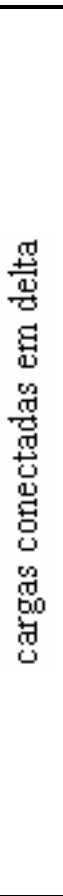 } & $\begin{array}{l}\text { Falta interna } \\
10 \% \text { delta } \\
\text { carga média }\end{array}$ & - & - & $\begin{array}{l}\text { relé opera pelo } \\
\text { instantâneo, } \\
\text { "REF" habilitado }\end{array}$ \\
\hline & $\begin{array}{l}\text { Falta interna } \\
10 \% \text { estrela } \\
\text { carga média }\end{array}$ & - & - & $\begin{array}{l}\text { relé opera pela } \\
\text { "REF" e restrição }\end{array}$ \\
\hline & $\begin{array}{l}\text { Falta interna } \\
50 \% \text { estrela } \\
\text { carga média }\end{array}$ & - & - & $\begin{array}{l}\text { relé opera pela } \\
\text { "REF" e restrição }\end{array}$ \\
\hline & $\begin{array}{l}\text { Falta interna } \\
15 \% \text { estrela } \\
\text { carga pesada }\end{array}$ & - & - & $\begin{array}{l}\text { relé opera pela } \\
\text { "REF" }\end{array}$ \\
\hline & $\begin{array}{c}\text { Falta interna } \\
25 \% \text { estrela } \\
\text { carga leve }\end{array}$ & - & - & $\begin{array}{l}\text { relé opera pela } \\
\text { "REF"" }\end{array}$ \\
\hline & $\begin{array}{l}\text { Falta interna } \\
25 \% \text { estrela } \\
\text { carga pesada }\end{array}$ & - & - & $\begin{array}{l}\text { relé opera pela } \\
\text { "REF" }\end{array}$ \\
\hline & $\begin{array}{c}\text { Falta interna } \\
30 \% \text { estrela } \\
\text { carga leve }\end{array}$ & - & - & $\begin{array}{l}\text { relé opera pela } \\
\text { "REF" e restrição }\end{array}$ \\
\hline & $\begin{array}{l}\text { Falta interna } \\
30 \% \text { estrela } \\
\text { carga pesada }\end{array}$ & - & - & $\begin{array}{l}\text { relé opera pela } \\
\text { "REF" e restrição }\end{array}$ \\
\hline & $\begin{array}{l}\text { Falta externa } \\
\text { Linha de } \\
\text { Distribuição }\end{array}$ & - & - & $\begin{array}{c}\text { relé não opera, } \\
\text { "REF" } \\
\text { desabilitado }\end{array}$ \\
\hline & $\begin{array}{c}\text { Falta externa } \\
\text { com saturação } \\
\text { de TC } \\
\end{array}$ & - & - & $\begin{array}{c}\text { relé opera, } \\
\text { "REF" habilitado }\end{array}$ \\
\hline & Sobreexcitação & - & - & $\begin{array}{l}\text { relé não opera, } \\
\text { "REF" habilitado }\end{array}$ \\
\hline
\end{tabular}


As oscilografias referentes às outras situações implementadas e analisadas no decorrer deste trabalho estão ilustradas no Apêndice B.

$\mathrm{O}$ anexo apresentado somente tem como objetivo ilustrar a lógica do elemento diferencial da proteção diferencial percentual do relé modelo SEL - 387A, o qual fora empregado em todo este trabalho de pesquisa. 


\section{CONCLUSÕES FINAIS}

Em linhas gerais, este trabalho apresentou uma metodologia para análise de um sistema de proteção digital diferencial aplicado a um transformador de potência, caracterizado laboratorialmente via software ATP, arquivo COMTRADE, caixa de teste e relé comercial sob análise. O modelo implementado permite a simulação de faltas internas ao transformador protegido, além de diversas manobras e distúrbios capazes de provocar a operação indevida da proteção diferencial empregada.

Para a realização deste trabalho foram analisadas algumas distintas situações como faltas nos enrolamentos internos do transformador de potência, condições de energização normal, energização com falta interna no enrolamento, faltas externas, condição de saturação de TC e condição de sobreexcitação.

$\mathrm{Na}$ etapa de geração de dados, utilizou-se o programa ATP - Alternative Transients Program - no qual os sinais de corrente observados pelos TC's foram obtidos para as diversas e distintas situações apontadas.

A conversão dos dados simulados para o arquivo COMTRADE se mostrou de fácil aplicação, manuseio, e de extrema e necessária importância para a aceitação dos valores simulados à caixa de testes.

Conforme evidenciado, as oscilografias registradas pelo software do relé analisado foram validadas de acordo com teoria e prática apresentada.

É de grande importância observar que para um correto funcionamento do relé diferencial digital, o operador deve ter o conhecimento e a sensibilidade para saber quando usar uma ou outra função disponível, ou mesmo realizar específicas análises (simulações, testes, etc) para uma melhor parametrização do relé. Atenta-se ao fato de que muitas das vezes o técnico responsável pela instalação do relé desconhece das inúmeras funções que estão disponíveis no dispositivo além da proteção diferencial percentual padrão, as quais 
podem melhorar o desempenho da proteção como um todo. Pela metodologia e rotina de testes proposta pôde-se evidenciar o funcionamento da proteção diferencial percentual e de diversas outras funções interligadas a esta, o que permitiu, por exemplo, distinguir quando se deve utilizar uma ou outra função do relé.

Além do esquema laboratorial montado para a análise e levantamento da operação dos relés comercialmente disponíveis, vale ressaltar a contribuição do trabalho na revisão do conteúdo teórico envolvido, a qual servirá como base para estudos mais avançados no sentido de se sobrepor a eventuais limitações observadas à filosofia.

Outra questão a ser comentada, diz respeito à contribuição do ponto de vista didático para a exemplificação e elucidação dos problemas associados à área.

Em suma, todo o processo envolvido na metodologia foi considerado extremamente útil e de importância para futuros projetos, ensaios e análises de equipamentos, onde os resultados obtidos nesta, podem ser facilmente validados. A metodologia como apresentada, torna-se um meio atrativo e uma opção economicamente viável para estudos e soluções de problemas enfrentados na área de sistemas elétricos de potência.

\subsection{Sugestões para a continuidade da pesquisa}

Como proposta de continuidade da pesquisa, podemos destacar:

- A aplicação de novos e diferentes testes visando caracterizar problemas e suas possíveis soluções.

- A adequação da metodologia para aplicação em diferentes segmentos da proteção digital de sistemas elétricos de potência, como por exemplo, à proteção de linhas de transmissão, de barramentos, máquinas e geradores, etc.

\subsection{Participações em eventos científicos}

Vale comentar que o trabalho acima apresentado já foi exposto no VIII Seminário Técnico de Proteção e Controle - VIII STPC, realizado de 28 de junho a 01 de julho de 2005, no Rio de Janeiro - RJ, sob o título: "Um esquema completo de proteção diferencial 
de transformadores para testes em relés digitais", fazendo parte dos Anais do referido seminário. Além desta participação, tem-se a aceitação do trabalho intitulado "Prática laboratorial para a avaliação da proteção diferencial de transformadores de potência considerando um relé digital", no Seminário Brasileiro de Sistemas de Energia - SBSE, a ser realizado em Campina Grande, Paraíba, Brasil, no período de 17 a 19 de julho de 2006. 


\section{REFERÊNCIAS BIBLIOGRÁFICAS}

ANDERSON, P. M. (1999). "Power System Protection”, McGraw-Hill e IEEE Press, New York, NY.

ATP, (1987). “Alternative Transients Program, Rule Book”, Leuven EMTP Center (LEC).

CAMINHA, A.C. (1977). "Introdução a Proteção dos Sistemas Elétricos”, São Paulo, Edgard Blücher Ltda.

BRONZEADO, H. and YACAMINI, R. (1995). "Phenomenon of Sympathetic Interaction Between Transformers Caused by Inrush Transients". IEE Proceedings - Science, Measurement and Technology, Vol.142, n.4, p.323-329.

CHRISTOPOULOS, C. and WRIGHT, A. (1999). "Electrical Power System Protection", Kluwer Academic Publishers, Great Britain, UK.

CIGRE Working Group 34.01. "Digital Protection Techniques and Substation Functions". A.G. Phadke (Convener), France, June 1989.

COURY, D.V. (2004). "Notas de Aulas do Curso de Proteção Digital em Sistemas Elétricos", EESC, USP, Brasil. 
CROSSLEY, P.A. ; LI, H.Y and PARKER, A.D. (1998). "Design and Evaluation of a Circulating Current Differential Relay Test System", IEEE Transactions on Power Delivery, Vol.13, No. 2, p.427-433.

DOMMEL, H.W. (1984). "Electro-Magnetic Transients Program - Rule Book”, Oregon.

ELMORE, W. A. (1982). "Protective Relaying: Theory and Applications", ABB Power T \& D Company Inc., Coral Springs, Florida.

GUZMÁN, A. ; ZOCHOLL, S. ; BENMOUYAL, G. and ALTUVE, H. J. (2001). “A Current-Based Solution for Transformer Differencial Protection - Part I: Problem Statement”, IEEE Transactions on Power Delivery, vol.16, n.4, p.485-491.

GUZMÁN, A. ; ZOCHOLL, S. ; BENMOUYAL, G. and ALTUVE, H. J. (2002). “A Current-Based Solution for Transformer Differencial Protection - Part II: Relay Description and Evaluation", IEEE Transactions on Power Delivery, vol.16, n.4, p.886-893.

HOROWITZ, S.H. and PHADKE, A.G. (1992). "Power System Relaying”, John Wiley and Sons Inc.

IEEE standard C37_111_1991. (1991). “Common Format for Transient Data Exchange (COMTRADE) for Power Systems".

IEEE standard C37_111_1999. (1999). “Revision: Common Format for Transient Data Exchange (COMTRADE) for Power Systems". IEEE Transactions on Power Delivery, vol.12, n.1, p.116-124.

KANG, Y. C.; KANG, S. H. ; PARK, J. K. ; JOHNS, A. T. and AGGARWAL, R. K. (1996). "Development and Hardware Implementation of a Compensation Algorithm for the Secondary Currents of Current Transformers". IEEE Transactions on Power Delivery, vol.143, n.1, p.41-49. 
KANG, Y. C.; PARK, J. K. ; KANG, S. H. ; JOHNS, A. T. and AGGARWAL, R. K. (1997). "An Algorithm for Compensation Secondary Currents of Current Transformers". IEEE Transactions on Power Delivery, vol.12, n.1, p.116-124.

KASZTENNY, B. and KEZUNOVIC, M. (1998), "Digital Relays Improve Protection of Large Transformers”. IEEE Computer Applications in Power, vol.11, n.4, p.39-45.

KEZUNOVIC, M. ; FROMEN, C. W. and PHILLIPS, F. (1994), "Experimental Evaluation of EMTP-Based Current Transformer Models for Protective Relay Transient Study”. IEEE Transactions on Power Delivery, “vol.9, n.1, p.405-413.

KOLLA, S.R. and GEDEON, D.V. (1995). "Microprocessor-based Protection Scheme for Power Transformers", Proceedings of the 1995 22nd IEEE Combined Electrical/Electronic Insulation Conference and Electrical Manufacturing \& Coil Winding Conference and Exhibition, p.195-198.

KOLLA, S.R. (1995), “Digital Protection Of Power Transformers Using Artificial Neural Networks". Proceedings of the Second International Conference on Advances in Instrumentation and Control, p.141-150.

LIN, C.E.; CHENG, C.L. ; HUANG, C.L. ; YEH, J.C. (1993) "Investigation of Magnetizing Inrush Current in Transformers - Part I: Numeric Simulation, and Part II: Harmonic Analysis". IEEE Transactions on Power Delivery, vol.8, n.1, p.246-254,255-263.

LING, P.C.Y. and BASAK, A. (1988). "Investigation of Magnetizing Inrush Current in a Single-Phase Transformer". IEEE Transactions on Magnetics, vol.24, n.6, p.3217-3222.

LING, P.C.Y. and BASAK, A. (1989). “A New Detection Scheme for Realization Inrush of Magnetizing Inrush Current in Transformers", Fourth International Conference on Developments in Power Protection, p.239-243. 
MOZINA, C. J. (1999), "Protection of Power Transformers Using Digital Technology". Transmission and Distribution Conference IEEE, vol.1, p.421-432.

OLIVEIRA, J.C. ; COGO, J. R. e ABREU, J. P. G. (1984). "Transformadores: Teoria e Ensaios”, Editora Edgard Blücher Ltda, p.8-10.

PIHLER, J.; GRCAR, B. and DOLINAR, D. (1997). "Improved Operation of Power Transformer Protection Using Artificial Neural Network”. IEEE Transactions on Power Delivery, vol.12, n.3, p.1128-1136.

PIOVESAN, L.S. (1997). “Avaliação de Algoritmos para Proteção Diferencial de Transformadores", tese de dissertação, USP, SP.

PHADKE, A.G. and THORP, J.S. (1988). “Computer Relaying for Power Systems”, John Wiley and Sons Inc.

SEGATTO, E.C. (1999). "Redes Neurais Artificiais Aplicadas a Proteção Diferencial de Transformadores de Potência”, Dissertação de Mestrado, EESC, USP, SP.

SEGATTO, E.C. (2005). "Relé Diferencial Para Transformadores de Potência utilizando Ferramentas Inteligentes", Tese de Doutorado, EESC, USP, SP.

SEL-387A, "Current Differential Relay - Instruction Manual". Schweitzer Engineering Laboratories, Pullman, USA.

STIGANT, S.A. and LACEY, H.M. (1925) “The J\&P Transformer Book”. Johnson \& Phillips Ltda, Charlton, Londres, Great Britain.

STRINGER, N. T.; LAWHEAD, L.; WILKERSON, T. ; BIGGS, J. and ROCKEFELLER, G. D. (1997). “Testing and Performing of Transformer Differential Relays". IEEE Industry Applications Magazine, vol.3, p.36-42. 


\section{APÊNDICE A}

Máscara do programa (arquivo fonte) que serve como entrada para as situações geradas e simuladas dispondo do software ATP. Esta máscara ilustra uma situação de energização do transformador de potência com secundário em aberto.

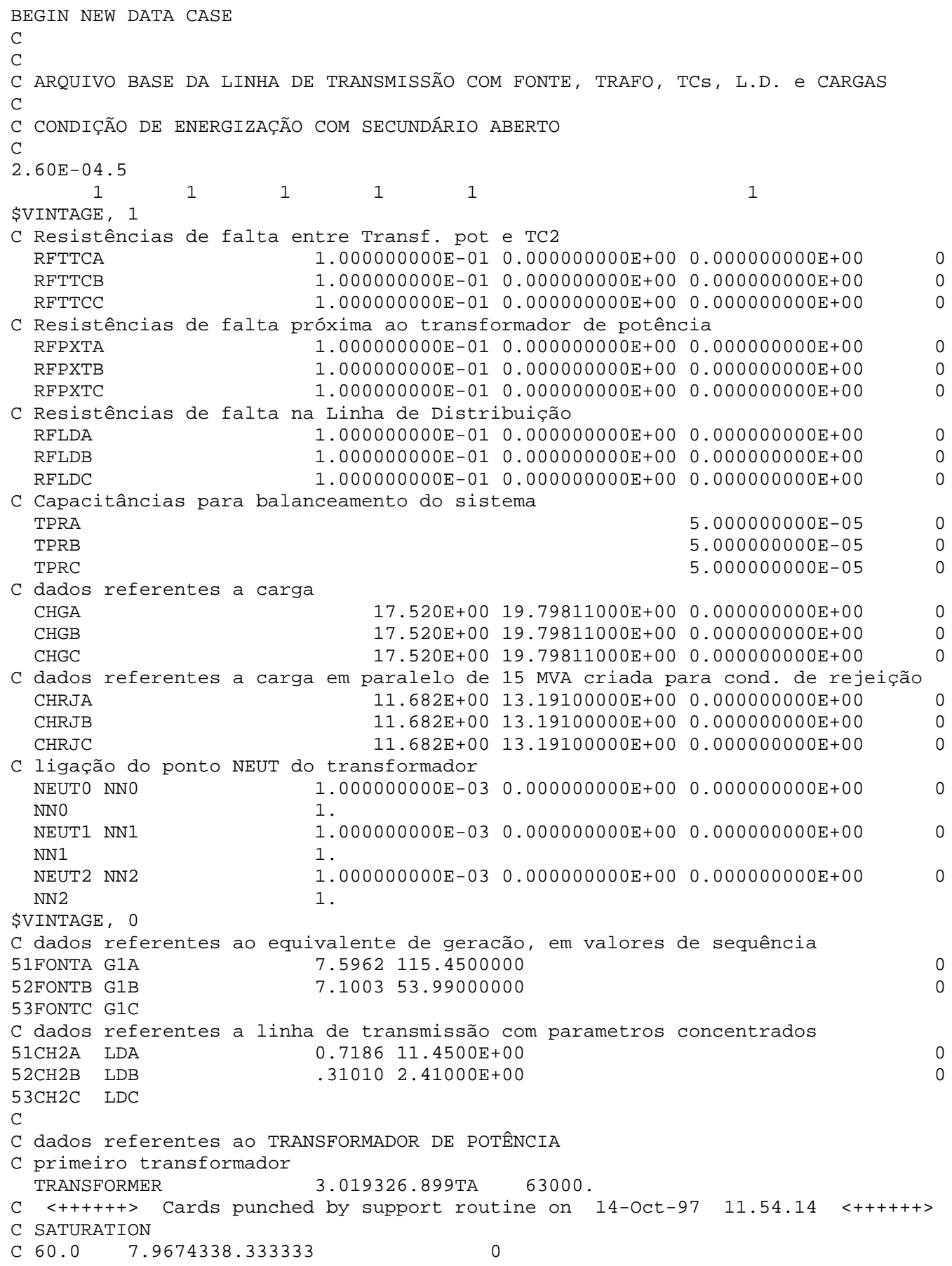




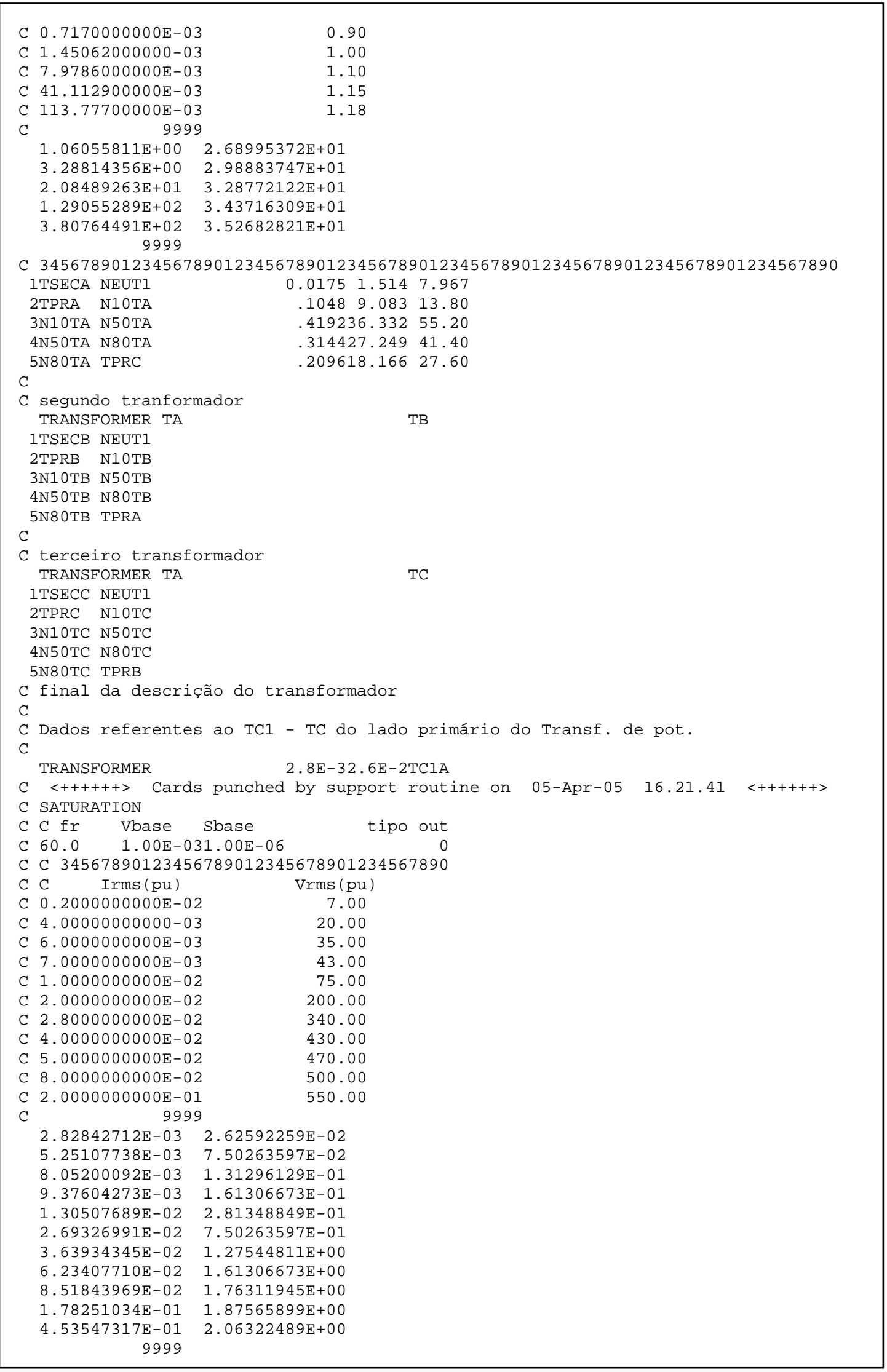




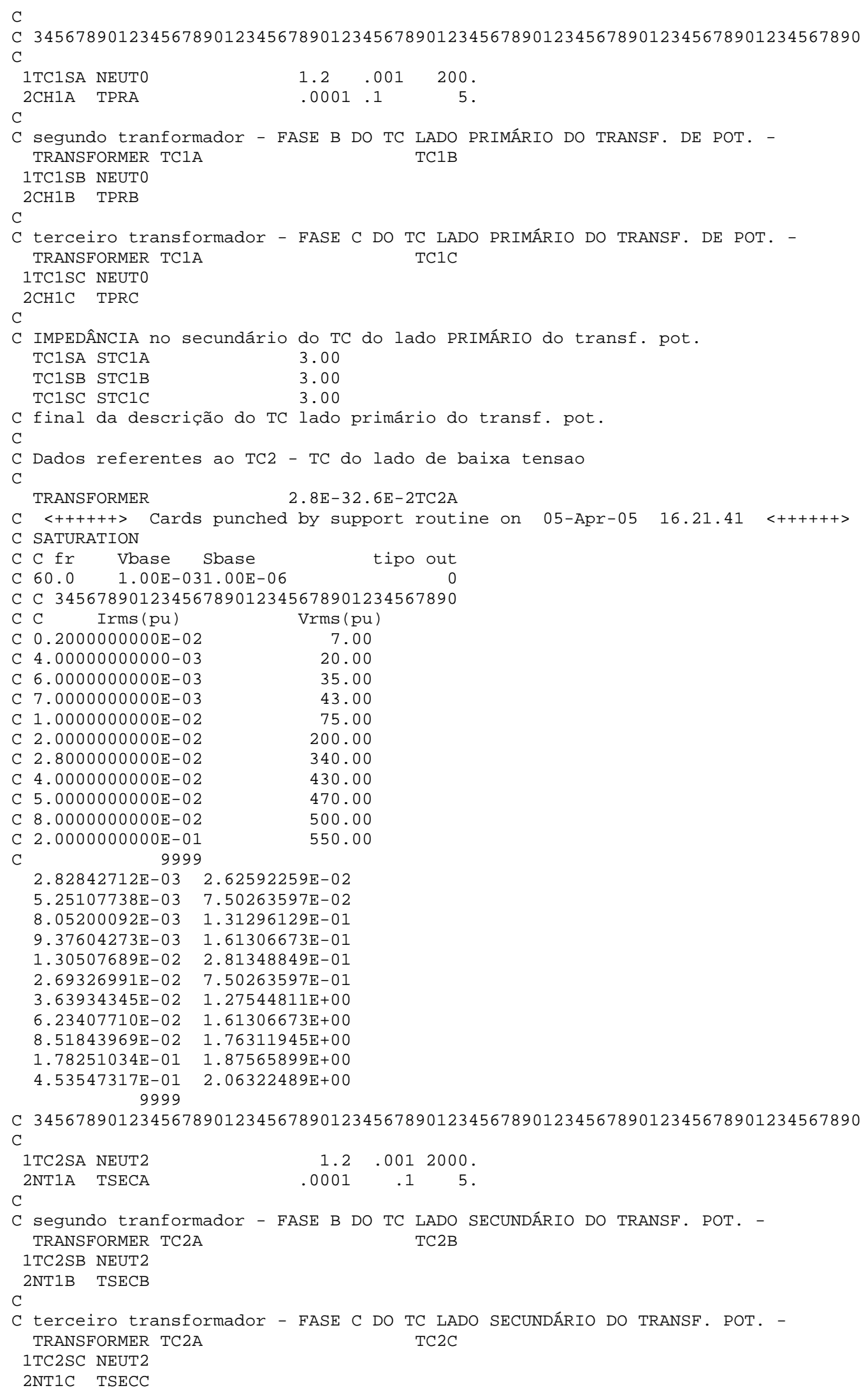


C

C IMPEDANCIA no secundário do TC do lado SECUNDÁRIO do transf. pot.

$\begin{array}{ll}\text { TC2SA STC2A } & 3.00 \\ \text { TC2SB STC2B } & 3.00 \\ \text { TC2SC STC2C } & 3.00\end{array}$

TC2SC STC2C

C final da descrição do TC lado secundário do transf. pot.

C

BLANK card terminating network

$C$ dados referentes as chaves do sistema elétrico

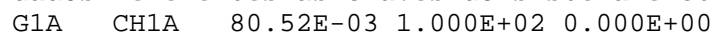

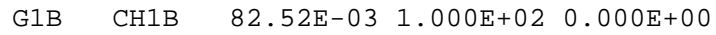

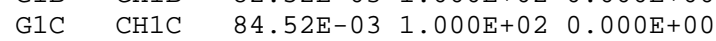

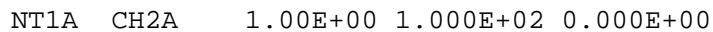

NT1B CH2B 1.00E+०० 1.000E+०2 $0.000 \mathrm{E}+0 \odot$

NT1C CH2C 1.00E+0๑ 1.000E+02 $0.000 \mathrm{E}+00$

LDA CHGA $-1.00 \mathrm{E}+0 \odot 1.000 \mathrm{E}+020.000 \mathrm{E}+0 \odot$

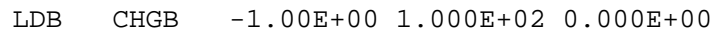

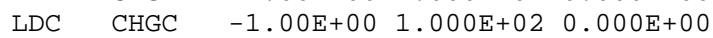

C Chaves referentes a ligação dos taps do transformador a terra

C Ligação TRIANGULO

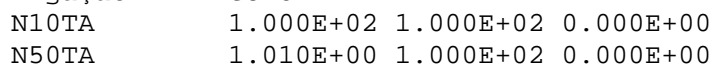

N80TA $\quad 1.010 E+0 \odot 1.000 \mathrm{E}+02 \quad 0.000 \mathrm{E}+0 \odot$

C Chave referente a ligação entre as fases do enrolamento TRIANGULO

C N50TA N50TB 1.010E+00 1.000E+02 $0.000 \mathrm{E}+00$

C Chaves referentes a falta entre Trafo e TC2

TSECA RFTTCA 1.00E+०० 1.000E+०2 $0.000 \mathrm{E}+00$

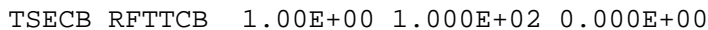

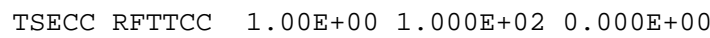

C Chaves referentes a falta externa próxima ao transformador de potência

$\mathrm{CH} 2 \mathrm{~A}$ RFPXTA 1.000E+02 1.000E+02 $0.000 \mathrm{E}+0 \odot$

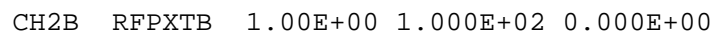

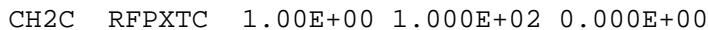

C Chaves referentes a falta na linha de distribuição

LDA RFLDA 1.00E+02 1.000E+02 0.000E+00

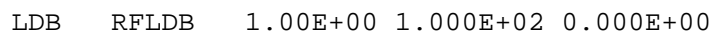

LDC RFLDC 1.00E+०० 1.000E+02 $0.000 \mathrm{E}+00$

C Chaves referentes a condição de rejeição de carga

CHGA CHRJA 1.00E+०० 1.000E+02 $0.000 \mathrm{E}+0 \odot$

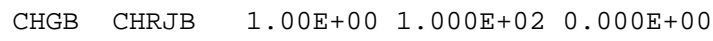

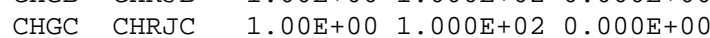

C Saída dos TCs

STC1A

STC1B

STC1C

STC2A

STC2B

STC2C

C CHAVE DE MEDIDA DO NEUTRO TRAFO PRINCIPAL

NEUT1 NN1

BLANK card terminating switches

$C$ dados referentes ao gerador

14FONTA $\odot 112.7 \mathrm{E}+03 \quad 6.000 \mathrm{E}+01 \quad 0.000 \mathrm{E}+0 \odot$

14FONTB $\odot 112.7 \mathrm{E}+03$ 6.000E+01-1.200E+02

14FONTC $\odot$ 112.7E+03 6.000E+01 1.200E+02

BLANK card terminating sources

C CH1A CH1B CH1C NT1A NT1B NT1C

BLANK card terminating outputs

BLANK card terminating plots

BEGIN NEW DATA CASE

MEASURING

MEASURING

MEASURING

MEASURING

MEASURING

MEASURING

MEASURING

$-1.000 \mathrm{E}+0 \odot \quad$ 1. $000 \mathrm{E}+\odot 2$

$-1.000 \mathrm{E}+00$ 1. $1.000 \mathrm{E}+02$

$-1.000 \mathrm{E}+00$ 1.000E+०2 


\section{APÊNDICE B}

No que segue, são apresentadas as oscilografias resultantes quando da aplicação de situações de faltas internas nos enrolamentos delta e estrela aterrado, considerando-se carga leve e ou pesada, conectada em delta ou estrela e estando a função "falta terra restrita" habilitada ou não.

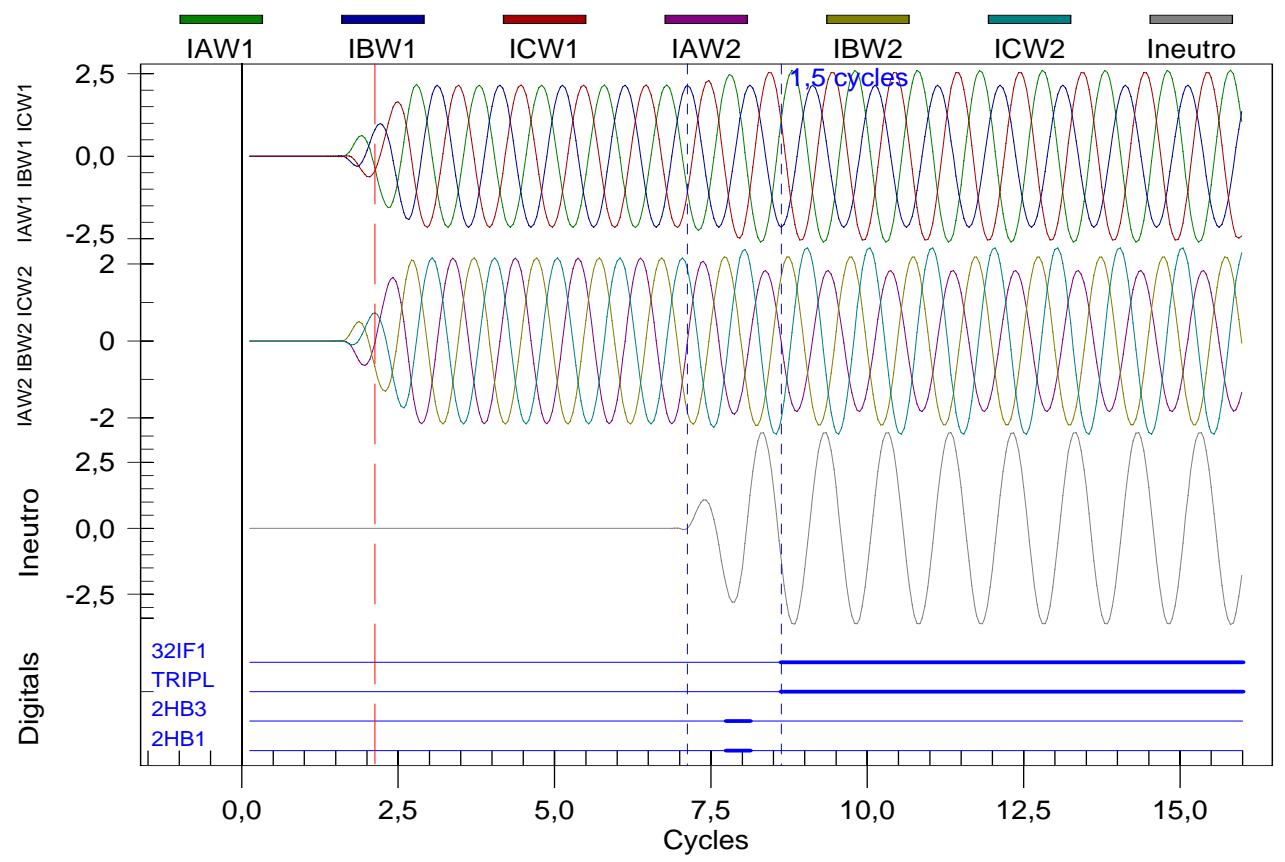

Figura 59. Oscilografia das correntes observadas nos TC's na proteção para uma falta interna, aplicada a $20 \%$ do enrolamento (estrela), carga pesada e conectada em estrela com a "função falta terra restrita" habilitada. 


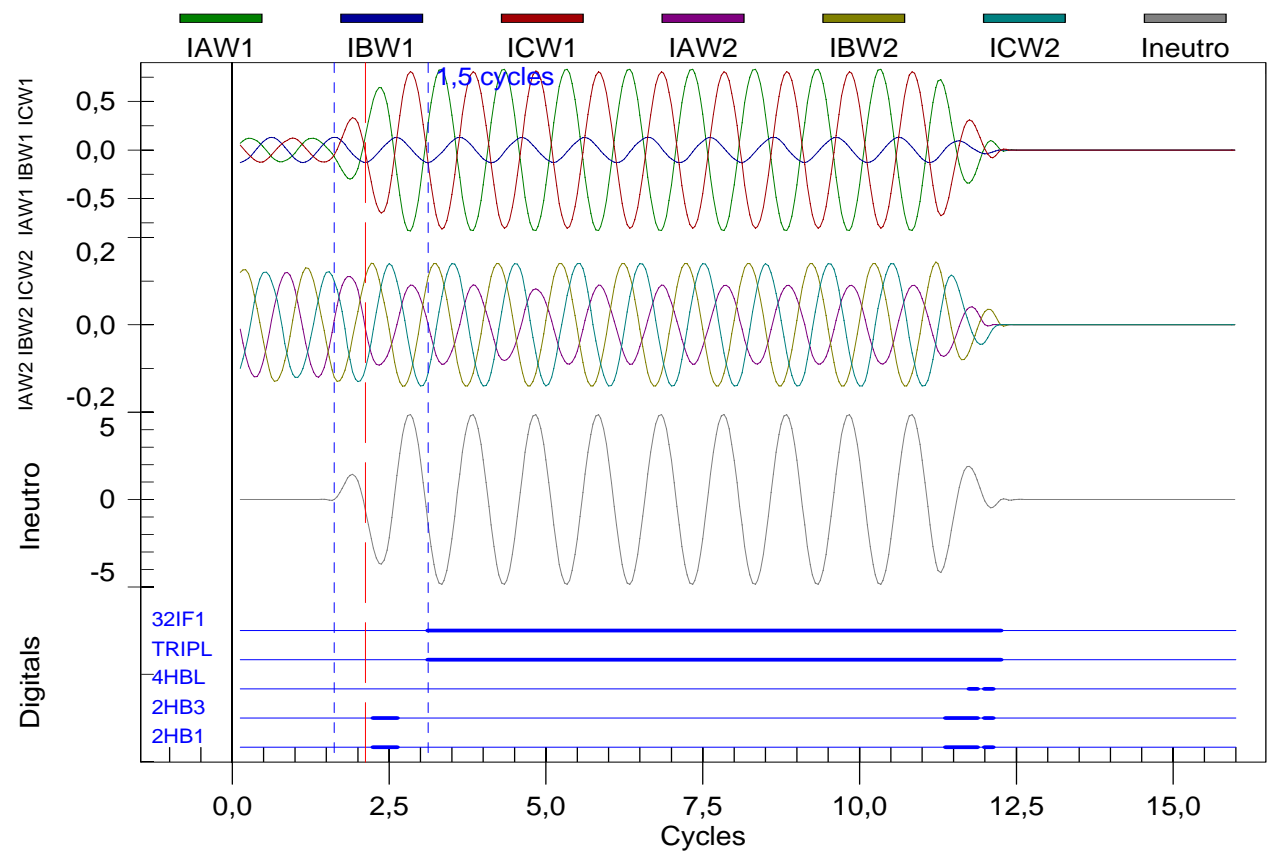

Figura 60. Oscilografia das correntes observadas nos TC's na proteção para uma falta interna, aplicada a $25 \%$ do enrolamento (estrela), carga leve e conectada em estrela com a função "falta terra restrita" habilitada.

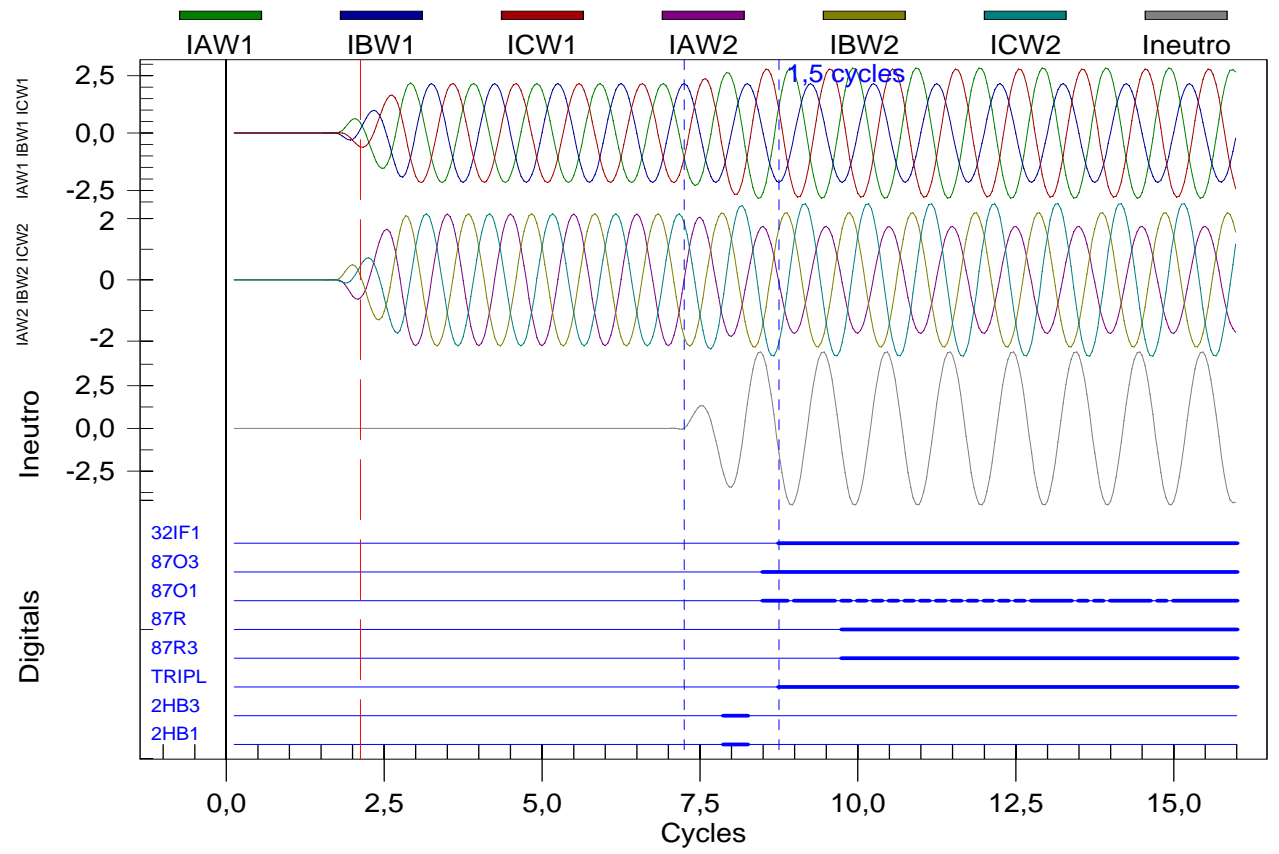

Figura 61. Oscilografia das correntes observadas nos TC's na proteção para uma falta interna, aplicada a $25 \%$ do enrolamento (estrela), carga pesada e conectada em estrela com a função "falta terra restrita" habilitada. 


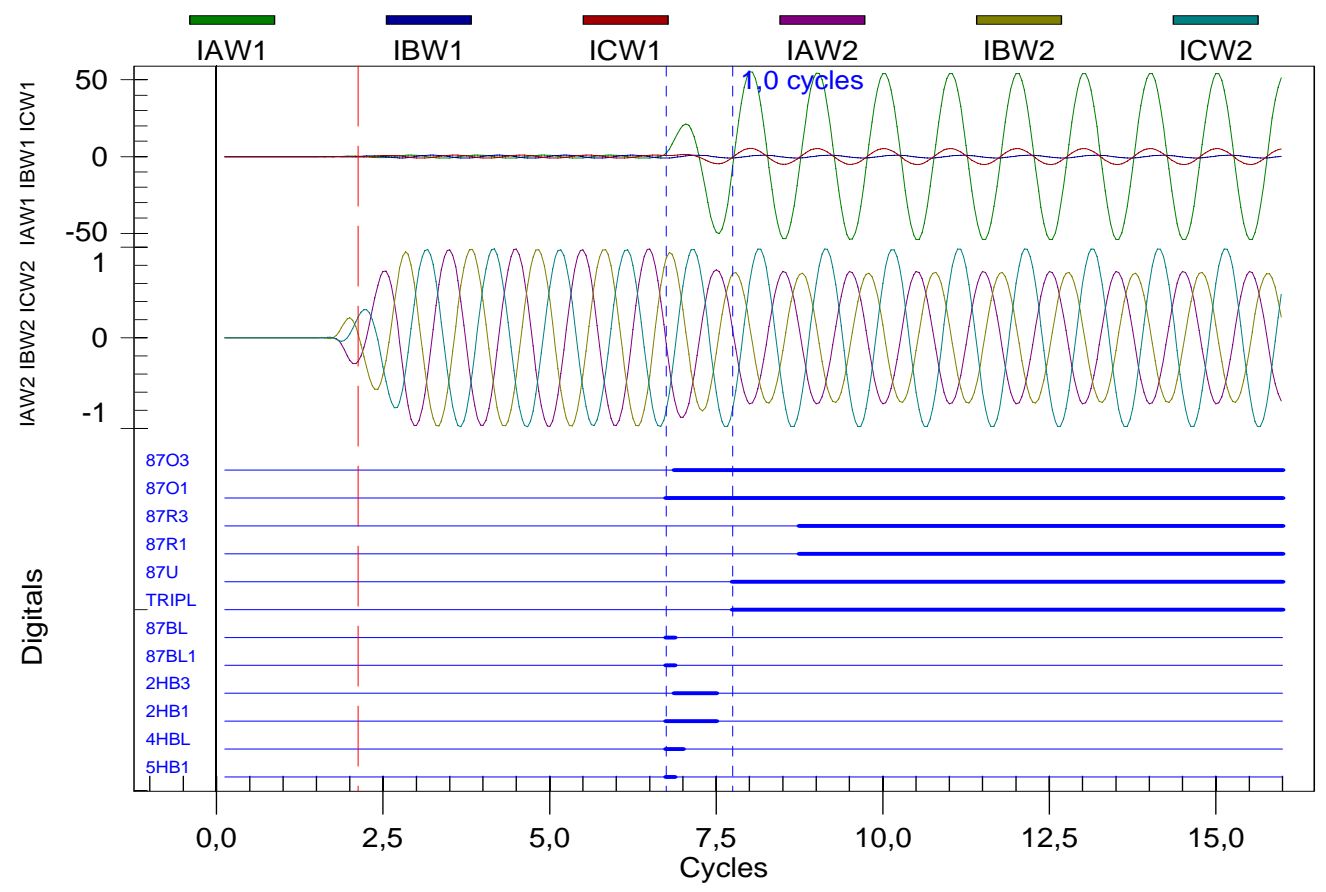

Figura 62. Oscilografia das correntes observadas nos TC's na proteção para uma falta interna, aplicada a $10 \%$ do enrolamento (delta), carga média de 10 MVA sendo conectada em delta com a função "falta terra restrita" desabilitada.

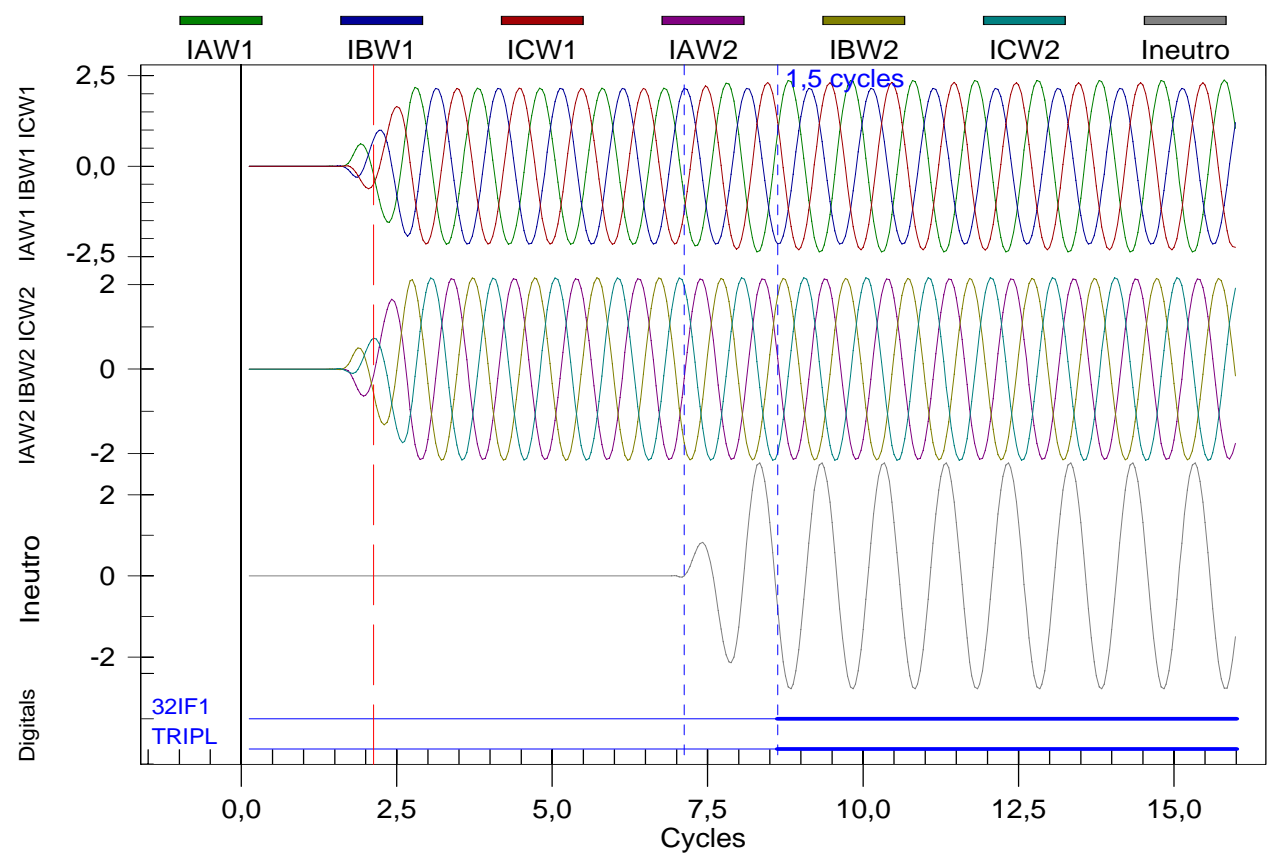

Figura 63. Oscilografia das correntes observadas nos TC's na proteção para uma falta interna, aplicada a 15\% do enrolamento (estrela), carga pesada e conectada em delta com a função "falta terra restrita" habilitada. 


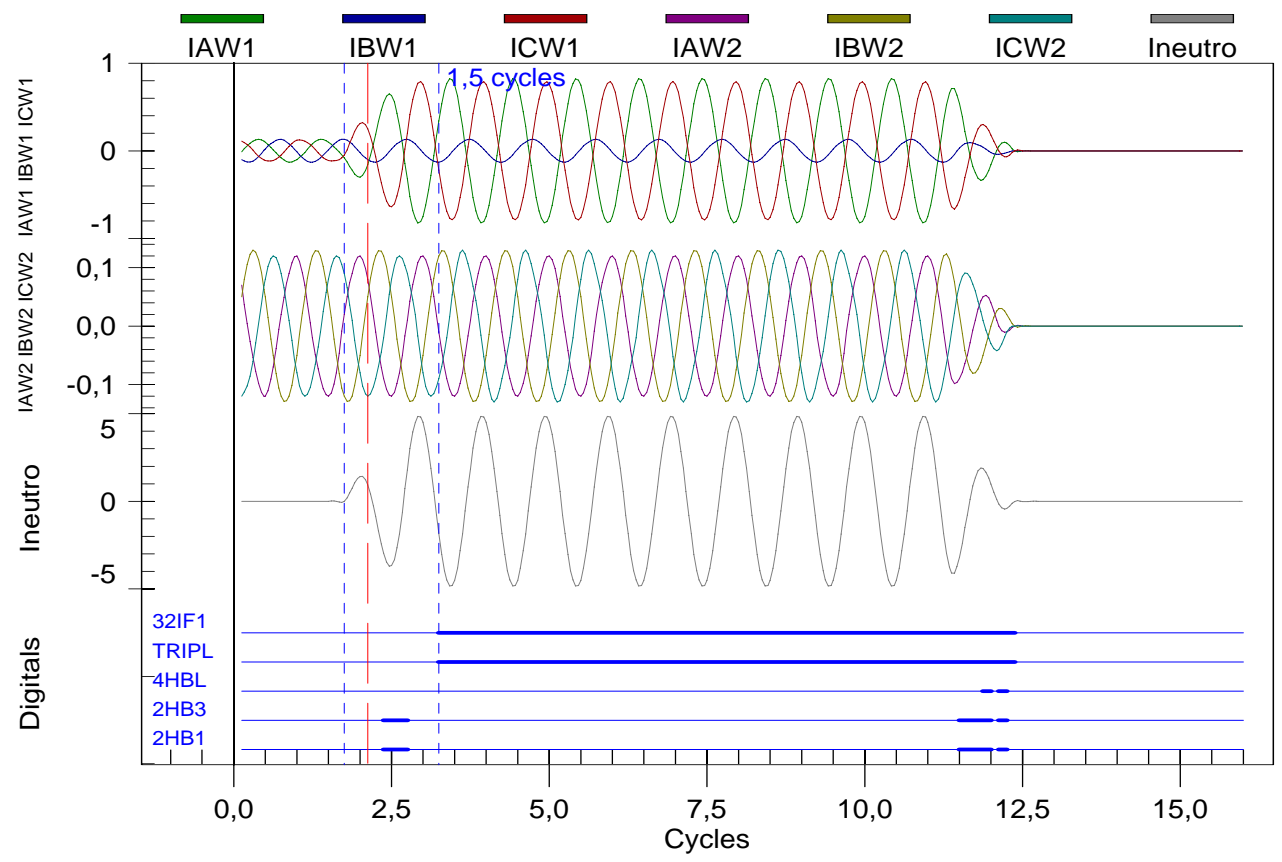

Figura 64. Oscilografia das correntes observadas nos TC's na proteção para uma falta interna, aplicada a $25 \%$ do enrolamento (estrela), carga leve e conectada em delta com a função "falta terra restrita" habilitada.

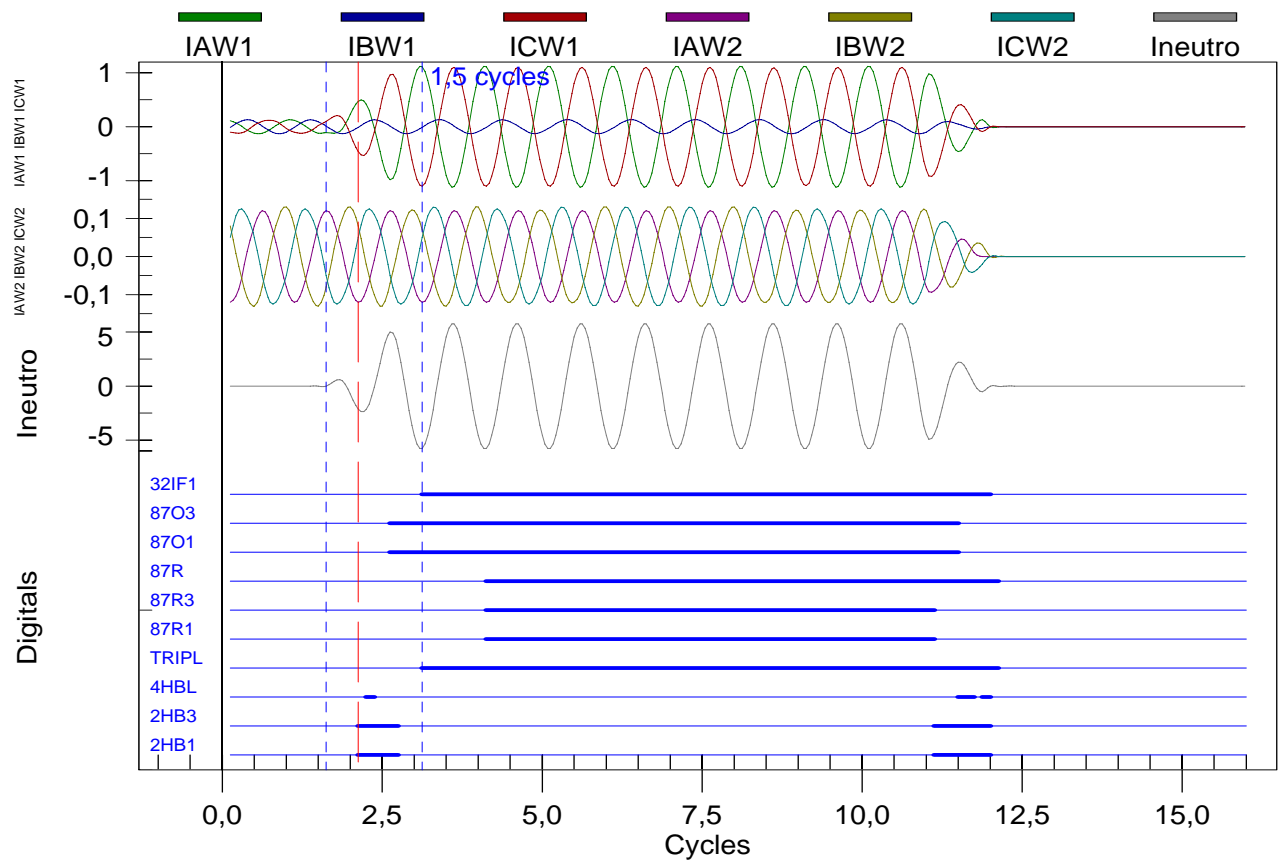

Figura 65. Oscilografia das correntes observadas nos TC's na proteção para uma falta interna, aplicada a $30 \%$ do enrolamento (estrela), carga leve e conectada em delta com a função "falta terra restrita" habilitada. 


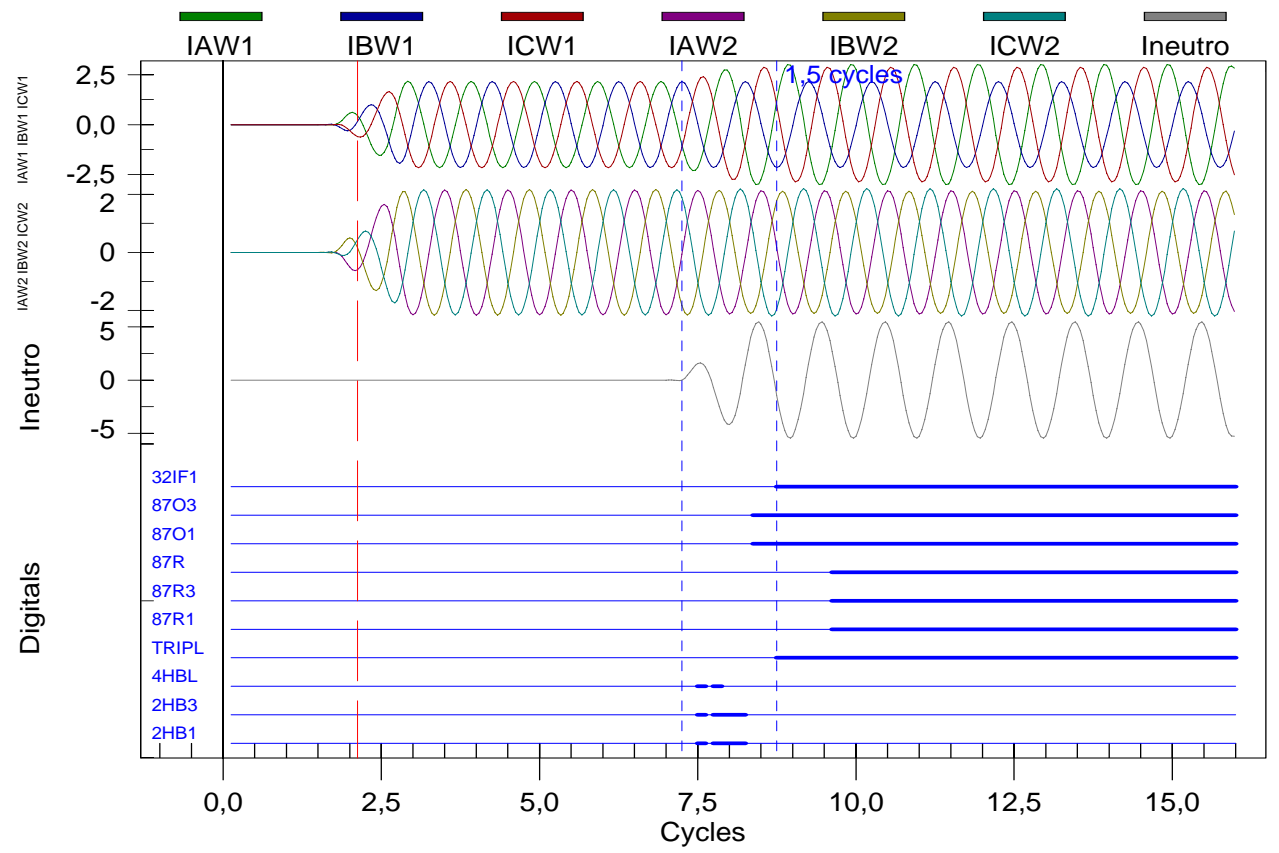

Figura 66. Oscilografia das correntes observadas nos TC's na proteção para uma falta interna, aplicada a $30 \%$ do enrolamento (estrela), carga pesada e conectada em delta com a função "falta terra restrita" habilitada.

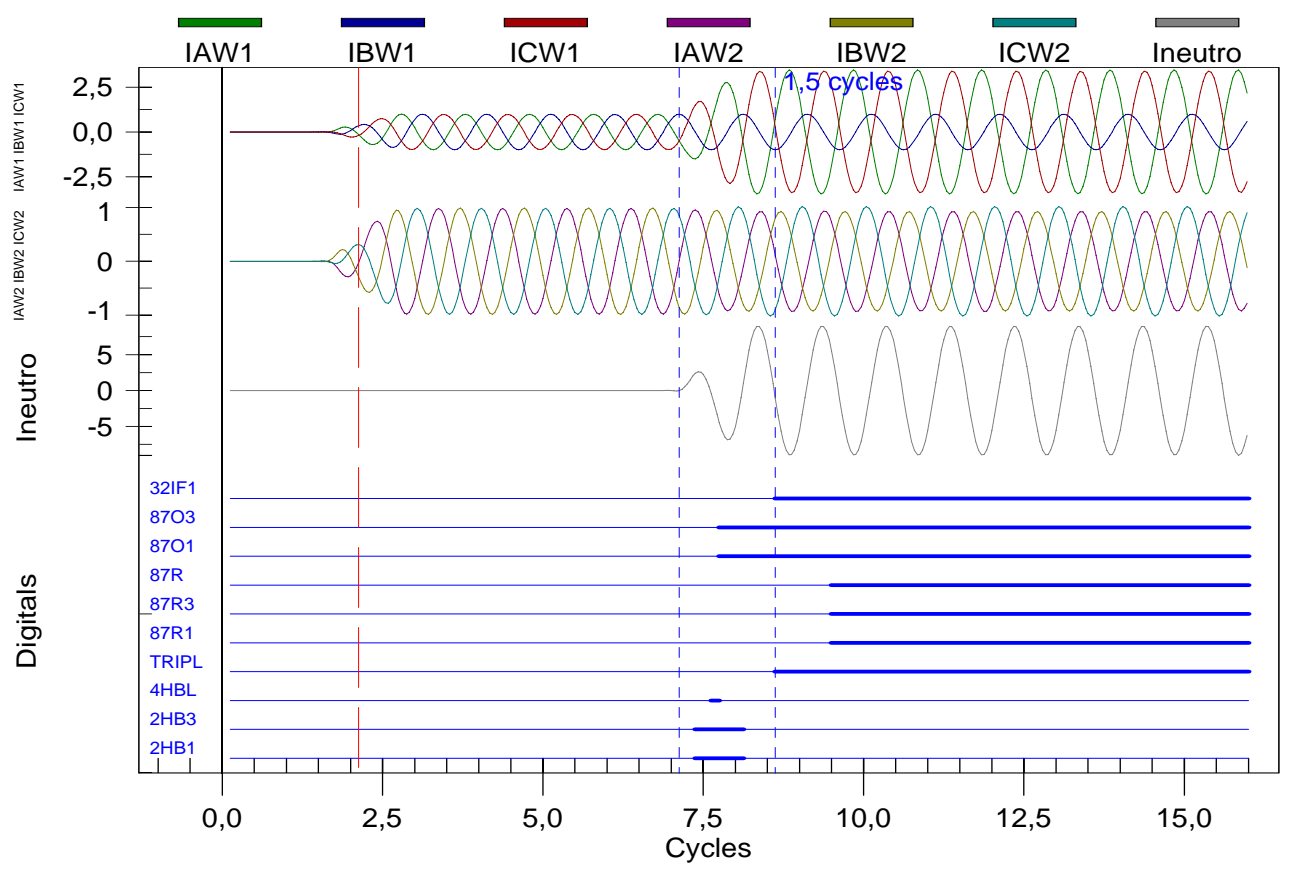

Figura 67. Oscilografia das correntes observadas nos TC's na proteção para uma falta interna, aplicada a 50\% do enrolamento (estrela), carga média de 10 MVA e conectada em delta com a função "falta terra restrita" habilitada. 


\section{ANEXO}

Lógica do elemento diferencial da proteção diferencial percentual do relé modelo SEL - 387A.

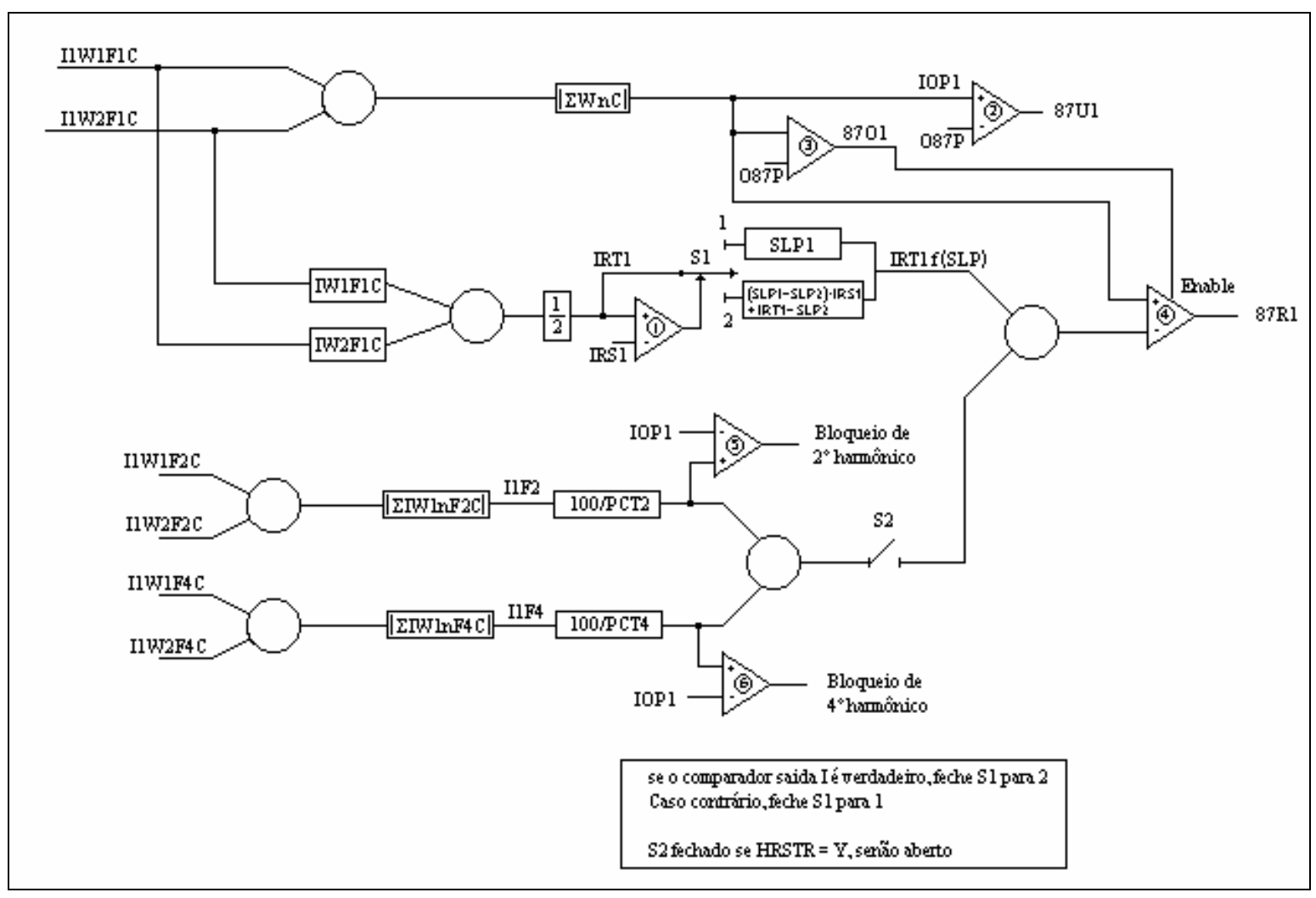

